\title{
WestVirginiaUniversity
}

THE RESEARCH REPOSITORY @ WVU

Graduate Theses, Dissertations, and Problem Reports

2006

\section{Measurements of the electrical properties of coal measure rocks}

Nikolay D. Boykov

West Virginia University

Follow this and additional works at: https://researchrepository.wvu.edu/etd

\section{Recommended Citation}

Boykov, Nikolay D., "Measurements of the electrical properties of coal measure rocks" (2006). Graduate Theses, Dissertations, and Problem Reports. 1726.

https://researchrepository.wvu.edu/etd/1726

This Thesis is protected by copyright and/or related rights. It has been brought to you by the The Research Repository @ WVU with permission from the rights-holder(s). You are free to use this Thesis in any way that is permitted by the copyright and related rights legislation that applies to your use. For other uses you must obtain permission from the rights-holder(s) directly, unless additional rights are indicated by a Creative Commons license in the record and/ or on the work itself. This Thesis has been accepted for inclusion in WVU Graduate Theses, Dissertations, and Problem Reports collection by an authorized administrator of The Research Repository @ WVU. For more information, please contact researchrepository@mail.wvu.edu. 
Measurements of the Electrical Properties of Coal Measure Rocks

Nikolay D. Boykov

Thesis Submitted to the College of Engineering and Mineral Resources

at West Virginia University in fulfillment of the requirements

for the degree of

\author{
Master of Science \\ in \\ Mining Engineering
}

Syd S. Peng, Ph.D., Chair

Yi Luo, Ph.D.

Keith Heasley, Ph.D.

Department of Mining Engineering

Morgantown, West Virginia

2006

Keywords: Radio Imaging Method (RIM), Drill String Radar (DSR), Dielectric Constant, Attenuation Rate, Electrical Resistivity, Electromagnetic Waves, Geological Anomalies, Longwall Mining 


\section{ABSTRACT \\ Measurements of the Electrical Properties of Coal Measure Rocks}

\section{Nikolay D. Boykov}

Subsurface imaging technologies are part of the electromagnetic (EM) geophysical methods. EM technologies such as radio imaging method (RIM), ground penetrating radar (GPR), and drill string radar (DSR) have great application potentials in the mining industry.

However, the success for applying the EM methods to subsurface observations is largely dependant on the correct evaluation of the electrical properties (e.g., wave attenuation rate and dielectric constant) of the rocks in the domain of interest. Study of the electrical properties of rocks was performed in order to gain better understanding about their variations across the country. The study was done specifically for rocks associated with coal seams. The findings are to be used for improvement of the exploration capabilities of the electromagnetic (EM) technologies in the mining industry.

A large amount of data was collected and available for use to the potential users via the database that was developed. 


\section{TABLE OF CONTENTS}

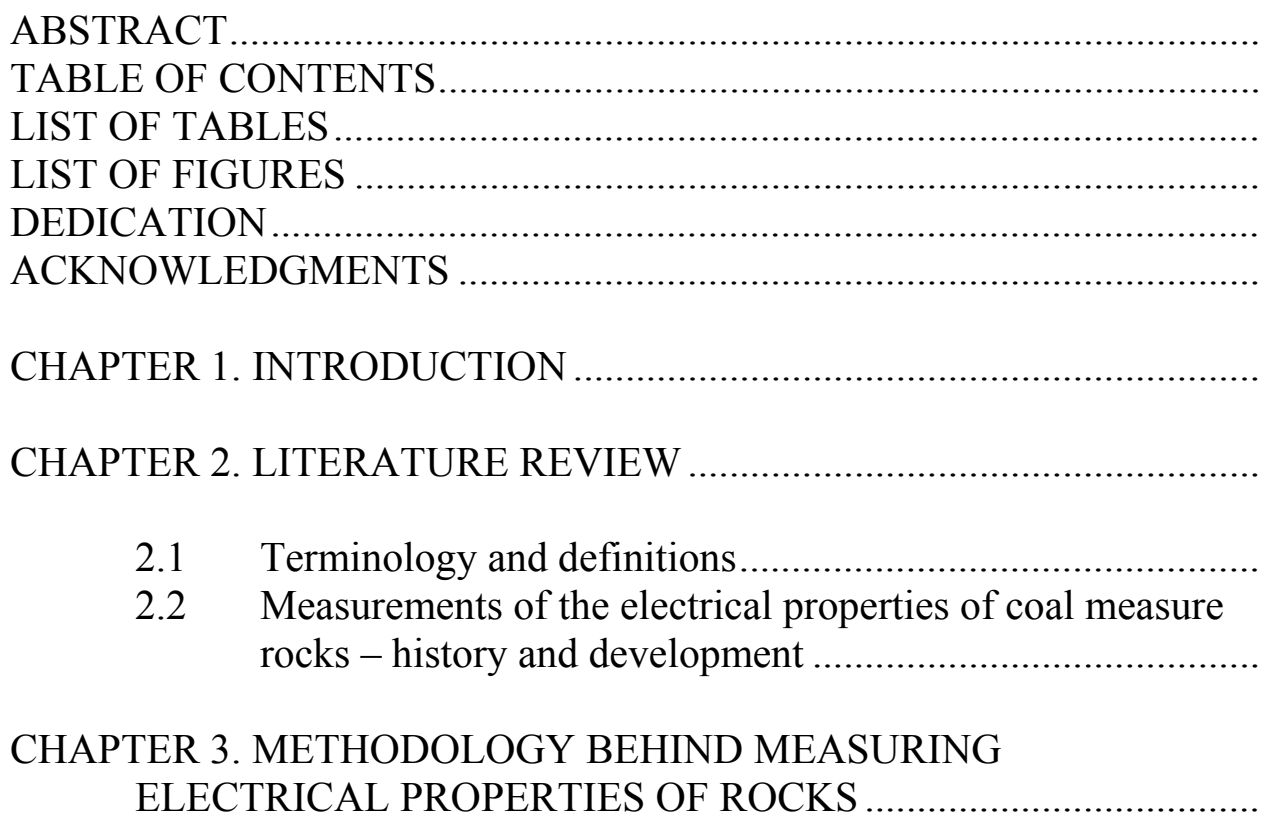

3.1 Sample collection.

3.2 Preparation of the rock samples for testing.

3.3 Measurement techniques and instrumentation used in the study

3.3.1 Low-frequency measurement testing setup

3.3.2 High-frequency measurement testing setup

3.4 Control of the moisture content for the coal measure rocks tested.

4.1 Algorithm for calculating the electrical properties of coal measure rocks.

4.2 Results of electrical properties measurements 


\section{TABLE OF CONTENTS (Concluded)}

CHAPTER 5. DATABASE ..................................................................

5.1 Database for the electrical properties of rocks.................... 76

5.2 Data summary in Pivot Tables ...........................................

CHAPTER 6. CONCLUSIONS AND RECOMMENDATIONS ..................

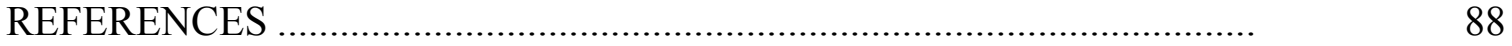




\section{LIST OF TABLES}

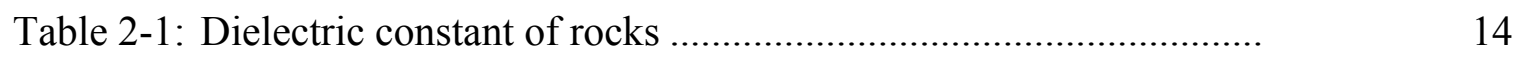

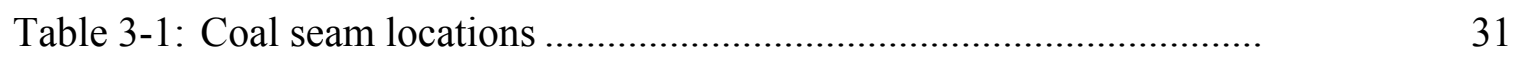

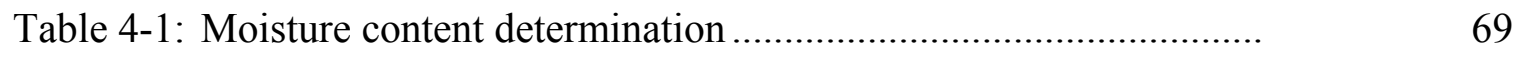

Table 4-2: Typical average ranges for the dielectric constant for the

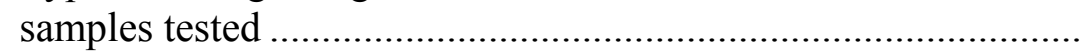

Table 4-3: Typical averages for the attenuation rate for the samples tested ................................................................. 


\section{LIST OF FIGURES}

Fig. 1-1: RIM Imaging Instrumentation ....................................................

Fig. 1-2: $\quad$ Drill String Radar Technology .......................................................... 2

Fig. 2-1: Layers near the Earth's surface........................................................

Fig. 2-2: The model of the Earth's crust.....................................................

Fig. 2-3: Variation of the dielectric constant in wet and absolutely dry coals as a function of the carbon content ......................................

Fig. 2-4: Relationship between the dielectric constant and moisture content: dolomite, marl, siltstone, sandstone.

Fig. 2-5: Relationship between the resistivity and the quality of coal:

A-anthracite; B-brown coal, D-long-burning coal, PSh-bituminous, PS-super bituminous, K-cooking coal, T-sub anthracite

Fig. 2-6: Natural waveguide anomalies in coal seams

Fig. 2-7: Cross section of coal seam presenting the electromagnetic (EM) wave path.

Fig. 3-1: Examples of coal and rock samples collected from major U.S. coal seams

Fig. 3-2: Coal samples prepared for testing under high frequencies

Fig. 3-3: Sandstone and coal samples prepared for testing under low frequencies

Fig. 3-4: HP-4192A Impedance Analyzer ………………………………...

Fig. 3-5: Low-frequency dielectric test fixture ...........................................

Fig. 3-6: Agilent 8714 ES high-frequency network analyzer....................... 38

Fig. 3-7: The dielectric probe and supporting jig ........................................ 


\section{LIST OF FIGURES (Continued)}

Fig. 3-8: The chamber used to control the moisture content of the rock samples

Fig. 4-1: Dielectric constant vs. frequency in coal sample from the Sewickley Seam

Fig. 4-2: Attenuation rate vs. frequency in coal sample from the Sewickley Seam

Fig. 4-3: Comparison of the dielectric constant of a coal sample from the Sewickley Seam in two tests separated by a couple of months ...

Fig. 4-4: Comparison of the attenuation rate of a coal sample from the Sewickley Seam in two tests separated by a couple of months ...

Fig. 4-5: Comparison of the resistivity of a coal sample from the Sewickley Seam in two tests separated by a couple of months ...

Fig. 4-6: Dielectric constant and attenuation rate vs. frequency for a shale sample from the Sewickley Seam

Fig. 4-7: Comparisons of the results for the dielectric constant and attenuation rate vs. frequency for shale samples from the Sewickley Seam

Fig. 4-8: Comparisons of the dielectric constants and attenuation rates observed at different moisture levels for a coal sample from the Sewickley Seam

Fig. 4-9: Comparisons of the electrical resistivity observed at different moisture levels for a coal sample from the Sewickley Seam.......

Fig. 4-10: Comparisons of the dielectric constant, attenuation rate and resistivity at different moisture levels of a sandy shale sample from the Pittsburgh Seam.

Fig. 4-11: Comparisons of the dielectric constant, attenuation rate and resistivity at different moisture levels of a sandstone sample from the Pittsburgh Seam.

Fig. 4-12: Comparison of the dielectric constant between the Pittsburgh and Sewickley coal seams 


\section{LIST OF FIGURES (Continued)}

Fig. 4-13: Comparison of the attenuation rate between the Pittsburgh and Sewickley coal seams

Fig. 4-14: Results of the measurements of the basalt sample, Hawaii dielectric constant and attenuation rate

Fig. 4-15: Results of the measurements of the basalt sample, Hawaii resistivity.

Fig. 4-16: Dielectric constant and attenuation rate for phonolite sample from Colorado.

Fig. 4-17: Dielectric constant and attenuation rate for biotite-gneiss sample from Colorado

Fig. 4-18: Dielectric constant vs. frequency comparison for the three samples tested

Fig. 4-19: Measured dielectric constant from coal samples collected from the Pittsburgh and Sewickley Seams in low- and highfrequency range

Fig. 4-20: Comparison of the attenuation rate between the Pittsburgh and Sewickley coal seams in low- and high-frequency range

Fig. 4-21: Comparison of the dielectric constant for "wet" and dry sandstone samples from Colorado

Fig. 4-22: Comparison of the dielectric constant for "wet" and dry claystone samples from Colorado

Fig. 4-23: Comparison of the dielectric constant for "wet" and dry sandstone and claystone samples from Colorado

Fig. 4-24: Dielectric constant and attenuation rate for high-frequency measurements of the basalt sample, Hawaii ....

Fig. 5-1: Scheme of the database developed for the electrical properties of coal measure rocks.

Fig. 5-2: Main switchboard of the database for the electrical properties of rocks.

Fig. 5-3: Sub-menus in the database. 


\section{LIST OF FIGURES (Concluded)}

Fig. 5-4: Example of a report created by using the database for the

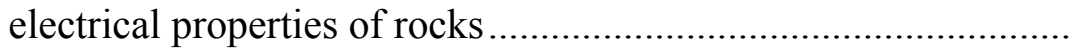

Fig. 5-5: Measurement sets included in the database for the electrical

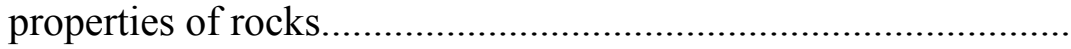

Fig. 5-6: Pivot Table for the electrical properties of coal measure rocks...

Fig. 5-7: Example of a graph created using the Pivot Table 


\section{DEDICATION}

This Master thesis is dedicated to my parents Antoaneta and Dimitar Boykovi and to my sister Adriana. They encouraged me during the study and gave me strength and faith in the past years of research. I am very grateful for their love and support. Their unconditional love kept me working and enabled me to complete this work. 


\section{ACKNOWLEDGMENTS}

I would like to extend my sincere respect and appreciation to all those who helped with this Master thesis and made it possible. I am grateful to Professor Syd S. Peng and Professor Yi Luo for their valuable guidance that helped me during the time of research and writing of this thesis.

I would also like to express thanks to Professor Keith Heasley of the Department of Mining Engineering for being a member of my committee.

Last, but not least, I am grateful to Stolar Research Corporation for the opportunity they gave me to conduct a summer internship in their research laboratory during the summer of 2005 . 


\section{CHAPTER 1}

\section{INTRODUCTION}

Coal mining is a process of removing subsurface coal resources. Two major methods predominate today: surface mining and underground mining. The largest effort in surface mining is removing the overburden, while underground mining usually faces a great many other problems. The modern high productive longwall method is of great importance for the U.S. coal output. A critical factor in longwall mining success is an accurate evaluation of production capabilities. Poor geology is the major cause of decreasing production for underground mining. Geological anomalies in the longwall panel, such as sandstone channels, dykes, fracture zones, faults, etc., may cause severe difficulties to longwall operations and can be extremely expensive to the mine operator. In addition to causing production problems, poor geologic conditions can also produce serious safety hazards for people working underground. One of the main causes of underground mining fatalities is unexpected roof falls, which in most cases are due to poor roof geology.

Several exploration methods have been used to map the geological conditions ahead of mining. These include horizontal drilling, surface drilling, radar, and in-seam and surface seismic. In the past twenty years there has been great advancement in the remote observation of longwall panels. Technologies such as the Radio Imaging Method (RIM) and Drill String Radar (DSR) apply EM geophysical theory to the mining industry. 
These technologies for underground explorations have been developed to detect geological anomalies ahead of mining. The main difference between the two technologies is their principle of operation. Figures 1-1 and 1-2 illustrate the primary modes of operation for these two technologies when they are applied to longwall mining.

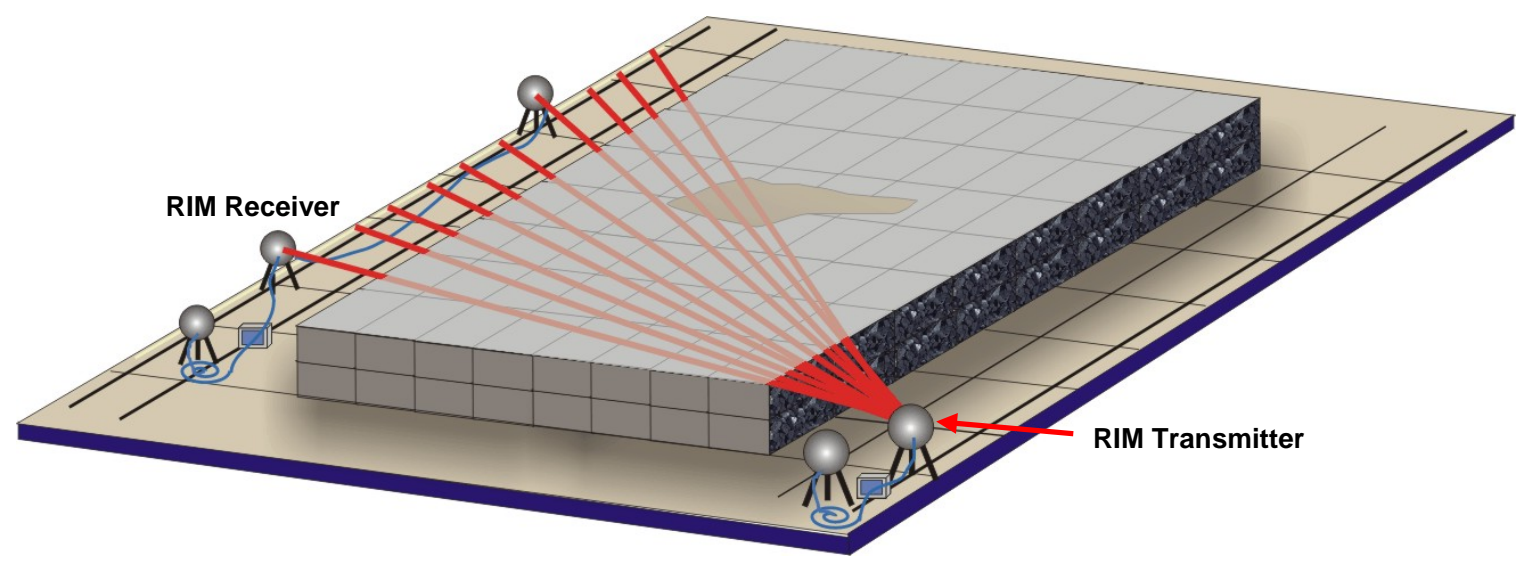

Fig. 1-1: RIM Imaging Instrumentation (Stolarczyk and Peng, 2003)

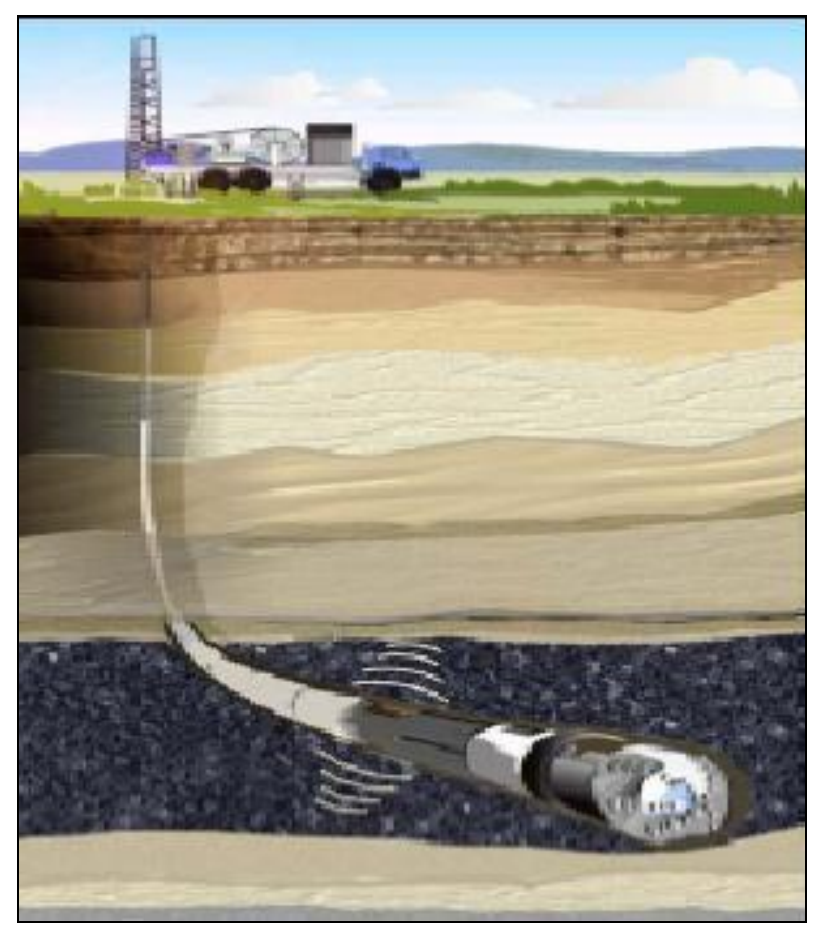

Fig. 1-2: Drill String Radar Technology (Stolarczyk, et al., 2003) 
The Radio Imaging Method (RIM) was originally developed for coal mining observations by Stolar Horizon, Inc., about twenty years ago (Stolarczyk, 1986). The technique has been considered to be one of the most powerful tools for geophysical exploration that is able to detect potential geological hazards in the longwall panel. The system operates at low frequency range $(20 \mathrm{kHz}$ to $10 \mathrm{MHz})$ and primarily uses four different frequencies that allow different depth of penetration of the electromagnetic (EM) waves into the longwall panel. Because the coal seam is bounded by rocks of different electrical properties, the coal seam itself usually behaves as a dielectric wave guide.

The other technology that could be applied for observations ahead of mining is the Drill String Radar (DSR). The technology is planned to operate in the high frequency range $(200 \mathrm{MHz}$ to $3 \mathrm{GHz}$ ). The radar system is under development by Stolar Horizon, Inc., and it would be mounted on exploration drill strings. The radar system will be used to navigate the exploration drill within the coal seam thickness. In addition, the technology would be able to estimate the coal quality based on the electrical properties of the rocks, and to detect geological anomalies ahead of mining. That will significantly improve the mining process and help operators make the right decisions in advance.

As mentioned before, both technologies are based on electromagnetic geophysical principles. In general, an EM field can be generated by passing an alternating current, between transmitter and receiver, through antennas (Reynolds, 2003). When the electromagnetic (EM) signal travels through the subsurface media it is modified slightly relative to that which travels through the air. Consequently, the measured by the receiver EM signal will differ in both phase and amplitude relative to the unmodulated field that 
was generated by the transmitter. The degree to which these components differ reveals important information about the geometry, size, and electrical properties of the earth materials. In other words, the propagation of the EM waves is strongly dependent on the electrical characteristics of the coal seam and its surrounding strata. Therefore, the detection capabilities of RIM and DSR depend on a few main electromagnetic properties of the earth materials under investigation, of which the most important are dielectric constant, electrical resistivity/conductivity, and wave attenuation rate. The dielectric constant controls the speed of propagation of the EM waves in any medium. It is the contrast in the dielectric constant between adjacent layers in the coal seam that gives rise to reflection of the EM waves (Reynolds, 2003). A fundamental cause of the loss of energy is the wave attenuation, which is a complex function of the electrical properties of the media through which the EM signal is traveling. The attenuation is dependent upon the resistivity/conductivity of the media through which the signal is propagating, as well as the frequency of the signal itself. The depth of penetration of the EM signal in the strata is given to be inversely proportional to the wave attenuation (Reynolds, 2003)

Therefore, in this research, the main focus is on the measurement of the electrical properties of rocks associated with coal seams. First, studies of the EM properties of the coal measure rocks in various U.S. coal fields will be shown. Moreover, the study has been extended to rocks that are not associated with coal seams due to the extended application range of the technology - for example for observations in oil wells. Second, interpretation of the collected data will be presented and comparisons between the different coal seams will be made. In order to make the results of this study useful to the mining industry, a database for the electrical properties of coal measure rocks has been 
built and is presented in this thesis. As mentioned previously, the accuracy of many electromagnetic geophysical methods depends on good estimations of the electric properties of the rocks of interest.

The objective of this research is to collect rock samples, measure and analyze the electrical properties of coal measure rocks, and to build a database for the collected data. Moreover, the collected data will help improve the two technologies-Radio Imaging Method (RIM) and Drill String Radar (DSR) — and will increase their accuracy in finding geological anomalies in longwall panels.

Rock and coal samples from various U.S. coal fields have been collected. An electromagnetic (EM) property measurement laboratory has been established. The collected rock samples were prepared to meet the testing requirements. The prepared samples were tested in low- and high-frequency ranges. The measured electrical properties were analyzed.

In addition, the database for EM characteristics in different rocks was developed. The database allows easy access to the collected data for various types of rocks and for wide frequency ranges. 


\section{CHAPTER 2}

\section{LITERATURE REVIEW}

Commonly used terminology and definitions with respect to electrical measurements of earth materials are presented in this chapter. Also, the research that has been done in the subject area of electrical measurements of earth materials is presented. This is important to know because studies of the electrical properties of soils and other earth materials have been done in the past, but not many of them have been done specifically for coal measure rocks. The theories behind the electrical tests performed on rocks covering different frequency ranges will be discussed. At the end of the chapter, an overview of the potential use of the electrical properties of rocks is given.

\subsection{Terminology and definitions}

The electrical properties of a material might be described in terms of dielectric constant, resistivity (or conductivity), and dielectric loss. As mentioned earlier, the Radio Imaging Method (RIM) and Drill String Radar (DSR) technologies are strongly dependent on these electrical properties. In order to better understand this study, definitions of the terms used in this work are provided here.

- Dielectric constant is the relative permittivity of a dielectric material. It is an important parameter in characterizing capacitors. It is the ratio of the charge that would be stored in a vacuum as the dielectric to that stored in the material of interest as the dielectric. The dielectric constant has a real part and an 
imaginary part. It is frequency dependent and dimensionless. Also, it determines the speed with which the electromagnetic (EM) wave will propagate through the medium of interest. The lower the value of the dielectric constant, the higher the speed of wave propagation. The dielectric constant of air is equal to 1 and that of water is equal to 80 . In this study, the term dielectric constant refers to the real part of the dielectric constant only.

- Attenuation refers to any reduction in the strength of an electromagnetic signal (loss of signal), usually measured in decibels (dB).

- Attenuation rate is the rate of reduction of average power with respect to distance along a transmission path, usually presented in decibels per meter, feet, etc. $(\mathrm{dB} / \mathrm{m}, \mathrm{dB} / \mathrm{ft}, \mathrm{dB} / 100 \mathrm{ft})$.

- Loss tangent determines the loss in the medium. Similar to the dielectric constant, low-loss tangents result in a "fast" substrate while large-loss tangents result in a "slow" substrate. It is the ratio of the real part to the imaginary part of the dielectric constant.

- Electrical resistivity (or electrical resistance) is a measure of how strong the material opposes the flow of electric current. The SI unit for electrical resistivity is ohm meter. It is commonly represented by the Greek letter $\rho$.

- Electric current is the rate of charge flow past a given point in an electric circuit, measured in coulombs/second, which is called amperes. In most DC electric circuits, it can be assumed that the resistance to current flow is a constant so that the current in the circuit is related to voltage and resistance by Ohm's law: $\mathrm{V}=\mathrm{I} \times \mathrm{R}$. 
- Electric charge is the fundamental property of some materials that determines their electromagnetic interactions.

- The electromagnetic field is a physical influence (a field) that permeates through all of space and that arises from charged objects and describes one of the four fundamental forces of nature-electromagnetism. It can be generally explained as a combination of an electric field and a magnetic field. The electric field is produced by non-moving charges and the magnetic field by moving charges (currents); these two are often described as the sources of the field (Zhdanov, 1994).

- Electrical conductivity is a measure of a material's ability to conduct an electric current. Conductivity is the reciprocal (inverse) of electrical resistivity, and has the units of Siemens per meter $(\mathrm{S} / \mathrm{m})$. It is commonly represented by the Greek letter $\sigma$.

- Frequency is the measurement of the number of times that a repeated event occurs per unit of time. Measuring the frequency of sound, electromagnetic waves (such as radio or light), electrical signals, or other waves, the frequency in hertz is the number of cycles of the repetitive waveform per second.

\subsection{Measurements of the electrical properties of coal measure rocks - history and development}

Recently there has been a growing interest in application of the electromagnetic (EM) method in the mining industry. Different types of radar systems for detecting geological conditions underground have been developed in the past twenty years. There are many benefits of using the geophysical methods in the coal mining industry, such as 
high speed of exploration and high effectiveness; also, the observation process does not require direct contact with the surface. To improve the capabilities of such radar systems, one must know the electrical properties of the materials composing the Earth's interior. In connection with the geological conditions that the EM technologies can face in coal mines during explorations, the electrical properties of the coal measure rocks should be studied in laboratory conditions under various circumstances. With the advancement of the EM geophysical techniques, more knowledge for the electromagnetic properties of the Earth is required. However, studies of the electrical properties of rocks specifically associated with coal seams have not been done in detail.

One of the works that examines the electrical properties of the Earth's crust was done in early 1960s (Watt et al., 1963). The research observed the electrical characteristics of materials forming the Earth's crust in general. Since the propagation of electromagnetic waves through different geological materials is not only frequency dependent, but also depends on the electrical properties of the rocks under investigation, a study of those characteristics is necessary. The authors give a general scheme of the geological materials that are most commonly found near the Earth's surface in a paper published in the Proceedings of the Institute of Electrical and Electronics Engineers (Watt et al., 1963). The general scheme presented in the publication is illustrated in Fig. 2-1. 


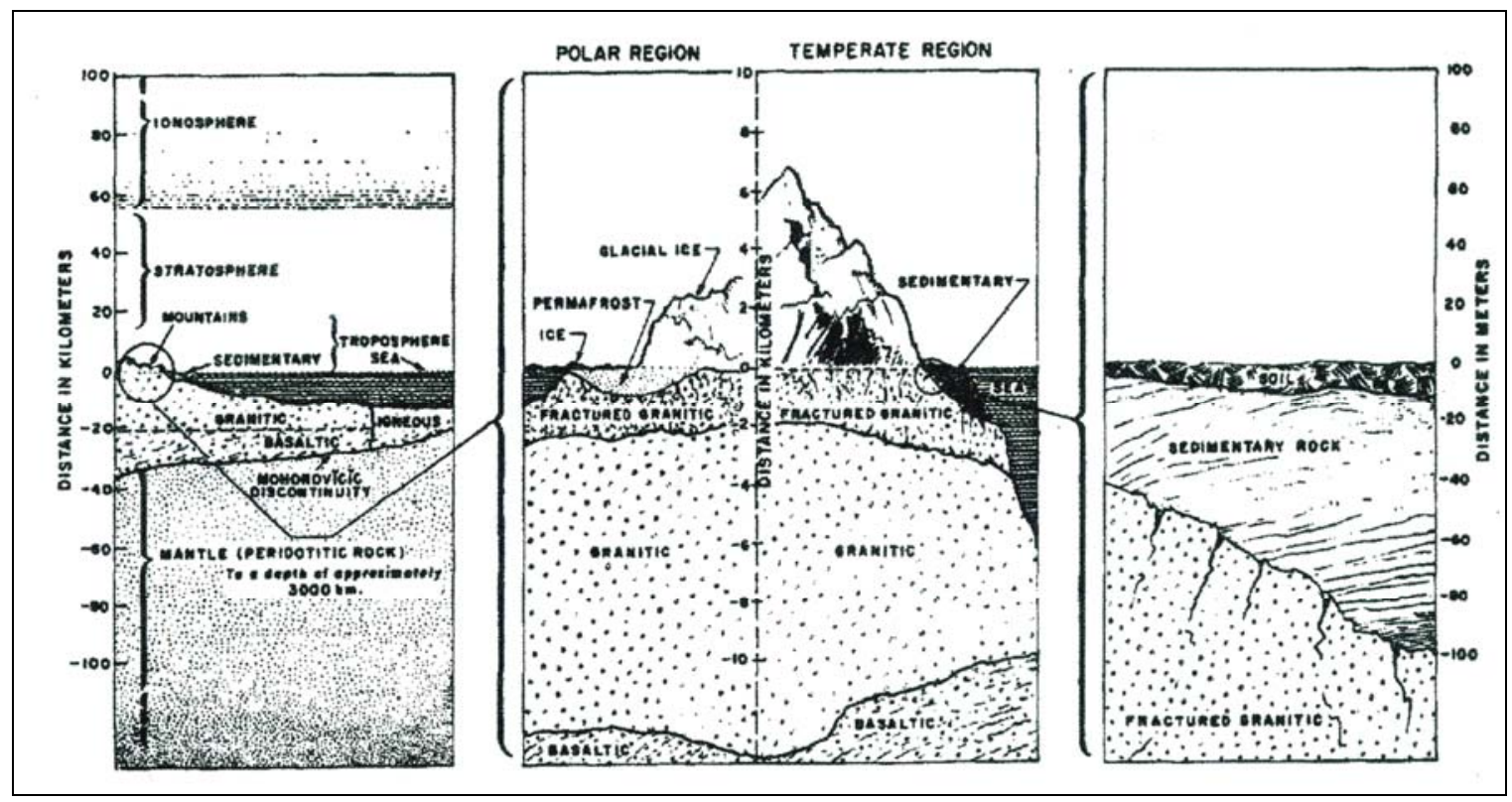

Fig. 2-1: Layers near the Earth's surface (Watt et al, 1963)

The electrical conductivity of various materials that have been studied is discussed in the publication. Laboratory and in-situ conductivity measuring techniques used in the research were described. The in-situ methods for measuring the electrical properties of the rocks were highlighted in the paper. Once the conductivity is known, the resistivity of the samples can be derived. The conclusions reached by this research showed several important factors that have an effect on the electrical properties of the rock strata. First, the amount and the conductivity of the water in the rock fractures affect the electrical characteristics of the rock itself. Second, the pressure in which the rock was formed affects its electrical properties. Finally, the temperature at the depth of interest also plays a role in the electrical properties of the rocks. The most important conclusion made was that the pressure will influence the pore volume in the rocks. Therefore, it will control the water filling in the rock's pores and cracks. For that reason, the electrical properties in the region from the surface to about $3 \mathrm{~km}$ below the Earth's surface are 
expected to be greatly influenced by the water content of the rocks. Due to these factors, the electrical characteristics of different rocks will vary widely. The research showed that the effects of water content, pressure, temperature, etc., are quite complex and control the electrical characteristics of the different rock types.

The paper, "The Possibility of Guided Electromagnetic Waves in the Earth's Crust" (Wait, 1963), discussed the possibility that a natural waveguide in the Earth's crust may exist. The publication explained the complexity of the Earth's crust. It is considered that the extension of the rock layers in the near surface zone ranges from 10 to $50 \mathrm{~km}$ in depth. In this zone, many different rock types are found. Those rocks are assumed to have different electrical properties. The concept of the natural waveguide assumes that the upper boundary of the waveguide consists of highly conductive and fractured sedimentary rocks. The zone consists of a series of sedimentary rocks, along with fractured crystalline and metamorphic rocks. All of them are moderately good conductors of electricity because they hold relatively large amounts of water in their pore spaces and other voids. The bottom of the waveguide channel is presented by the high conductivity region of the basement rocks. The basement rocks beneath this surface zone are crystalline, igneous, or metamorphic rocks that are much heavier and have little pore space in which water may held. An idealized situation to help understand the nature of the waveguide is presented in Fig. 2-2. 


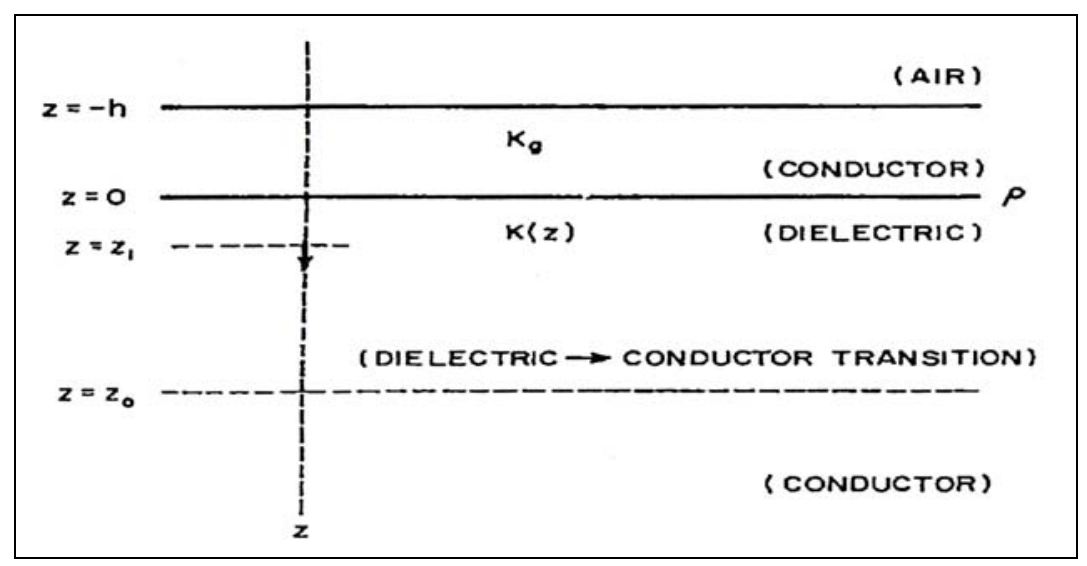

Fig. 2-2: The model of the Earth's crust (Wait, 1963)

The model used in this study is shown above. The cylindrical coordinate system was chosen by the author. The highly conductive upper layers were stacked together and represented as a homogeneous layer. Then a plane defines the boundary between the upper conducting region and the basement dielectric. Even with ideal conditions for the dielectric basement layer and the perfectly conducting upper layer, the electromagnetic field was attenuated from leakage. It was concluded that a low attenuation in the waveguide will be associated with a very highly conducting upper layer, a low loss in the dielectric basement, and a rapid increase of the conductivity with depth. In cases in which a better understanding of the wave propagation in an inhomogeneous stratified medium is desired, studies of the electrical properties of the rocks must be done, as suggested by the author.

Electrical Properties of Rocks, written by Parkhomenko (1967) is the first book ever written specifically focused on the electrical properties of rocks. The book gives detailed explanations for the electrical and electromagnetic geophysical methods and their use. It explains how the use of these techniques requires knowledge of the various 
characteristics of sedimentary, metamorphic, and igneous rocks. Giving the most important elements for the results of investigations of dielectric constant, dielectric loss (loss tangent), resistivity, etc., for different rocks and minerals, this research is a great reference for the electrical properties of rocks. The porosity of the rocks and their water content, as factors that have great influence on their electrical properties, are described. Pores and fractures in rocks are very important for their inhomogeneous structure and texture. Porosity describes the total empty space that exists between the solid material and particles in the rock. These gaps are due to the influence of various factors during the process of formation of the strata. The existence of fractures and pores in the rocks determines the volume of water that they contain. The water content of sedimentary rocks varies over a wide range, depending on grain size and density of the rocks. On the other hand, igneous and metamorphic rocks are generally characterized by low water content. In the literature, the ratio of the weight of the rock freshly extracted from the seam to the weight of a dry rock is frequently used as a measure of moisture content. Rocks are complicated materials. However, the electrical properties of a material might be characterized in terms of dielectric constant, resistivity, and dielectric loss. The research that had been done gives values for the dielectric constant of minerals and rocks. Some of these values vary over two orders of magnitude. Therefore, variability in the electrical properties of the rocks can be considered normal. One could expect differentiation between rock types based on their dielectric constant. In addition, the quantity of liquid that is locked in the rock affects the dielectric constant and the rest of the electrical characteristics (resistivity, conductivity). It was found by the author that this is 
particularly true at low frequencies. Values for the dielectric constant of rocks with various amount of moisture are given in Table 2-1.

Table 2-1: Dielectric constant of rocks (Parkhomenko, 1967)

\begin{tabular}{|c|c|c|c|c|}
\hline Rock & $\begin{array}{l}\text { Source, mineral } \\
\text { composition in } \%\end{array}$ & $\begin{array}{l}\text { Dielectric } \\
\text { constant }\end{array}$ & $\begin{array}{l}\text { Frequency, } \\
\text { cps }\end{array}$ & $\begin{array}{c}\text { Water } \\
\text { content, } \\
\%\end{array}$ \\
\hline \multicolumn{5}{|l|}{ Sedimentary Rocks } \\
\hline gypsum & gypsum, 8 & 6.3 & & dry \\
\hline Shale & & $10-45.0$ & $10^{2}-10^{6}$ & 10 \\
\hline Shale & & $\begin{array}{r}4-7.0 \\
9.5-10\end{array}$ & $\begin{array}{l}10^{2}-10^{6} \\
10^{2}-10^{6}\end{array}$ & $\underset{n}{\text { dry }}$ \\
\hline Dolomite & & $8.0-8.6$ & $10^{3}-10^{7}$ & $n$ \\
\hline$\underset{\text { Limestone }}{\text { Lim }}$ & Georgian SSR & $\begin{array}{c}7.3 \\
8.0-12.0\end{array}$ & & - \\
\hline Arkosic sandstone & $\begin{array}{l}\text { quartz, } 23 \\
\text { feldspar, } 75\end{array}$ & & & \\
\hline $\begin{array}{l}\text { Quartz-fe ldspar } \\
\text { sandstone }\end{array}$ & $\begin{array}{l}\text { mica, } 2 \\
\text { quartz, } 40 \\
\text { feldspar, } 45 \\
\text { other, } 15\end{array}$ & 5.1 & & dry \\
\hline Sandstone & & $\begin{array}{l}4.66 \\
3.96\end{array}$ & $\begin{array}{l}5 \cdot 10^{5} \\
5 \cdot 10^{5}\end{array}$ & $\begin{array}{l}\text { dry } \\
\text { dry }\end{array}$ \\
\hline Variegated sandstone & & $9.0-11.0$ & & \\
\hline Shaly sandstone & & 5.53 & & dry \\
\hline The same & & 7.17 & & 0.2 \\
\hline
\end{tabular}

Parkhomenko (1967) stated that the upper limits of the dielectric constant for sedimentary rocks are a function of their moisture content and mineral composition. Moreover, the dielectric constant of coal, as well as the electrical conductivity (or resistivity), was discussed in the book. The research discovered that the electrical characteristics of coal are strongly dependent on the degrees of metamorphism that the coal went through. The relationship between the dielectric constant and the carbon content of wet and dry coals that was found experimentally is shown in Fig. 2-3. In Fig. 2-3, it can be seen that moisture plays a more important role in coals that are of low quality. 


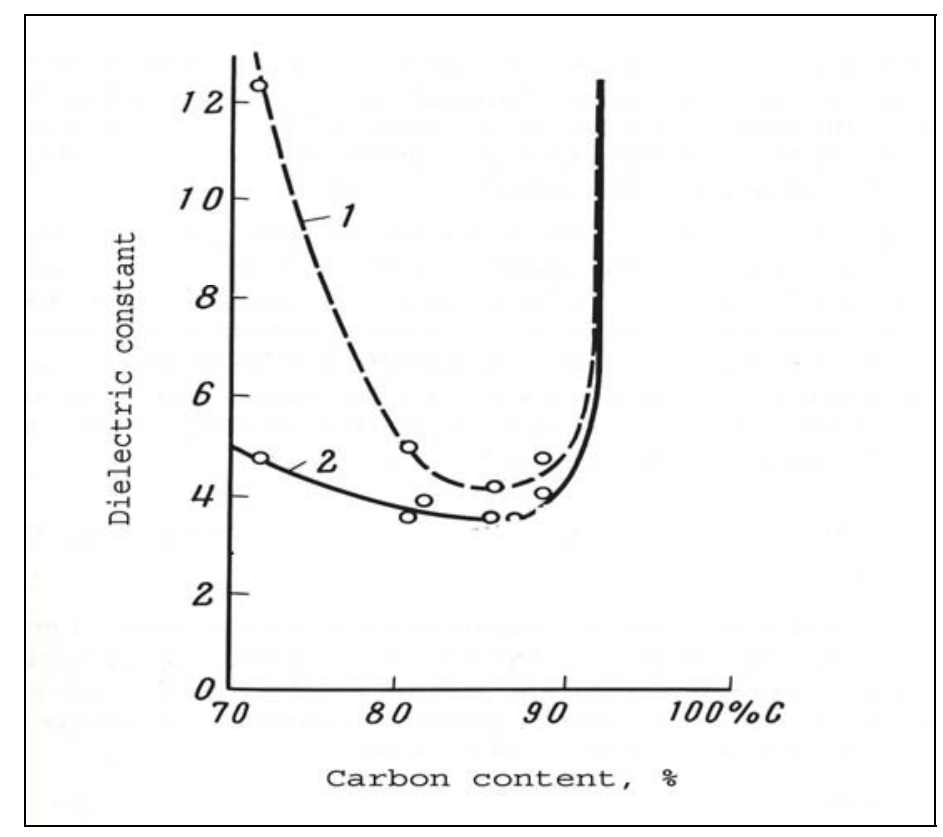

Fig. 2-3: Variation of the dielectric constant in wet (1) and absolutely dry (2) coals as a function of the carbon content (Parkhomenko, 1967)

Since the dielectric constant of water is 80 , as mentioned earlier, even a small amount of water in the rocks will increase the dielectric constant rapidly. The frequency dependence of the dielectric constant is relatively small compared to the influence of the moisture content. Figure 2-4 shows the relationship between the water content and the dielectric constant for different types of rocks observed. The values were studied at a frequency range of $10^{5}-10^{6} \mathrm{~Hz}$. 


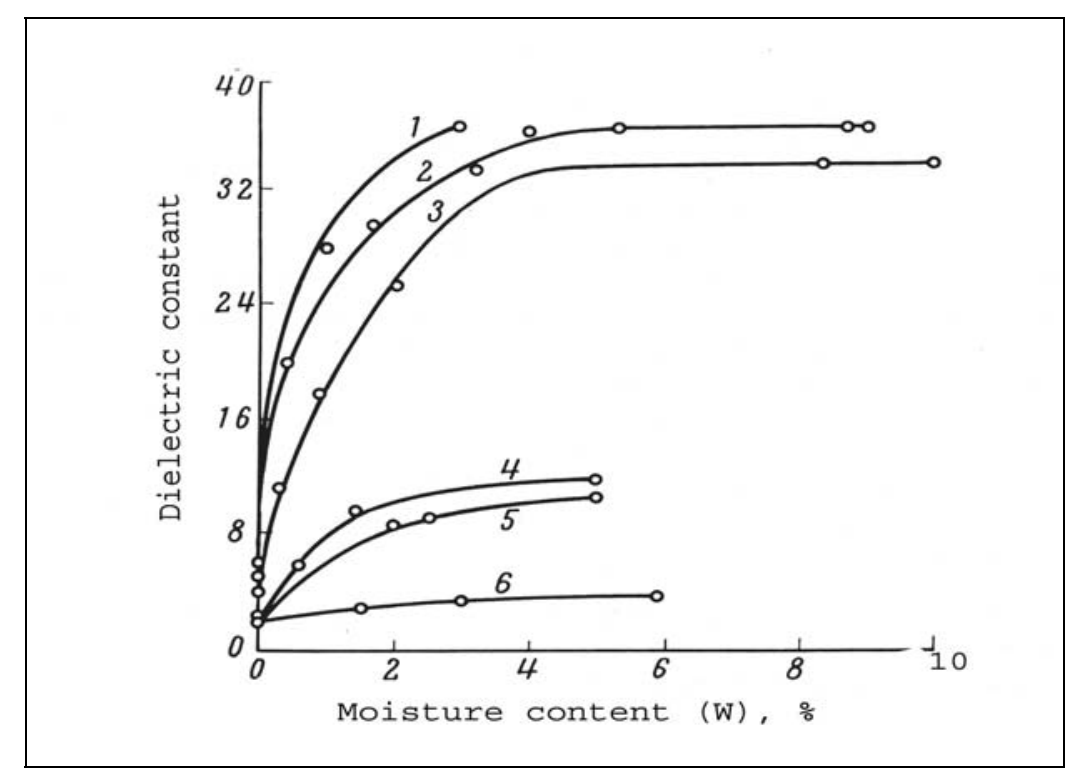

Fig. 2-4: Relationship between the dielectric constant and moisture content: (1) dolomite, (2) marl, (3, 4, and 5) siltstone, (6) sandstone (Parkhomenko, 1967)

From the graph presented above, it is obvious that the dielectric constant varies considerably when the moisture content is $3-4 \%$ and becomes almost constant at higher water content. The spread in values of similar rocks for the dielectric constant is due to measurements that have been made at different frequencies, as explained by the author (Parkhomenko, 1967). Irregular variations in the dielectric constant have been explained by the amount of water present in the rocks. Also, as noted, the frequency has an effect on the observed range.

The anisotropy of the rocks is another very important factor that must be considered when studies of the electrical properties are performed (Parkhomenko, 1967). The orientation of the grains composing the rocks has an influence on their electrical properties. The dielectric constant of a layered rock depends on the direction relative to the bedding planes in which it was measured. As a result, variation in the dielectric constant could be expected. Studies made in three equally perpendicular directions have 
been done. In order to perform that type of observations, three samples of each rock type must be prepared.

Another very important characteristic of the rocks is their electrical resistivity (or electrical conductivity). The hard materials, such as rocks and other solid materials, can be divided into three groups on the basis of the magnitude and mechanism of electrical conduction; conductors, semiconductors, and dielectrics. It is well known that the metals have highest conductivity ranging from $10^{3}$ to $10^{6} \mathrm{mS} / \mathrm{m}$. For semiconductors, the range given is from $10^{4}$ to $10^{-9} \mathrm{mS} / \mathrm{m}$. In general, in contrast to the previous two categories, the dielectric materials have conductivities around $10^{-9} \mathrm{mS} / \mathrm{m}$ or less. The conductivity of rocks varies over much wider limits than any other physical properties. Parkhomenko (1967) previously gave a brief description of the electrical conductivity of dielectrics. In dielectric material, the movement of atoms, molecules, and ions is restricted to small distances and cannot exist over a large distance. However, any dielectric material will have some amount of weakly consolidated charged particles. Therefore, when external electrical current is applied, these weak particles are set in motion and form electrical current. Different formulas for the electrical current are given in Parkhomenko's book. To determine the electrical resistivity of rocks in laboratory conditions, two main groups of methods might be used. In one group of methods, direct current is used, and in the other, alternating current is used. The most commonly used direct current methods are the two-electrode and four-electrode techniques. One of the methods used is the parallel plate method, which employs two electrodes located symmetrical to each other on opposite sides of the rock sample. The resistivities of rocks cover a very wide range, as had been 
observed. In general, the resistivity of a rock is dependent on the electrical properties of the minerals composing the rock.

As mentioned earlier, the moisture content of a rock type has a great influence on its electrical properties. Water strongly affects the resistivity of a rock. This could be explained by the fact that its resistivity is many orders lower than the resistivity of most rock-forming minerals. The relationship between the resistivity and the water content depends on the type of rock and its porosity. In sedimentary rocks, the resistivity is determined mainly by the amount of water present and by the manner in which this water is distributed through the rock. On the other hand, the amount of water that can be held in rock is limited by the available porosity. The greater the porosity, the greater the potential water content. Published data show that the resistivity of rocks depends on factors such as texture, anisotropy, mineral composition, pressure, temperature, etc.

Parkhomenko (1967) presented studies of the electrical properties. The data concerning the resistivity of coals do not always indicate the moisture conditions under which the measurements were made. Lower values of resistivity were observed for naturally wet coals, while high values of resistivity were reported for dry coals. The resistivity is a function of the petrography of the coal, mineral composition, and degrees of metamorphism as mentioned by Parkhomenko. The conclusion was that the range of resistivity for coals is very wide.

The main factor that plays a role in determination of the resistivity of coal is the degree of metamorphism (Parkhomenko, 1967). This is due to the fact that the metamorphism causes differences in carbonization and carbon ratio. Weakly metamorphosed coals (brown coals) have high resistivity $10^{10}$ to $10^{11}$ ohm-m when dry, 
and $10^{5}-10^{6} \mathrm{ohm}-\mathrm{m}$ when wet. It was observed that further metamorphism decreases the resistivity rapidly. An example of the most probable values of various grades of coals is shown in Fig. 2-5. The figure shows that not only the carbon ratio, but also the ash content that is related to the carbon ratio, plays a role.

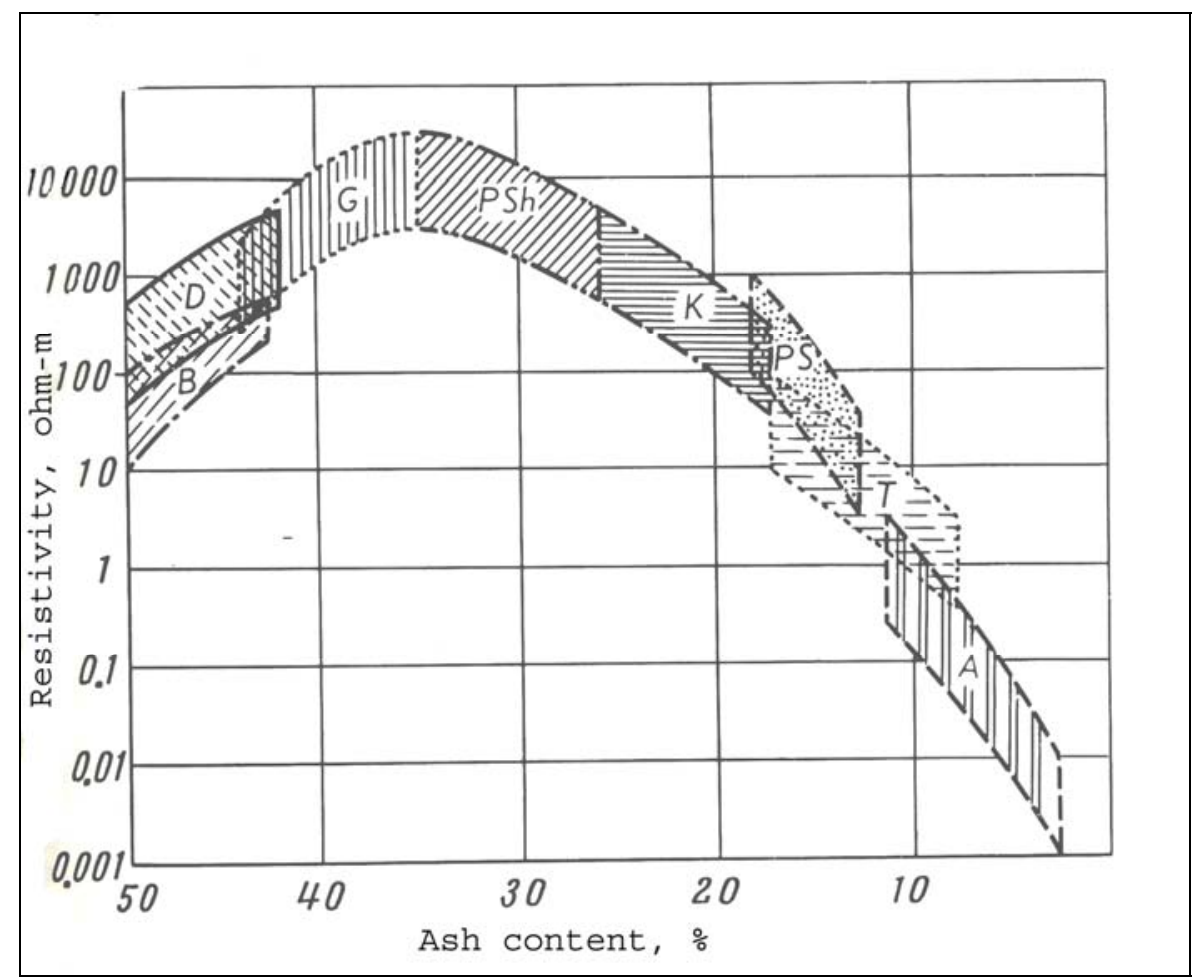

Fig. 2-5: Relationship between the resistivity and the quality of coal: A-anthracite; B-brown coal, D-long-burning coal, PSh-bituminous, PS-super bituminous, K-cooking coal, T-sub anthracite (Parkhomenko, 1967)

A dielectric material is frequently characterized by its dielectric loss. The dielectric loss (loss tangent) is described as the fraction of electrical energy lost to heat, rather than by its electrical conductivity. The energy loss occurs as a result of conductivity and polarization currents according to Parkhomenko. Also, relationships between the dielectric constant, dielectric loss, resistivity, and frequency were established. Once again it was mentioned that electrical properties are strongly dependent 
on water content. It was suggested that the electrical properties should be studied over a broad frequency range, due to the fact that they are frequency dependent. The final conclusions made are that with the development of new geophysical methods for studying the Earth's structures, detailed studies of the electrical properties of rocks are required.

It should be noted that the studies discussed in this chapter so far were made mainly for frequency ranges from $10 \mathrm{MHz}$ to $100 \mathrm{MHz}$. However, there is great interest in expanding the application of geophysical techniques for remote observations of the subsurface beyond the limits of previous studies. The development of electromagnetic (EM) methods offers an attractive new form for formation evaluation. Lately there has been great interest in determining the dielectric constant of earth formations by using downhole logging techniques. The EM wave propagation method of dielectric constant logging attempts to assume the electrical properties of rock formations from phase shift and attenuation measurements of EM fields that have been propagated in the formation.

Freedman and Vogiatzis (1979) discussed the basic physics underlying the operation of the downhole logging device called the Electromagnetic Propagation Tool (EPT), which was developed by Schlumberger's scientists. It describes the plane wave procedure for relating the phase shift and attenuation measurements made by such a device to the dielectric properties of the formation. The interest in the dielectric constant of the earth formations was raised because it was found that the dielectric constant is relatively independent of water salinity, but strongly related to the water content of the rocks. 
The application of downhole logging techniques in the petroleum industry for evaluation of reservoir rocks is of great interest. Dielectric constant logging at microwave frequencies (in the Gigahertz range) offers the capability of differentiating between oilbearing rocks, water, and non-oil-bearing rocks. The authors mentioned that one should be able to determine the complex electric properties of earth formations from phase shift and attenuation measurements made by an EM wave propagation logging device. The EM propagation logging device does not measure formation dielectric constant, but instead measures certain properties (e.g., a phase shift and an attenuation) of an electric field that has been propagated in the formation. Based on those measurements and empirical relationships, an evaluation of the electrical properties of the rocks under investigation can be made. The paper gives a formula for calculation of the EM wave travel times and explains in detail the EPT tool developed by Schlumberger. The formula presented is as follows:

$$
t_{p l}=\sqrt{\frac{\varepsilon^{\prime}}{2 \varepsilon_{0} \times c^{2}}\left(\sqrt{1+\tan ^{2} \delta}+1\right)},
$$

where: $\mathrm{c}=3 \times 10^{8}[\mathrm{~m} / \mathrm{s}]$ is the velocity of light in vacuum;

$$
\begin{aligned}
& \varepsilon_{0}=(36 \pi)^{-1} \times 10^{-9}, \text { [Farad per meter] is the dielectric constant of vacuum; } \\
& \tan \delta=\frac{\varepsilon^{\prime \prime}}{\varepsilon^{\prime}} \text {, where } \varepsilon^{\prime}\left(\varepsilon^{\prime \prime}\right) \text { is real (imaginary) part of the dielectric constant. }
\end{aligned}
$$

The porosity of rocks and its influence on electrical properties was also described (Freedman and Vogiatzis, 1979). The imaginary part of the dielectric constant, as a part of the loss tangent, was introduced to describe all loss mechanisms that lead to the attenuation of an electromagnetic field propagating in a rock formation. A theoretical 
model of the rock formation assuming perfectly conducting half-space separated from the strata by a layer of mud is described in detail. Using the electric hertz vector, which defines the EM field, a solution of the theoretical model is given in the paper. It was demonstrated that accurate values of the microwave electrical properties of the rocks from phase shift and attenuation measurements that have been made using the EM propagation tool could be obtained.

In 1984, the Bureau of Mines was involved in research on ground-probing radars for detection of geological dangers in advance of mining, and a report for the results from the investigation was published (Lindroth et al, 1984). It is well known that penetration capabilities and interpretation methods for observations performed by radar systems are dependent on dielectric properties and wave propagation characteristics of the coal measure stratified media. The authors developed the methodology behind the electrical measurements used. Also, the measurement techniques and apparatus used in their research are described. Moreover, the dielectric constants of coal measure rocks measured for the Pittsburgh Seam in the frequency range $20 \mathrm{MHz}$ to $100 \mathrm{MHz}$ are addressed in the paper.

Due to the fact that the electromagnetic (radar) probing techniques are of great interest for the mining industry, more detailed investigations of the electrical properties of coal measure rocks started in 1984. The electromagnetic data collected in the field by different radar technologies could lead to fault interpretation. Without the electromagnetic property data on the coal measure rocks for input into the interpretative algorithms, the results from the field observations might not be valuable. The studies showed that certain limestones and coals were able to provide low-loss wave 
propagation. The necessity of acquiring the electrical properties of rock overlying mine workings was recognized by the authors. They observed that a significant portion of the rock overlying a coal mine may have its characteristics modified by weathering. The measurements were done on drill cores taken from the upper Pittsburgh seam in Southwestern Pennsylvania. During the tests, the humidity of the samples was controlled. The experimental dielectric constant and dissipation factor (loss) values for various rock types were given in the publication. The values given were determined at 20, 40, 60, 80 , and $100 \mathrm{MHz}$. The calculated values for the attenuation rate were also provided in the report. The values of the dielectric constant, for the previously mentioned frequency range, spread from about 4 to almost 11 for the different rock types observed. The effects of humidity on the samples, as well as the mineral composition of the samples, are described. In conclusion, the authors mentioned that the moisture content of the samples tested was less than those in-situ (Lindroth et al, 1984). Diverse water saturations between the samples were explained with the difference in their porosities.

Knight and Nur (1987) studied the dielectric constant of eight sandstones in the low-frequency range from $60 \mathrm{kHz}$ to $4 \mathrm{MHz}$. The measurements were made using the two-electrode technique. The rock samples were tested under various levels of water saturation. The results presented in the paper showed a clear dependence of the dielectric constant upon the testing frequency. The magnitude of the frequency dependence was found to be proportional to the pore space of the studied sandstones. Also, it was mentioned that the dielectric constant increases rapidly at low water saturations up to some critical saturation, and then starts to increase more gradually with the changes in the 
water content. The values of the dielectric constant are of great interest because of the well-logging tools that could be used for formation evaluation.

The authors found that the electrical properties of the eight sandstones measured are strongly dependent upon frequency (Knight, Nur, 1987). Petrographic analysis of the samples was made and their porosity was also found. The data were collected using an HP-4192 A impedance analyzer. The complex impedance of the disk-shaped sandstone samples was measured. The effect of moisture on the dielectric constant was the major objective in the study. Because the dielectric constant and conductivity were dependent on the salinity, the samples were fully saturated with deionized water in order to remove any salts from the pore spaces of the rocks. After the salts were removed, the samples were dried and then partially moistened with deionized water. After studying the sandstones at different levels of water saturation, the authors suggested that a critical parameter that affects the electrical characteristics is the pore space in the samples, since it determines the capability to hold water in the rocks. The main conclusion was that the amount of water in the sandstones determines the magnitude of the frequency dependence. Therefore, in the frequency range of $60 \mathrm{kHz}$ to $4 \mathrm{MHz}$, it will have an effect on the dielectric constant as well.

As mentioned earlier, the electrical properties of rocks are one of the most important factors in performing electromagnetic geophysical surveys. The existence of natural waveguides in the Earth's crust was mentioned earlier in this section. The finding of natural waveguides in the Earth was made by Wait (1963). Stolarczyk and Fry (1990) reviewed the existence of a parallel-plate waveguide in stratified coals for transmission of electromagnetic waves. As indicated earlier, the presence of natural waveguides in coal 
seams is due to the electrical contrasts between the coal seam and its bounding strata. In other words, because the conductivity of the coal seam is lower than the conductivity of the bounding sedimentary rocks presented in roof rock and floor, the natural electromagnetic (EM) wave had been formed. In general, the waveguide in the coal seams is well presented when there is a difference of at least one order of magnitude in the electrical properties between the coal seam and its bounding sedimentary rocks. Once the waveguide is presented in the coal seam, it is assumed that the EM waves will travel only in the coal seam between roof and floor, without being additionally attenuated in the bounding rocks. Since the EM waveguide exists in the coal seam, the EM waves could be transmitted easily through the coal. Based on the idea of waveguides, it was found that the electromagnetic waves will be significantly attenuated if there are geological anomalies along the electromagnetic wave ray path. Some geological anomalies that could be found underground and that will affect the waveguide are shown in Fig. 2-6. The authors (Stolarczyk and Fry, 1990) give a brief description of the electromagnetic wave's flow in coal seams, as illustrated in Fig. 2-7. 


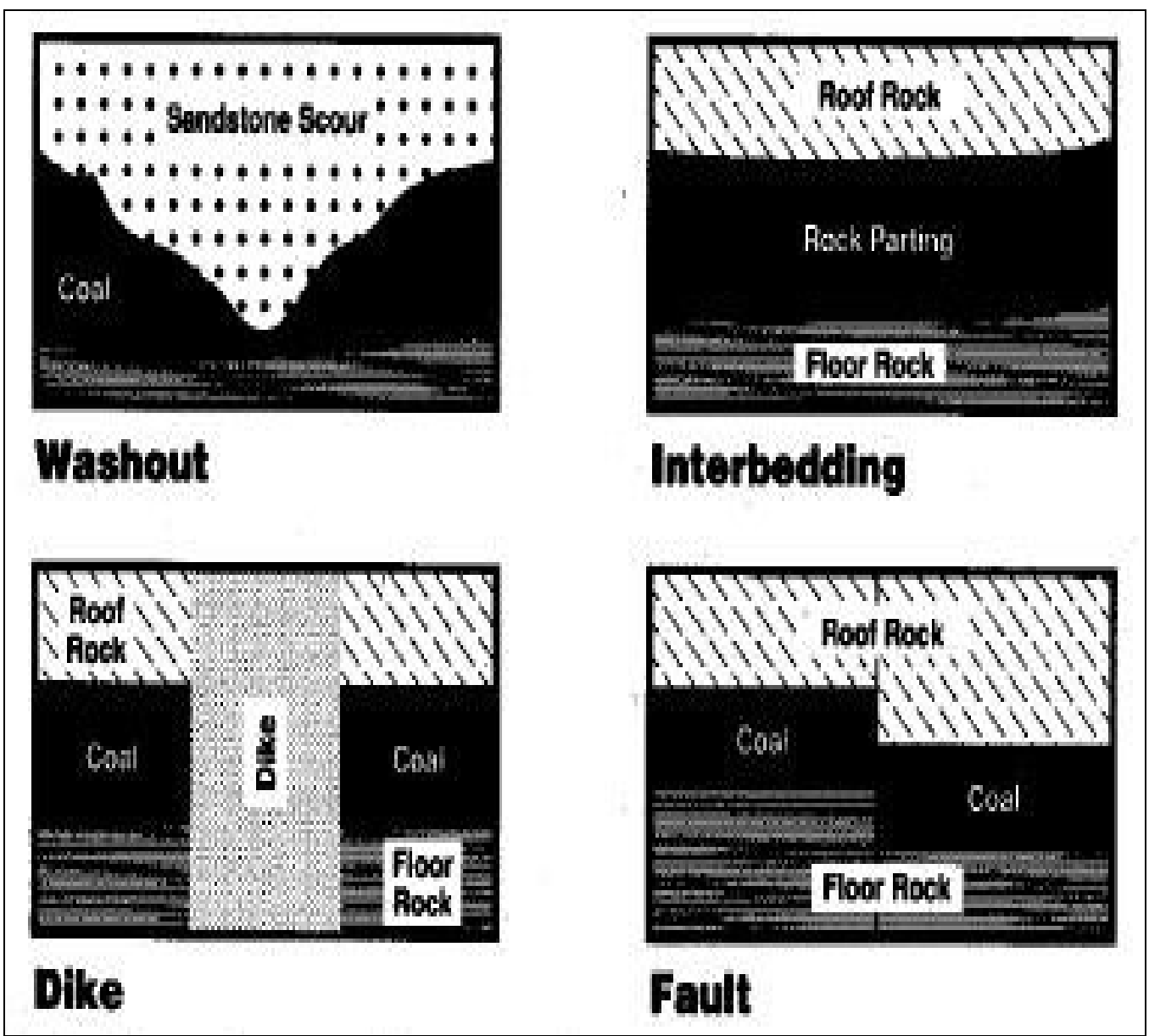

Fig. 2-6: Natural waveguide anomalies in coal seams (Stolarczyk and Fry, 1990)

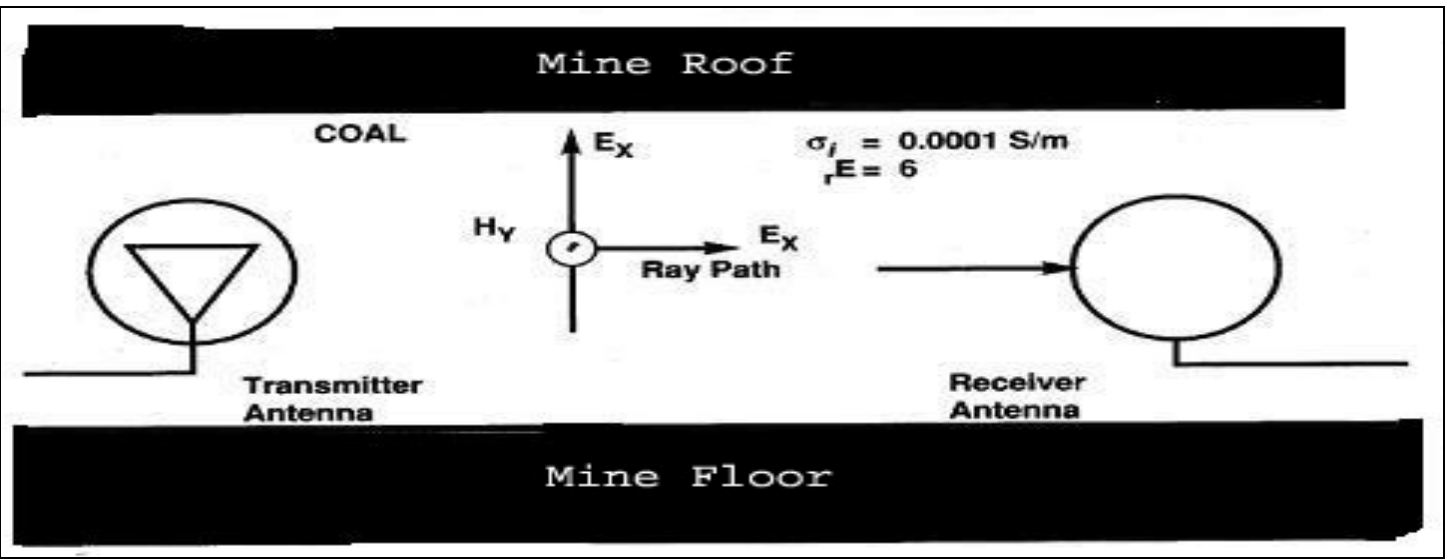

Fig. 2-7: Cross section of coal seam presenting the electromagnetic (EM) wave path (Stolarczyk and Fry, 1990) 
Figure 2-7 shows that there is a small electric field component $\left(E_{x}\right)$ that had been polarized between the mine roof and the mine floor. The magnetic $\left(\mathrm{H}_{\mathrm{ya}}\right)$ field component is directed into the page. The horizontal EM wave will travel in the coal seam between transmitting (Tx) and receiving $(\mathrm{Rx})$ antennas along a straight line without bouncing in the roof or floor rock. The power of the Radio Imaging Method (RIM) is that by using low frequencies for electromagnetic sounding, it could achieve much greater penetration depth than other geophysical methods. Therefore, it could be used for underground observations in modern longwall panels that have a width of $1000 \mathrm{ft}$ or more. However, in order to achieve the desired penetration depth and interpretation accuracy, one must know the approximate electrical characteristics, such as dielectric constant, conductivity, attenuation rate, etc., of the coal seam in order to make a proper selection of the frequencies that should be used in the surveys. The application of technologies like RIM is of great importance for the mining industry because the detection of potential geological hazards in advance of mining could not only save the mining companies money, but also improve mine safety. For this reason, an appropriate estimation of the electrical properties of coal measure rocks is greatly needed.

Finally, Martinez and Byrnes (2001) focused on the modeling of the dielectric constant values of geologic materials. The study was done for potential applications of Ground Penetrating Radar (GPR), which is a near-surface geophysical imaging method used for non-invasive subsurface, geologic, and engineering investigations. The dielectric constant is a crucial parameter for GPR surveys because it controls the velocity of propagation of electromagnetic waves through the earth materials and also the reflection coefficients across the interfaces of different materials. 
Last, but not least, the dielectric constant controls the vertical and horizontal resolution capabilities of a radar system. It is well known that the dielectric constant of rocks is primarily a function of pore fluids, porosity, mineral composition, frequency, etc. Reported dielectric constant values in the literature for sedimentary rocks provide general ranges of the expected values, but these average values might not be adequate for specific field conditions. In general, the dielectric constant decreases with increasing frequency, while the attenuation and dielectric loss increase with frequency.

The authors described in detail a model for prediction of the dielectric constant, which has been used in their research. They have used the so-called Time-Propagation (TP) model, which is considered to be the simplest and most appropriate when used for geologic conditions. The results of the study could be used not only in planning radar surveys, but also in interpreting the data. The velocity of electromagnetic waves and their travel times, as well as vertical and spatial resolution, were estimated and given in the paper. The effect of water saturation on the dielectric constant was indicated as an important factor. The performed modeling was for limestones and sandstones. Overall, the TP modeling of the dielectric constant presented in this study is in very good agreement with the measured values of the samples that had been modeled. It was concluded by the authors that this type of modeling of the electrical properties of rocks provides a good basis for better understanding the effects on the dielectric constant and consequently on the radar's response.

Not many examinations of the electrical properties of sedimentary rocks and coals have been performed. In addition, most of the studies presented here observed the electrical characteristics of the rocks either in very low-frequency range $(\mathrm{Hz})$ or in the 
microwave frequency range (Giga Hertz range). There is a lack of measurements for the megahertz frequency range of sedimentary rocks and coal. Also, it can be said that studies of the electrical properties in the low-frequency range $20 \mathrm{kHz}$ with an upper limit of about $10 \mathrm{MHz}$ are rare in the published literature. 


\section{CHAPTER 3}

\section{METHODOLOGY BEHIND MEASURING ELECTRICAL PROPERTIES OF ROCKS}

The measurements of the electrical properties of coal measure rocks are of great importance for correct evaluation of geological conditions when performing underground observations using different types of electromagnetic (EM) systems. For this reason, data for the electrical properties of rocks must be collected and analyzed. Moreover, once the data are accumulated, a better understanding of the rock behavior when an external electromagnetic field is applied will be gained. The methodology behind the electrical measurements of coal measure rocks is addressed here. Description of how the samples were collected from different coal seams, as well as the sample preparation procedure and the requirements that they should meet are presented. An overview of the instrumentation used in both low- and high-frequency ranges in this research, and the measurement techniques used, are described here in detail. Finally, there is a brief description of the device that was used to control the moisture content for part of the experiments conducted.

\subsection{Sample collection}

For the purposes of this research, coal and rock samples have been collected from major coal fields across the United States. The collected samples represent specific site conditions in different coal seams. As mentioned previously, this is important because of the fact that the approximate electrical characteristics of the rocks must be known in 
order to improve the detection capabilities of the electromagnetic system that is to be used. The samples collected represent five coal fields across the country. These coal seams are the Pittsburgh, Sewickley, Herrin, Fruitland, and Wasatch Plateau. The samples were collected from nine mine sites. Geographical information about the coal seams included in this study is presented in Table 3-1.

Table 3-1: Coal seam locations

\begin{tabular}{|l|l|l|l|l|}
\hline Seam Name & \multicolumn{1}{|c|}{ Mine } & \multicolumn{1}{c|}{ County } & \multicolumn{1}{c|}{ State } & \multicolumn{1}{c|}{ Country } \\
\hline Pittsburgh & $\begin{array}{l}\text { Mine A } \\
\text { Mine B } \\
\text { Mine C }\end{array}$ & $\begin{array}{l}\text { Marshall } \\
\text { Marion } \\
\text { Monongalia }\end{array}$ & WV & United States \\
\hline Sewickley & Mine D & Monongalia & WV & United States \\
\hline Fruitland \# 8 & Mine E & San Juan & NM & United States \\
\hline Herrin \# 5 & Mine F & Saline & IL & United States \\
\hline $\begin{array}{l}\text { Wasatch } \\
\text { Plateau }\end{array}$ & Mine F & Sanpete & UT & United States \\
\hline
\end{tabular}
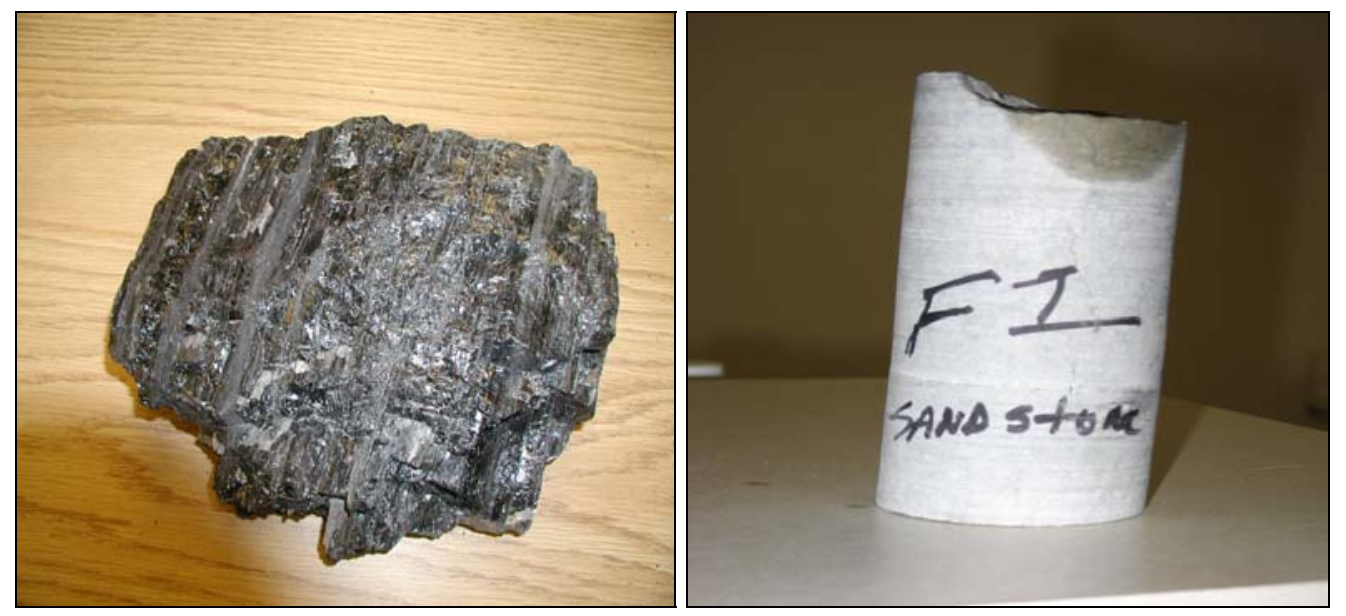

Fig. 3-1: Examples of coal and rock samples collected from major U.S. coal seams

\subsection{Preparation of the rock samples for testing}

The collected rock samples were prepared according to the specifications for testing in low- and high-frequency ranges. The low-frequency range $(20 \mathrm{kHz}$ to $10 \mathrm{MHz})$ 
is mainly encountered in the RIM applications, while the high-frequency range (200 MHz to $3 \mathrm{GHz}$ ) is used for DSR and Ground Penetrating Radar (GPR) applications. The samples collected were core samples from mines, as well as irregularly shaped blocks of coal and rocks. In addition, the irregularly shaped coal blocks were drilled in order to get cylindrically shaped core out of them.

Since there were specific requirements for the samples under test (such as smooth surfaces without any gaps, flat faces, limited thickness, etc.) in order to perform accurate measurements of their electrical properties, two kinds of samples were prepared. The samples were machine prepared and then tested. The first step in the preparation process was to cut the samples into sizes that could be used for performing the measurements using a diamond saw. Since one of the major requirements for the samples was that they must have polished surfaces without any gaps, polishing of the samples was needed. The polishing was done by hand due to the small size of the samples. The first type of samples was used for the low-frequency testing. They were small disk-shaped samples, with thicknesses varying from $3 \mathrm{~mm}$ to $1 \mathrm{~cm}$ and diameter of about $5 \mathrm{~cm}$. Both sides (top and bottom) must be polished. The second types of samples were used for the highfrequency tests. They had thicknesses of at least $2.5 \mathrm{~cm}$. The diameter of the second kind of samples should be $2 \mathrm{~cm}$ or greater, as suggested by the manufacturer of the test equipment. Only the top surface that is in contact with the dielectric probe should be polished. These requirements for the sample size are due to the restrictions of the equipment. Figures 3-2 and 3-3 illustrate the two types of rock samples prepared and used in this study. 

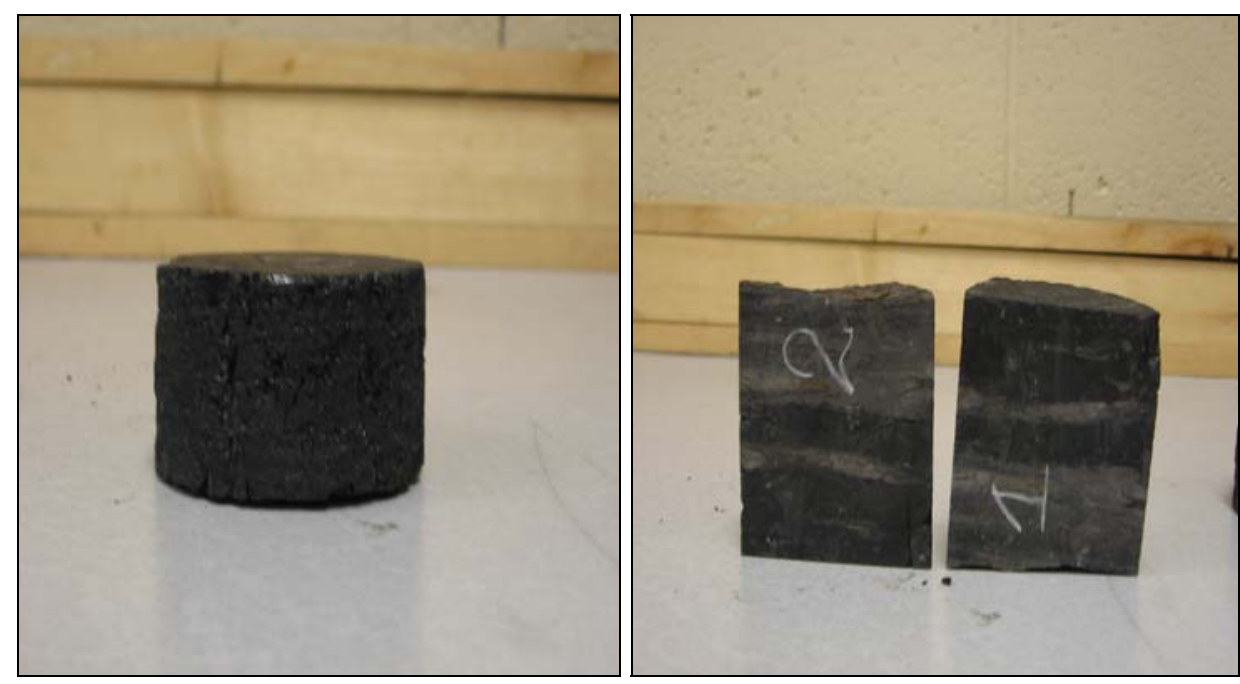

Fig. 3-2: Coal samples prepared for testing under high frequencies
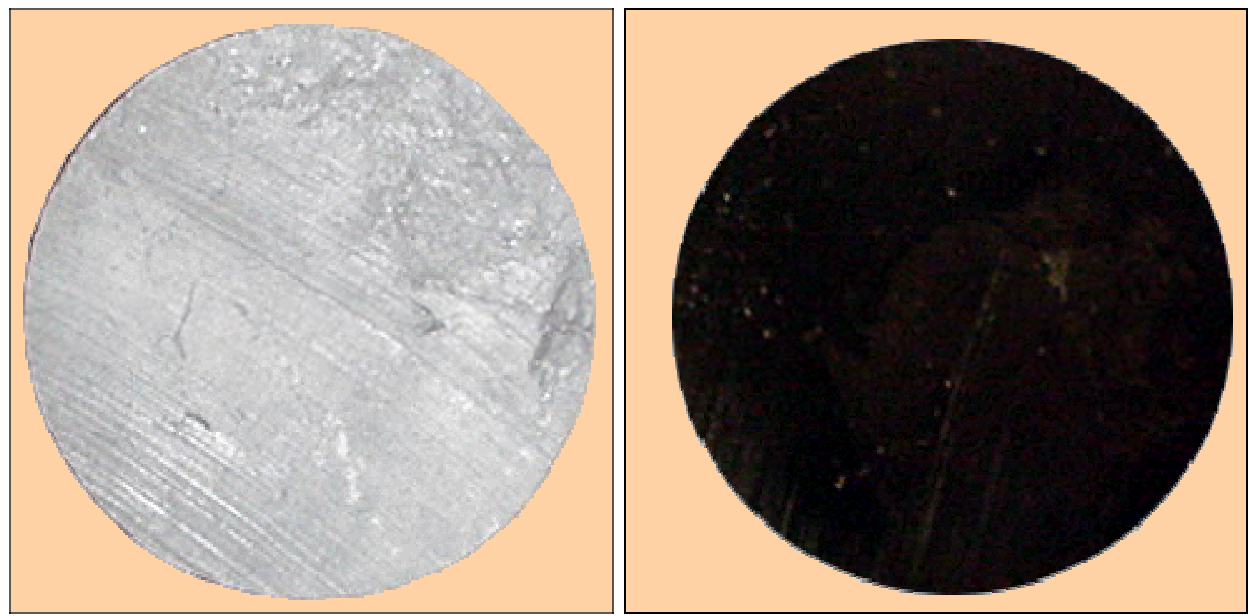

Fig. 3-3: Sandstone and coal samples prepared for testing under low frequencies

Another important fact that should be mentioned is that, whenever possible, the samples were cut in three directions mutually perpendicular to each other with the bedding plane direction being the primary one. By doing this, the effects of sample orientation on the electrical properties of the rocks can be studied. The preparation of rock and coal samples to meet these requirements is a very hard task, especially the preparation of samples from fragile coal blocks. 


\subsection{Measurement techniques and instrumentation used in the study}

The samples were tested in two different frequency ranges using two different sets

of equipment. An EM property measurement laboratory was established at West Virginia University. The facility includes two sets of electromagnetic property measurement systems in two frequency ranges: low-frequency $(20 \mathrm{kHz}$ to $10 \mathrm{MHz})$ and high-frequency (200 MHz to $3 \mathrm{GHz}$ ) ranges. The measurement techniques and the calibrations that need to be performed prior to starting the measurements are explained in the following paragraphs.

\subsubsection{Low-frequency measurement testing setup}

The low-frequency equipment consists of a Agilent $16451 \mathrm{~B}$ dielectric probe kit and an HP-4192 A Impedance Analyzer. It has a range of operation from $5 \mathrm{kHz}$ to $13 \mathrm{MHz}$ (Fig. 3-4).

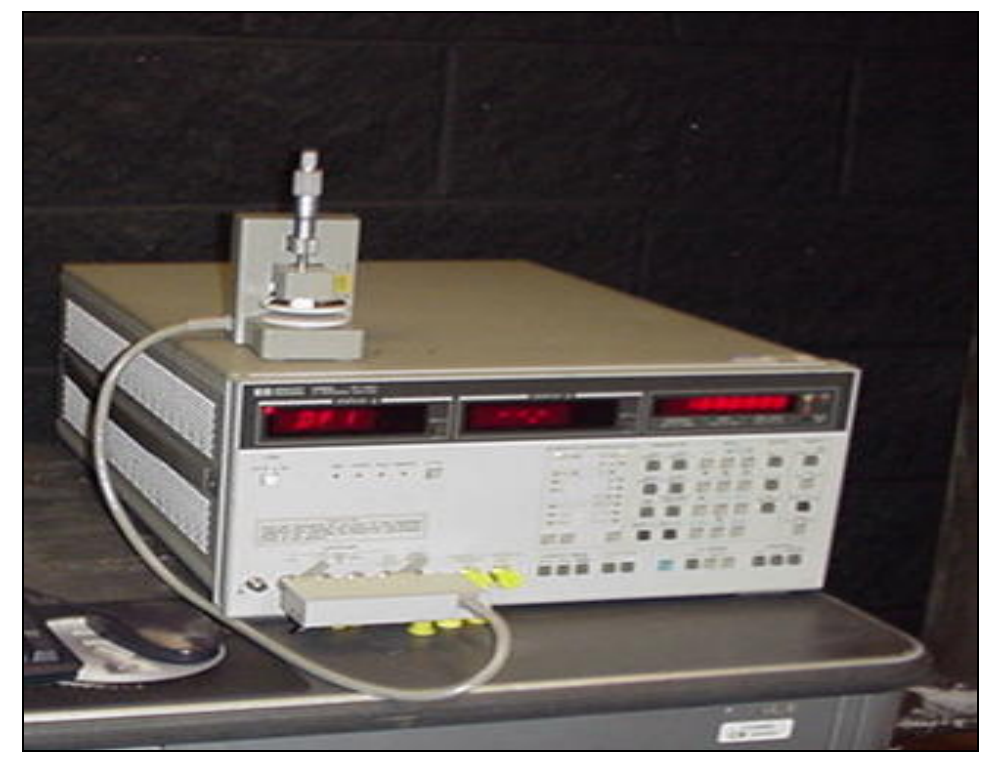

Fig. 3-4: HP-4192A Impedance Analyzer

The test fixture is designed for accurate dielectric constant and loss tangent measurements compatible with the impedance analyzer that has been used. It employs the 
parallel plate method, which sandwiches the material between two electrodes to form a capacitor. Then the HP-4192A measures the capacitance of the material created by the two electrodes of the test fixture and the loss that occurs in the sample (loss tangent). Based on the empirical relationships between the capacitance and loss tangent, given in the next chapter, the dielectric constant, attenuation rate, and resistivity/conductivity of the sample are then calculated. The dielectric probe kit consists of two fixed cylindrical electrodes (Fig. 3-5) that are parallel to each other. Their diameter is about two inches. Adjustment to ensure parallel electrodes is required when using the 16451B. The thickness of the test sample can vary from $3 \mathrm{~mm}$ up to $1 \mathrm{~cm}$.
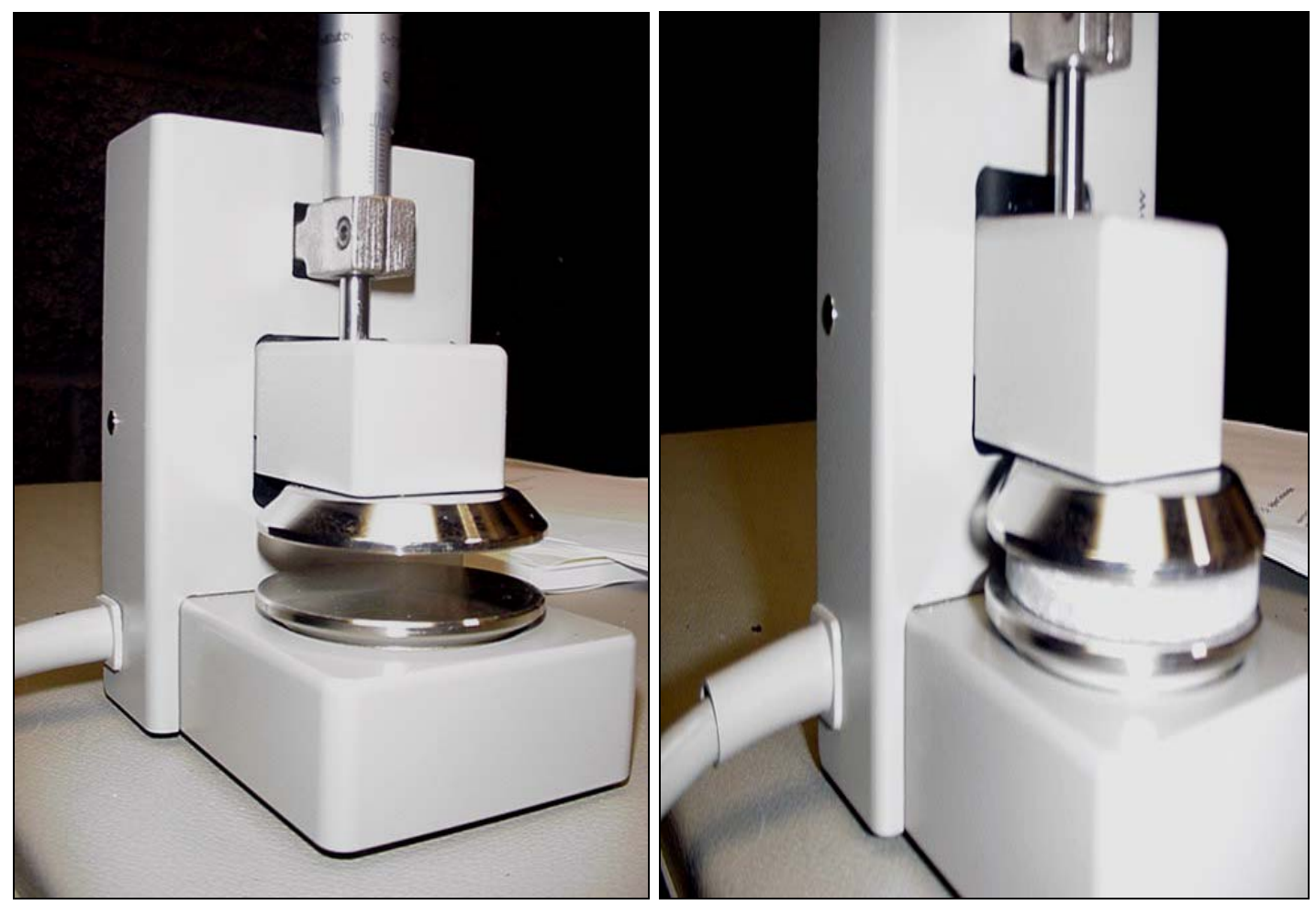

Fig. 3-5: Low-frequency dielectric test fixture

A major requirement for the test samples is that they should be at least the diameter of the electrodes or larger for the so-called "edge effect error" to be minimized. 
In other words, the samples must be disk shaped with two parallel faces. Another requirement when using this probe kit is that the samples should have very smooth surfaces to assure gap-free full contact between the electrodes and the sample observed. This is crucial for the final result of the measurements.

Due to the imperfections in preparing the samples, such as small gaps, not completely parallel to each other sample sides, etc., errors in the final result can occur. The effect of air gap between the electrodes and the samples can result in much lower values of the measured properties than the actual values. The lower values that can be obtained from the measurements when there is no full contact between the electrodes and the sample are normal due to the fact that the air and hard materials have different dielectric properties. Calibration of the instrument before each measurement is mandatory. Both open and short compensations are recommended before measurement. Open compensation is performed by separating the upper and the lower electrodes from each other. Then testing frequency should be chosen and the instrument calibrated by measuring the capacitance of the air created between the two electrodes. Short compensation is performed by connecting the high and low electrodes by using a special metal plate provided with the dielectric probe kit. After performing the calibration, the test sample can be inserted into the test fixture.

During the research, several issues with the calibration were encountered and solved; perhaps the most important of them was the effect of the calibration on the final results. It was found that the calibration procedure suggested by the manufacturer of the instrument is not appropriate for the measurements that needed to be performed. Agilent's technique requires calibration of the instrument after every single frequency 
tested. It was found that placing the sample in different positions between the electrodes could have an effect on the final results. Due to these movements, sometimes the values of the EM properties could vary, even if they are from the same sample and frequency. Due to this issue, two other methods of calibration were tested, and they showed their advantage over the manufacturer's procedure. The two new variants of the calibration process are similar to each other and basically required one calibration of the instrument for a certain frequency range. The calibration issue was solved, and success for many repetitive measurements of different materials was achieved. One other important problem that should be kept in mind is that the electrodes should be kept very clean. They have to be cleaned often between the measurements with methanol (methyl alcohol) to ensure an oil-free surface on the electrodes. This is important because the instrument is sensitive to that type of contamination and even the oil from the fingers of the person making the measurements can influence the final result.

The test was performed by placing the samples in the space between the two electrodes. Then the electrodes were adjusted, to assure that they were in full contact with the test sample. Then the testing frequency of interest was manually chosen by pressing the analyzer's keyboard. Once the frequency was chosen, the analyzer reads the values of the capacitance and the loss tangent formed in the material.

\subsubsection{High-frequency measurement testing setup}

As mentioned before, the high-frequency tests covered the frequency range from $200 \mathrm{MHz}$ to $3 \mathrm{GHz}$. The high-frequency measurement equipment in the West Virginia University laboratory consists of an Agilent 8714 ES network analyzer (Fig. 3-6) and an Agilent 85070 high-temperature dielectric probe kit. The network analyzer used for the measurements in this research was a newer version than the network analyzer that had 
been used previously. At the beginning of the EM measurements, the HP 8753 B network analyzer was used. The change between the analyzers was made in order to improve the accuracy of the testing results. The new analyzer used offers higher resolution (every $1 \mathrm{MHz}$ ) and faster sweep time between the frequencies tested. Measurement calibrations and data averaging provided performance improvement and flexibility.

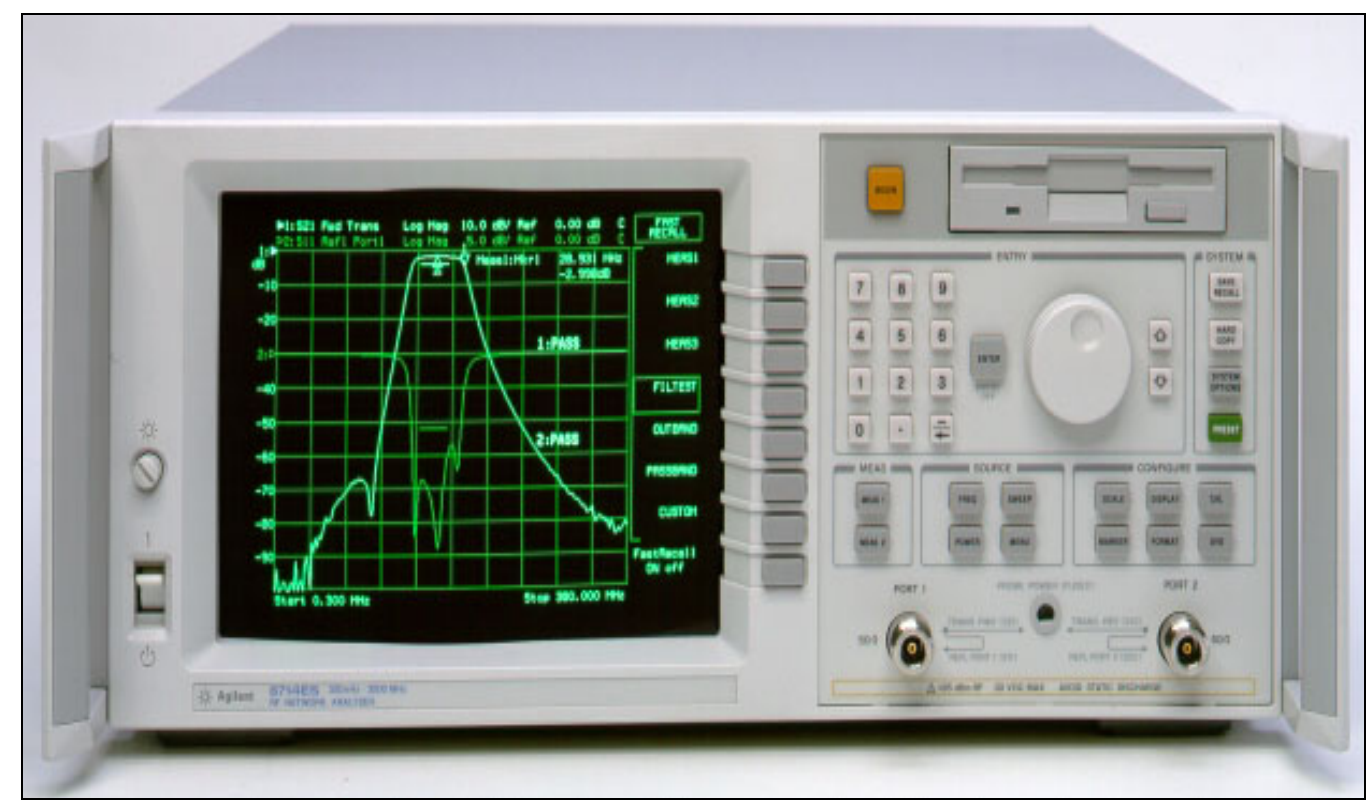

Fig. 3-6: Agilent 8714 ES high frequency network analyzer

Special software provided with the dielectric probe kit (Agilent IO libraries software suit) has been used to fully control the analyzer and perform the tests. In other words, the dielectric probe kit is connected to a computer through the network analyzer to measure the dielectric properties of the different materials. The analyzer measures the reflection coefficient between the probe kit and the material under test by transmitting the electromagnetic energy through the electrode of the probe kit. Then the algorithm on which the software is based calculates the dielectric constant of the test material and allows direct readings for the real part $\left(\varepsilon_{\mathrm{r}}^{\prime}\right)$ and the imaginary part of $\left(\varepsilon_{\mathrm{r}}{ }^{\prime \prime}\right)$ the dielectric 
constant. In addition, it calculates the loss tangent for the test material. Calibration of the instrument before the beginning of the measurements is required. Air, short, and water compensations are recommended before the measurement. Air compensation is performed by leaving the dielectric probe open to air. Then short compensation is performed by connecting a shorting block to the probe, and finally water compensation is done by inserting the electrode in water. It should be noted that the water for the water compensation should be deionized and at a temperature of $25^{\circ} \mathrm{C}$ (about $77^{\circ} \mathrm{F}$ ). Also, the frequency range in which the measurements were performed should be chosen and preset in the instrument by using the Agilent's software. Moreover, the software automatically generates the selected number of frequency points for the range $200 \mathrm{MHz}$ to $3 \mathrm{GHz}$ at equal steps. The instrumentation could be used to measure the EM properties of liquid and solid samples as well. For solid samples, a smooth flat surface of the samples is recommended by Agilent.

A simple small jig was constructed for the high-frequency measurements and has been used during the measurements and is shown in Fig. 3-7. 


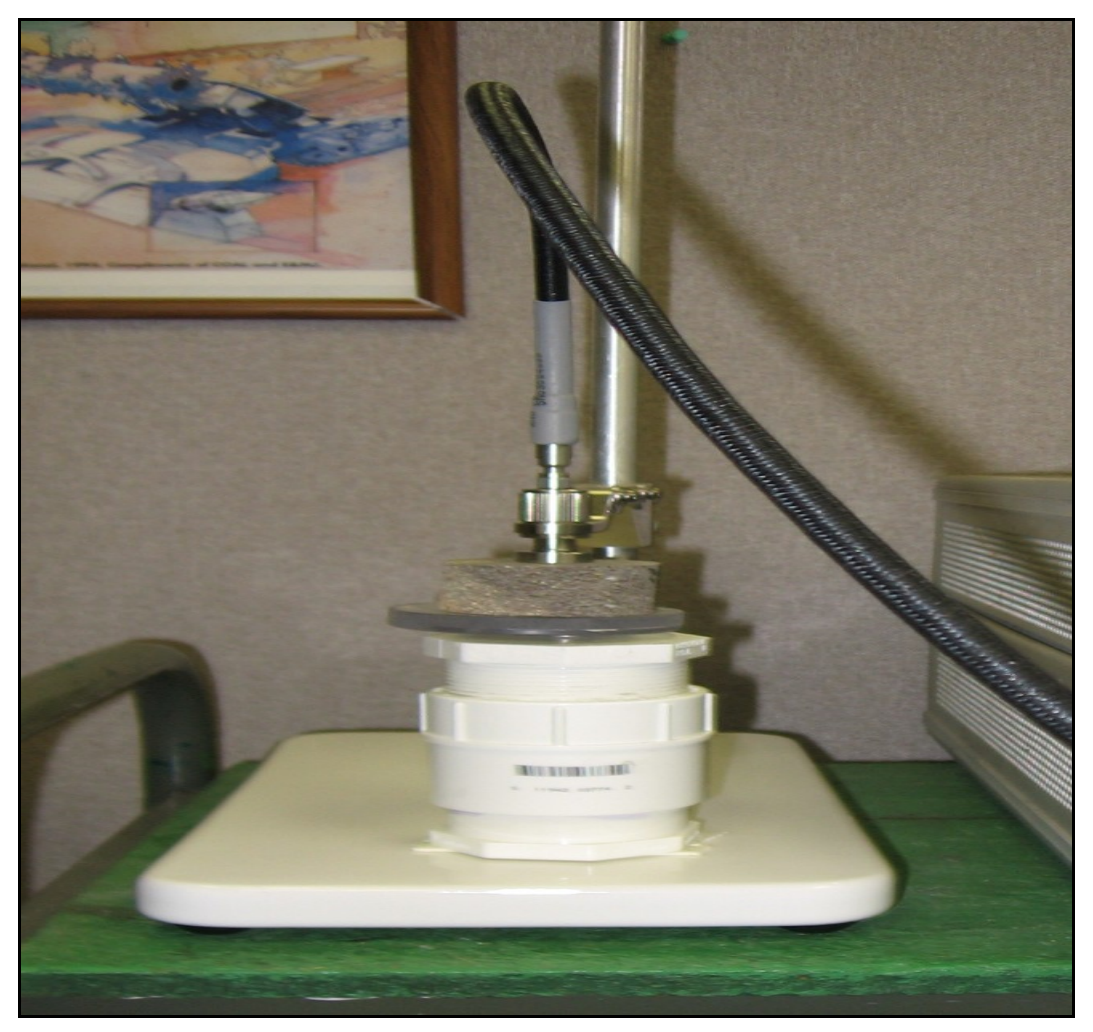

Fig. 3-7: The dielectric probe and supporting jig

The purpose of this jig is to ensure full, air-gap-free contact between the electrode and the material under test. The jig is adjustable in height, which allows us to perform tests for samples of different thicknesses. Another requirement from Agilent is that the thickness of the test sample should be at least $20 / \sqrt{\varepsilon^{\prime}}$, or at least one inch for most of the earth materials. This is due to the fact that the sample under test should represent an "infinite media" to the probe.

After the calibration has been performed, the measurement can start. For this purpose, the frequency range that is of particular interest should be pre-set in the software as mentioned previously. The number of frequency points that will be tested should be estimated so they could also be pre-set in the tested frequency range. The dielectric data in support of this study were measured over a frequency range from $200 \mathrm{MHz}$ to $3 \mathrm{GHz}$. 
For each rock type tested, the real and imaginary parts of the dielectric constant and loss tangent were measured at each of the 101 equally spaced frequency points covering the frequency range mentioned above. In other words, this corresponds to 404 data points for the real part $\left(\varepsilon^{\prime}\right)$ and the same number for the imaginary part $\left(\varepsilon^{\prime \prime}\right)$ of the dielectric constant, as well as for the loss tangent $(\tan \delta)$ for each rock sample tested.

Based on the measurements in low-and-high frequency spectrum, a better understanding of the variations of the EM rock properties with the frequencies for different materials can be gained. Such findings from the research will be useful in the improvement of the Radio Imaging Method and Drill String Radar.

\subsection{Control of the moisture content for the coal measure rocks tested}

One of the tasks in this research was to estimate the influence of the moisture content on the electrical properties of coal measure rocks. It has been mentioned that the moisture of the rocks affects the values for the dielectric constant and electrical resistivity/conductivity. To study those effects, test samples were studied under different moisture conditions. Stating that the samples were tested in different moisture conditions meant the samples were tested with natural moisture content first, and then dried out in an oven. The rocks were placed in an oven at $105^{\circ} \mathrm{C}\left(221^{\circ} \mathrm{F}\right)$ for 24 hours to see what quantity of their moisture would disappear. After words the idea was to study what is the effect on the electromagnetic properties with decrease in the moisture content. At the conclusion, part of the dried samples were placed in a special chamber that controls the moisture content, as shown in Fig. 3-8, and remoistened to the desired values. 

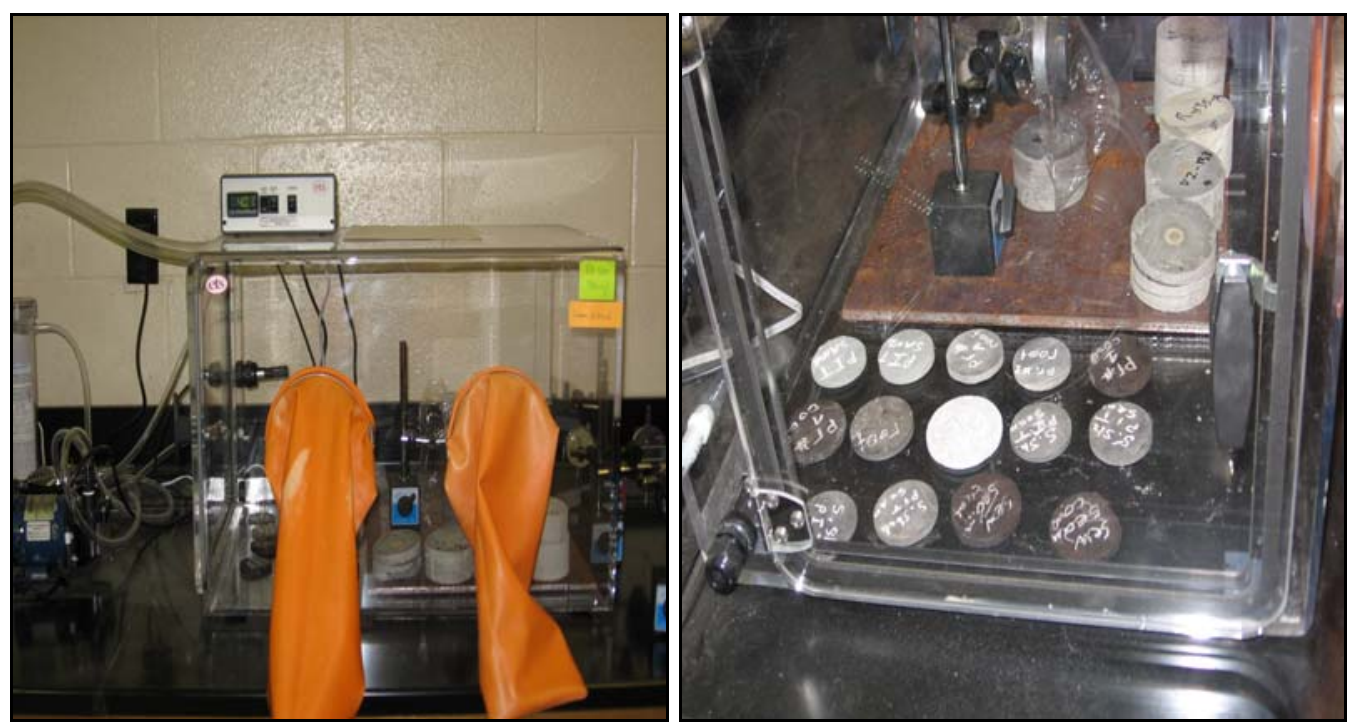

Fig. 3-8: The chamber used to control the moisture content of the rock samples

The chamber is capable of controlling the humidity from 5 to $95 \%$. The average time for saturation of the samples at the desired moisture level is approximately twenty days, according to the chamber manufacturer.

The samples were weighed before and after drying in the oven, as well as before and after placing them in the chamber. The moisture content in percentages was then calculated as the difference between the initial weight of the sample minus the weight of the sample after drying/saturating using the formula:

$$
\text { Moisture content }=\frac{W_{w}-W_{d}}{W_{w}} \times 100,[\%],
$$

where: $\mathrm{W}_{\mathrm{w}}=$ initial (wet) weight of the sample in grams;

$\mathrm{W}_{\mathrm{d}}=$ weight of the sample after drying in grams.

After all tests in the low- and high-frequency range were performed, the accumulated data were analyzed. Moreover, the data were used for building a database of the electrical properties of coal measure rocks to complete the study. The testing results 
and analyses, as well as the discussion of the database built, are addressed in the following chapters. 


\section{CHAPTER 4}

\section{ANALYSIS OF THE COLLECTED DATA}

The result of the laboratory testing of the electrical properties of coal measure rocks is presented in this chapter. The algorithm used for the calculations for the electrical properties of the rocks is shown. An example of the statistical data processing used in the study and which might be used in further investigations is suggested at the end of this chapter.

\subsection{Algorithm for calculating the electrical properties of coal measure rocks}

As mentioned earlier in this study, the resolution capabilities and range of operation of radar systems is strongly dependent on the electromagnetic (EM) properties of the rocks in the domain of interest. The EM properties of the rocks, such as the dielectric constant and attenuation rate, determine the speed of propagation of an electromagnetic wave, as well as the depth of penetration of the signal. In order to be successful, the radar system should be able to "read" underground the differences in the EM properties between the various rocks. In addition, it should be able to produce a real representation of the detected rock types, their orientation, and thickness.

For the purpose of this research, samples were collected in such a manner that they would represent major coal fields in the United States. Samples from five coal fields across the country - the Pittsburgh, Sewickley, Herrin, Fruitland, and Wasatch Plateauwere investigated. The measurements were performed in low- and high-frequency ranges. 
The dielectric constant in the low-frequency range was calculated based on measurements with the Agilent 4192A capacitance using the formula provided by the instrument's manufacturer. The formula used in this study is as follows:

$$
\varepsilon_{r}^{\prime}=\frac{C \times d}{\varepsilon_{0} \times A}
$$

where $A$ and $d$ are the area $\left(\mathrm{cm}^{2}\right)$ of the electrode and the sample thickness $(\mathrm{cm})$, respectively. $C$ is the measured capacitance; $\varepsilon_{0}$ is the permittivity of free space $\left(8.854 \times 10^{-12} \mathrm{Farad} / \mathrm{m}\right)$.

The attenuation rate for the measured samples was calculated by using the wellknown Heaviside formula, which is suitable for different types of materials:

$$
\alpha=8.68 \omega \sqrt{\frac{\mu_{0} \varepsilon_{0} \varepsilon_{r}}{2}\left[\sqrt{1+(\tan \delta)^{2}}-1\right]}, \mathrm{dB} / 100 \mathrm{ft}
$$

where: $\omega=2 \pi f$ angular frequency (also called angular velocity) at frequency $\mathrm{f}$, which is defined as multiple of a simple frequency. The units are radians per second.

$$
\begin{aligned}
& \varepsilon_{\mathrm{r}}=\text { dielectric constant; } \varepsilon_{0}=\text { permittivity of free space } \\
& \mu_{0}=4 \pi 10^{-7} \text { Henry } / \text { m-permeability of free space; }
\end{aligned}
$$

The resistivity of the measured rocks was calculated using the formula:

$$
R=\frac{1}{2 \pi f \times \varepsilon_{r} \times \tan \delta \times 8.854 \times 10^{-12}}, \text { ohm- m }
$$

where: $2 \pi \mathrm{f}=\omega$ at frequency $\mathrm{f}$;

$\tan \delta=$ the loss tangent, which is the ratio of $\varepsilon^{\prime \prime} / \varepsilon^{\prime}$;

$\varepsilon_{\mathrm{r}}=\varepsilon^{\prime}=$ real part of the dielectric constant.

Conductivity of material is exactly the inverse of its resistivity and has units of Siemens per meter $(\mathrm{S} / \mathrm{m})$. 


\subsection{Results of electrical properties measurements}

During the research, rock samples were collected and tested. Some older coal measure rock samples were re-tested a couple of months after they were tested for the first time in order to compare the results from the measurements. Not only sedimentary samples were tested, but also samples from igneous rocks including basalt, phonolite, and biotite-gneiss. Also, studies were performed to test the effect that the moisture content has on the electrical properties of rocks. In addition, studies how the orientation of the samples in regard to the electromagnetic field applied, has an effect on their electrical properties were performed.

Figures 4-1 and 4-2 represent the dielectric constant and attenuation rate (in $\mathrm{dB} / 100 \mathrm{ft}$ ) results for a coal sample collected from the Sewickley Seam and tested in the low-frequency range, respectively. The sample was tested parallel to the mine roof.

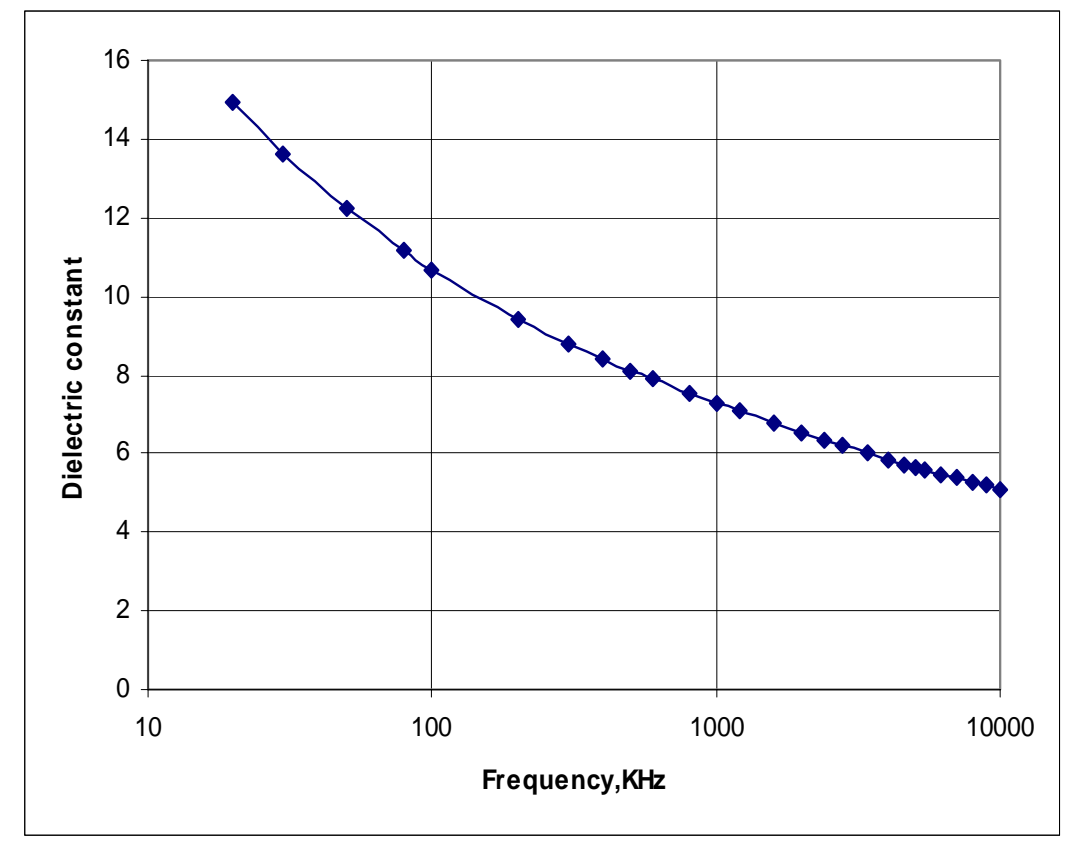

Fig. 4-1: Dielectric constant vs. frequency in coal sample from the Sewickley Seam 


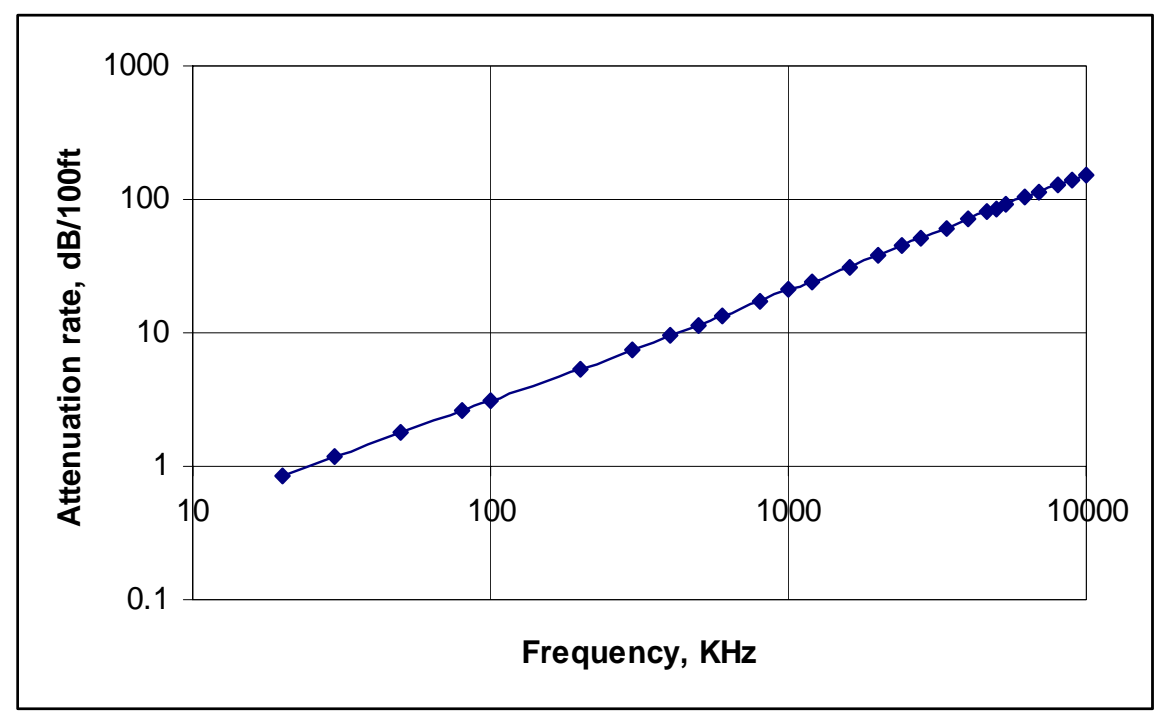

Fig. 4-2: Attenuation rate vs. frequency in coal sample from the Sewickley Seam

In the two figures, the changes in the dielectric constant and attenuation rate and their dependence on the frequency are obvious. The dielectric constant, attenuation rate, and the resistivity/conductivity of the coal (and other natural strata) are frequency dependent. Generally speaking, the dielectric constant and the resistivity decrease in value when there is an increase in frequency. The attenuation rate and conductivity generally increase with an increase in frequency.

As mentioned in the literature review, the EM properties of the geological materials depend on many factors. For the coal measure rocks, the most important of these factors are the moisture content, mineral composition, orientation of planes of weakness with respect to the electric field applied, and crystalline structure.

Comparison of the two tests results on the same coal sample from the Sewickley Seam for a period of a couple of months later is presented in Figs. 4-3, 4-4, and 4-5. The results show that there was a time effect, or indirectly the effect of moisture content, on the testing results. Since the sample was not kept in a moisture-controlled environment, it 
was exposed to air drying and the dielectric constant decreased with time because of the reduction in the moisture content. The moisture content of the coal sample has a great effect on its electrical properties. Usually, the moisture content in the rock samples has its highest values when it is first taken from the undisturbed coal seam.

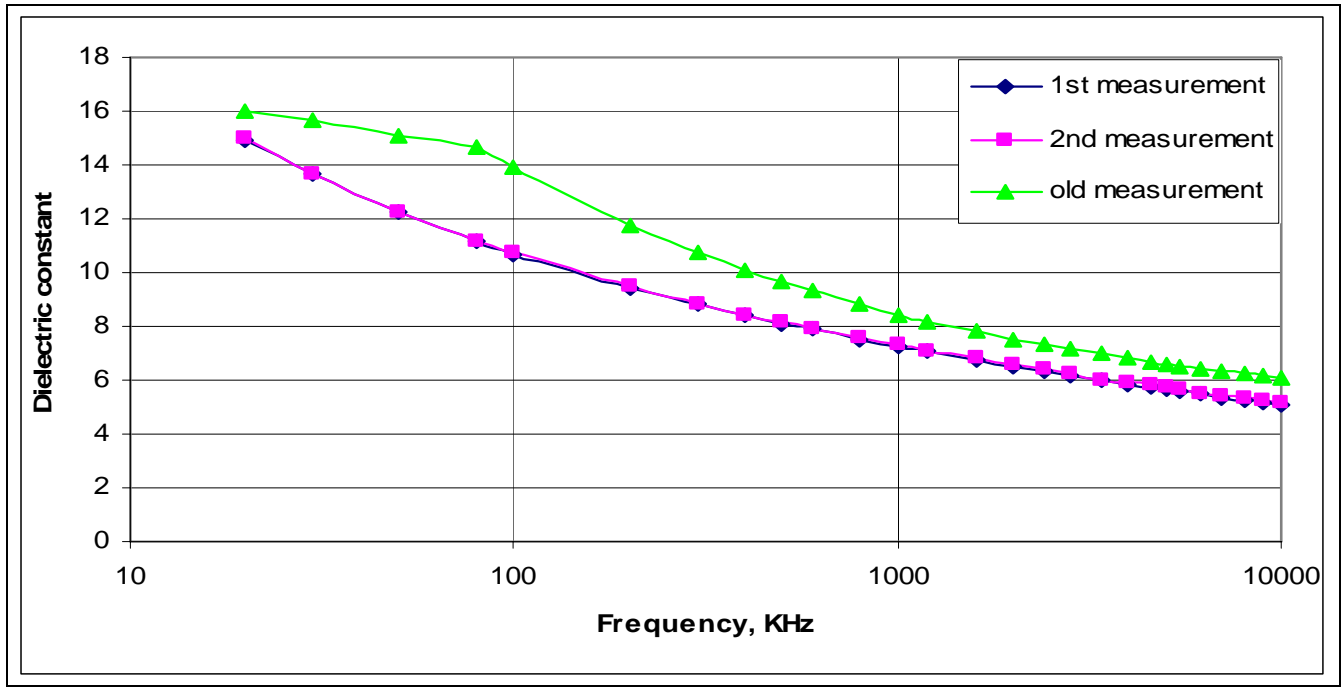

Fig. 4-3: Comparison of the dielectric constant of a coal sample from the Sewickley Seam in two tests separated by a couple of months

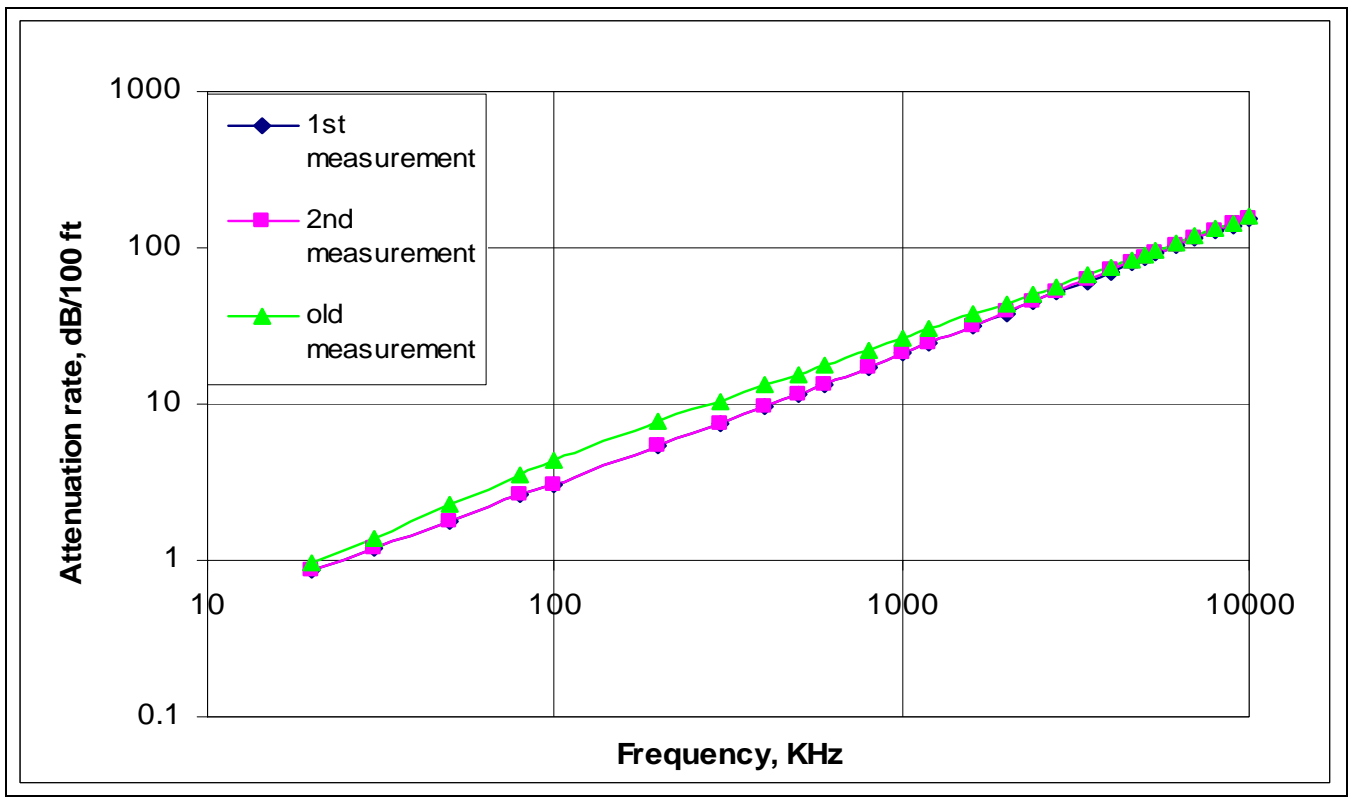

Fig. 4-4: Comparison of the attenuation rate of a coal sample from the Sewickley Seam in two tests separated by a couple of months 


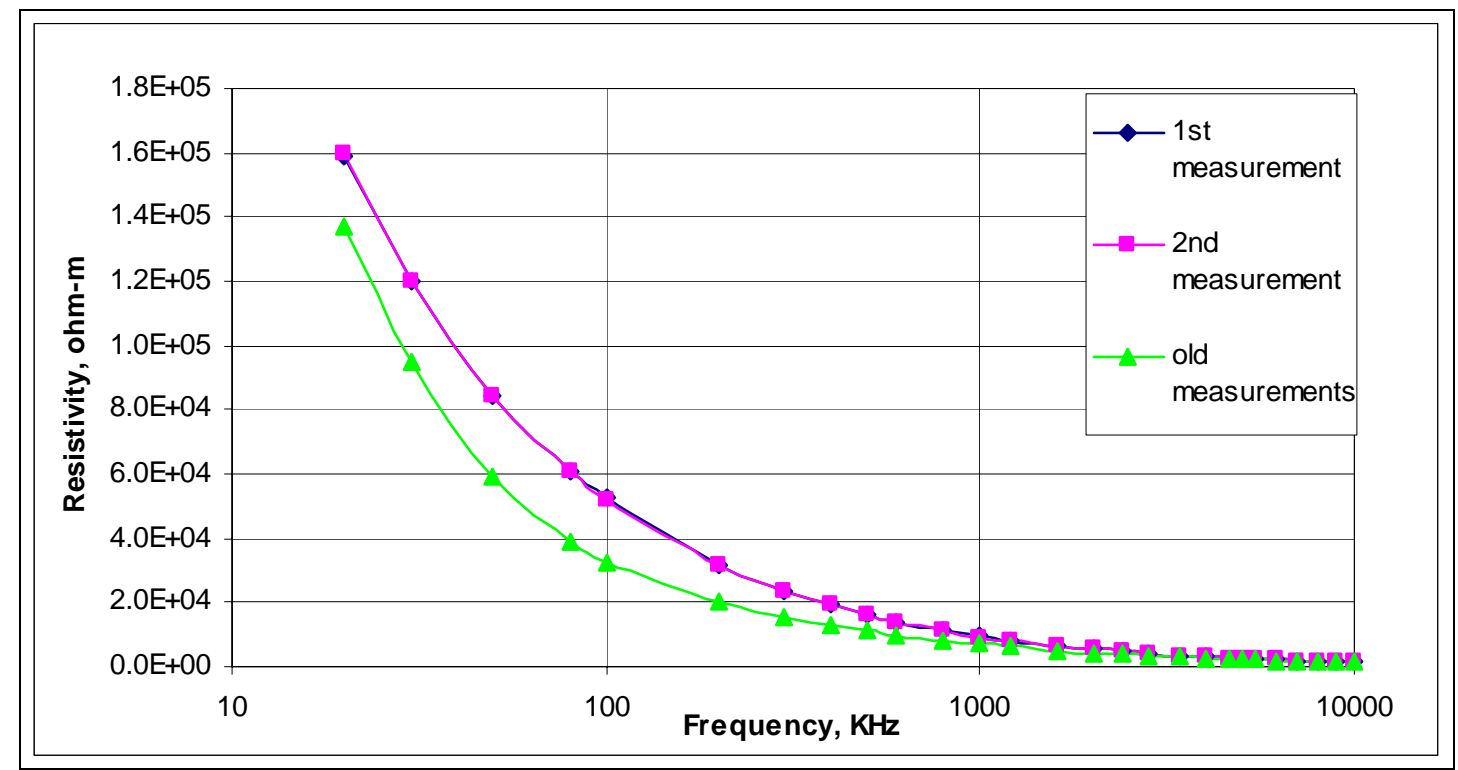

Fig. 4-5: Comparison of the resistivity of a coal sample from the Sewickley Seam in two tests separated by a couple of months

It can be seen from Fig. 4-3 that the dielectric constant originally was about $\varepsilon^{\prime} \approx 16$ for measurement made at $20 \mathrm{kHz}$, and the value decreased to $\varepsilon^{\prime} \approx 14.5$ during the second test. The minimum value of the dielectric constant initially was $\varepsilon^{\prime} \approx 6$ when the moisture content was higher and about $\varepsilon^{\prime} \approx 5.1$ a couple of months later. Since the samples were exposed to air drying, there was a decrease in their water content of about 3\%. In Fig. 4-4 the values of the attenuation rate for the samples can be observed. The attenuation rate varies between $0.95 \mathrm{~dB} / 100 \mathrm{ft}$ at $20 \mathrm{kHz}$ and it has maximum value of $158 \mathrm{~dB} / 100 \mathrm{ft}$ at $10 \mathrm{MHz}$. In Fig. 4-5 it can be seen that the resistivity increases with the decrease of the moisture content over time. The changes in the dielectric properties are more noticeable in the frequency range below $1000 \mathrm{kHz}$.

Black shale rock representing the roof rock for the same coal seam was also tested twice and the results of the first test are presented in Fig. 4-6. It is clear from Fig. 4-6 that 
the dielectric constant of the freshly prepared shale sample has a value of approximately $\varepsilon^{\prime} \approx 36.5$ at $20 \mathrm{kHz}$.
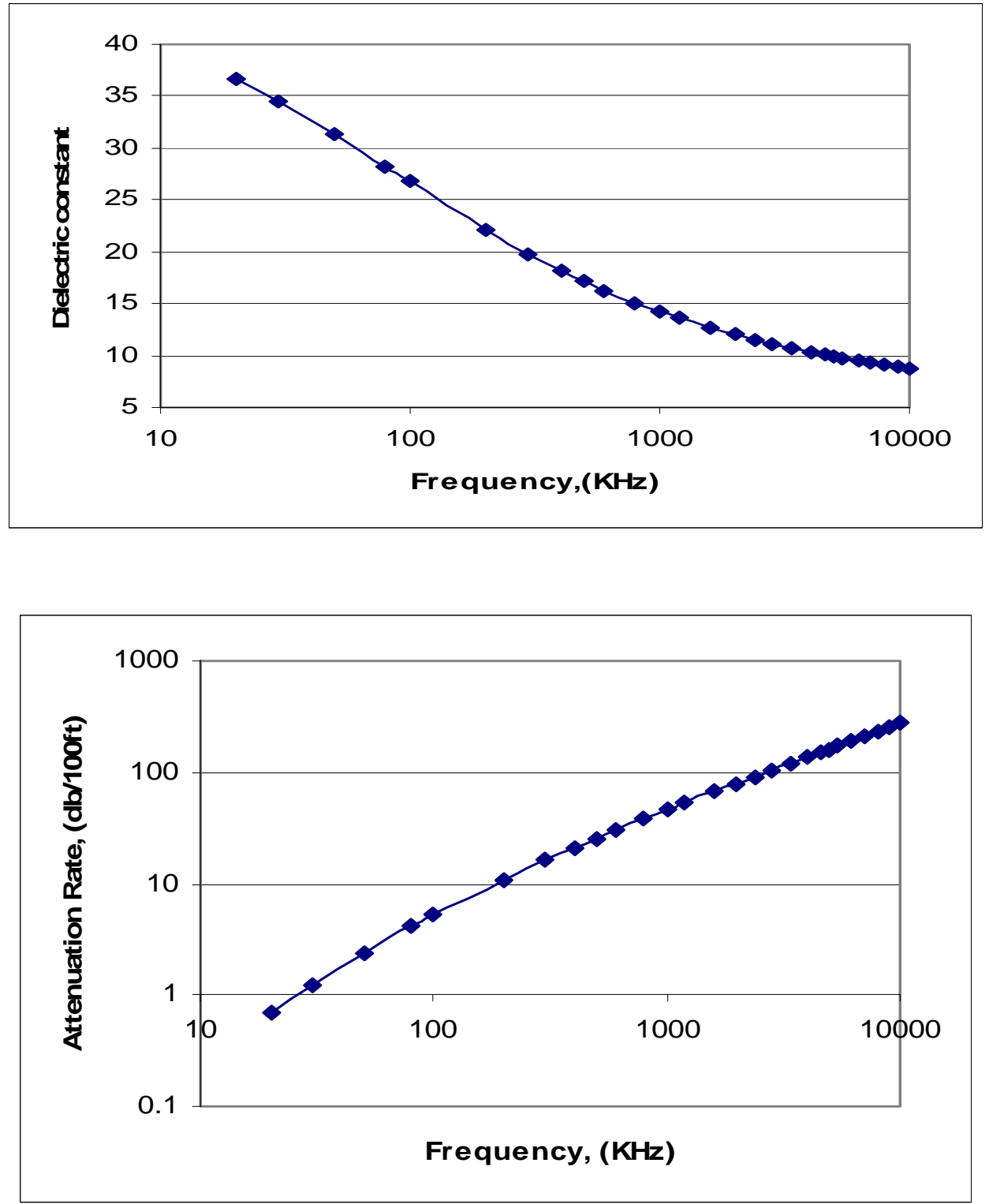

Fig. 4-6: Dielectric constant and attenuation rate vs. frequency for a shale sample from the Sewickley Seam 

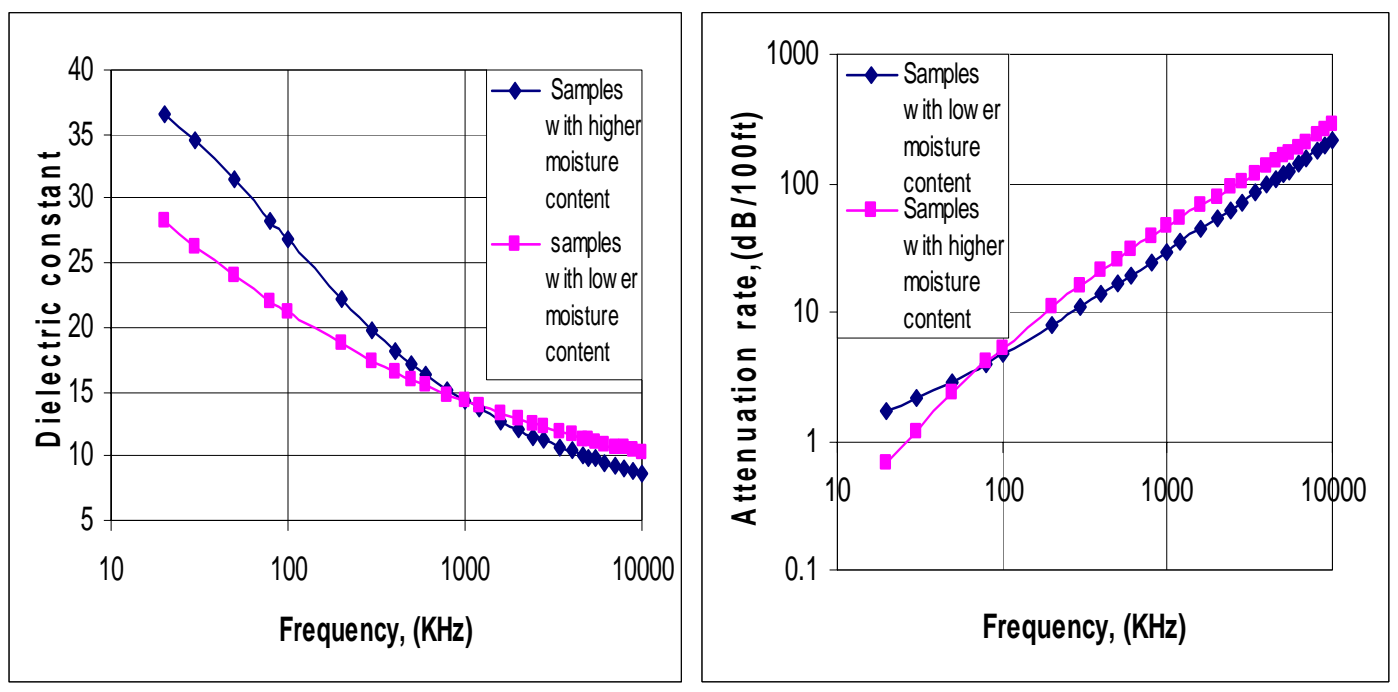

Fig. 4-7: Comparisons of the results for the dielectric constant and attenuation rate vs. frequency for shale samples from the Sewickley Seam

Comparisons of newly prepared and old shale samples from the Sewickley Seam are shown in Fig. 4-7. The newly prepared samples had higher moisture content than the old ones. The overall difference in the moisture content between the samples was about $5 \%$. Again, it is apparent that the change in moisture content has an effect on the electric properties of the samples.

A relatively big difference in the dielectric constant is clearly presented again in the frequency range below $1000 \mathrm{kHz}$. The drop in the value of the dielectric constant of the old samples as a result of their different moisture content is clearly observed on the graph. The dielectric constant at lower humidity is about $\varepsilon^{\prime} \approx 28$ at $20 \mathrm{kHz}$ while that at higher moisture content is about $\varepsilon^{\prime} \approx 36.5$ at $20 \mathrm{kHz}$. For the attenuation rate, the values follow the same pattern as for the dielectric constant. Based on those measurements, it is apparent that the differences in the EM properties are more pronounced at the lower frequencies when the water content changes. 
To further investigate the effect of moisture on the electrical properties of coal measure rocks, experiments in the low-frequency range $(20 \mathrm{kHz}-10 \mathrm{MHz})$ were performed. The samples were placed in a humidity chamber that allows full control of the moisture content in the range from 5 to $95 \%$, as mentioned previously. The samples were tested at their "natural" or in-situ moisture content after they had first been extracted from the seams. After that, the rocks were placed in the chamber at different humidity levels. The time required by the equipment to achieve a certain humidity level is approximately twenty days.

New tests to study the effects of the moisture on the electrical properties of rocks were performed after the samples were placed at 40 and $80 \%$ air humidity at room temperature. The first sample tested was a coal sample collected from the Sewickley Seam. The sample was tested parallel to the mine roof. The so-called "natural" or in-situ moisture content of the sample was around $3-4 \%$ based on the information from the site where the sample was collected. Regardless of whether the sample was placed at 40 or $80 \%$ air humidity, the overall change in its moisture content compared to the initial one was approximately $8 \%$. In other words, the maximum final moisture content of the sample observed was around $13 \%$. A possible explanation of these phenomena is the fact that the coal was very hard and well consolidated with no visible porosity. As explained earlier, the porosity of the samples plays a significant role in the amount of water that can be contained inside their structure. Figure 4-8 represents the effects of the moisture content on the dielectric constant and attenuation on this coal sample. From the figure it can be clearly seen that moisture content plays an important role in the electrical properties. 

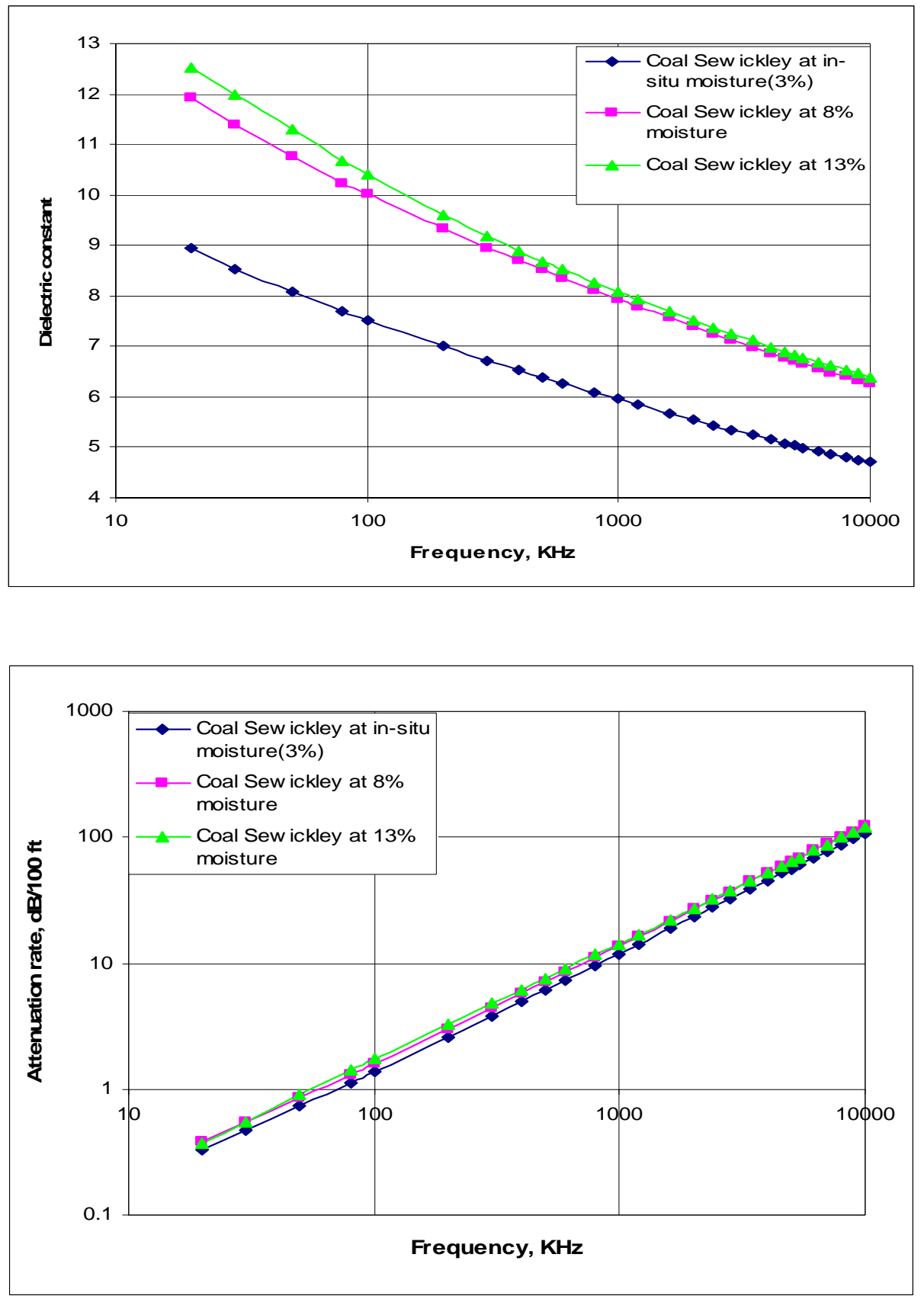

Fig. 4-8: Comparisons of the dielectric constants and attenuation rates observed at different moisture levels for a coal sample from the Sewickley Seam

Figure 4-8 shows that the moisture affects the electrical properties of rocks. The dielectric constant of the coal when measured at natural moisture content ranged from $\varepsilon^{\prime} \approx 10$ at $20 \mathrm{kHz}$ and went down to approximately $\varepsilon^{\prime} \approx 5.2$ at $10,000 \mathrm{kHz}(10 \mathrm{MHz})$. The 
observed values at increased humidity levels vary from $\varepsilon^{\prime} \approx 12$ (at $8 \%$ humidity) and $\varepsilon^{\prime} \approx 12.5$ (at $13 \%$ humidity) for the lower part of the frequency range at $20 \mathrm{kHz}$. It is interesting to note that an increase in the moisture content significantly affects the electrical properties of the test material predominately in the low-frequency region below $1000 \mathrm{kHz}$. Once again, a relationship between the "sensitivity" of the samples to their moisture content is clearly presented in this region. Based on the studies in the literature and the results observed in this research, it can be concluded that moisture, when present in small amounts in the coal, has a great effect on its electrical properties, but when the moisture content of the samples is high and when they have been tested at higher frequencies, the values start to change very slowly. However, the increase in the values of the dielectric constant is an important change that must be studied. This is due to the fact that the dielectric constant of a material affects how electromagnetic signals move through the material. A high value of dielectric constant makes the distance inside the material "appear" bigger. This basically means that electromagnetic waves will travel more slowly. It also makes the waves behave as if the signal had a shorter wavelength at particular frequency, which means that the depth of penetration of the EM wave will be significantly reduced. The graph for the attenuation rate shows that there will be excessive loss of signal of approximately $23 \mathrm{~dB} / 100 \mathrm{ft}$ at frequency $10 \mathrm{MHz}$ when different levels of the moisture content are observed. In other words, this excessive loss means that the initial signal strength that was transmitted through the material has been decreased, which once again leads to shallow propagation depth. Figure 4-9 illustrates the changes that occurred in the resistivity values for the same coal sample tested. As expected, the values of the resistivity decrease with an increase in the moisture levels. 


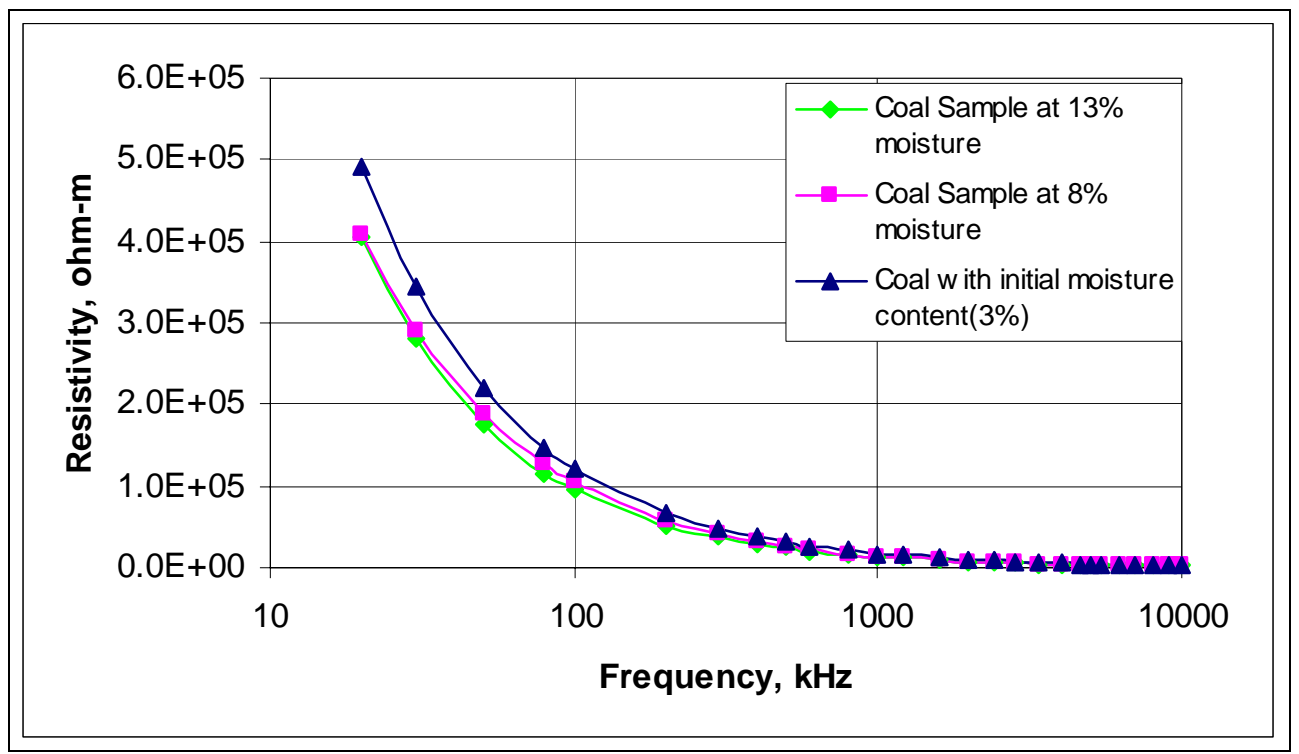

Fig. 4-9: Comparisons of the electrical resistivity observed at different moisture levels for a coal sample from the Sewickley Seam

As referred to earlier, the electrical resistivity is a physical property describing how strongly the material opposes the flow of electrical current. In fact, the easier electrical current is conducted through a substance, the higher its conductivity and the lower its resistivity. The current is mostly carried out by the ions of the fluid (generally water) present in pores, cracks, and gaps and along grain boundaries. Hence, the major factors determining the resistivity of earth materials will be their porosity, fluid saturation, etc., and the resistivity of the fluid. Figure 4-9 shows unmistakably the effect of the moisture content on the electrical resistivity of coal. That effect is much more noticeable in the range below $1,000 \mathrm{kHz}$, while above this frequency the values of the resistivity for this particular sample are in fairly good agreement and have almost constant values, regardless of whether they have been studied at different humidity levels.

The frequency sensitivity in regard to the moisture content of the samples is presented again. As previously mentioned the lower electrical resistivity of the material 
means higher conductivity since they are reciprocal. Therefore, highly conductive rocks rapidly attenuate electromagnetic signal, which means that in order to penetrate them, a stronger signal must be used. On the other hand, it could be expected that it will be difficult to distinguish geological disturbances in highly conductive subsurface regions when this type of rock dominates.

Effects of the different moisture levels on the electrical properties were studied not only for coal, but also for sandy shale and sandstone samples collected from the Pittsburgh Seam. The results for the two types of rocks studied are presented in Figs. 4-10 and 4-11.

From Fig. 4-10 it can be observed that the electrical properties of the sandy shale are greatly affected by the different levels of moisture. The initial moisture of the samples was changed significantly during the experiment. As a result, the final overall increase in the moisture content was approximately $25 \%$. There is a large difference in the pattern by which the dielectric constant changes with an increase in the moisture content, compared to the example given for the coal sample. The "sensitivity" of the sample and its moisture content to the frequency disappear, and three different series of values for the dielectric constant can be observed. Moreover, the values vary greatly between each other with an increase of the water content from an average in-situ moisture content of $2.1 \%$ to $14 \%$ and from $14 \%$ to $25 \%$. Again, that could be explained by the amount of water that the samples were able to absorb in their pores. 

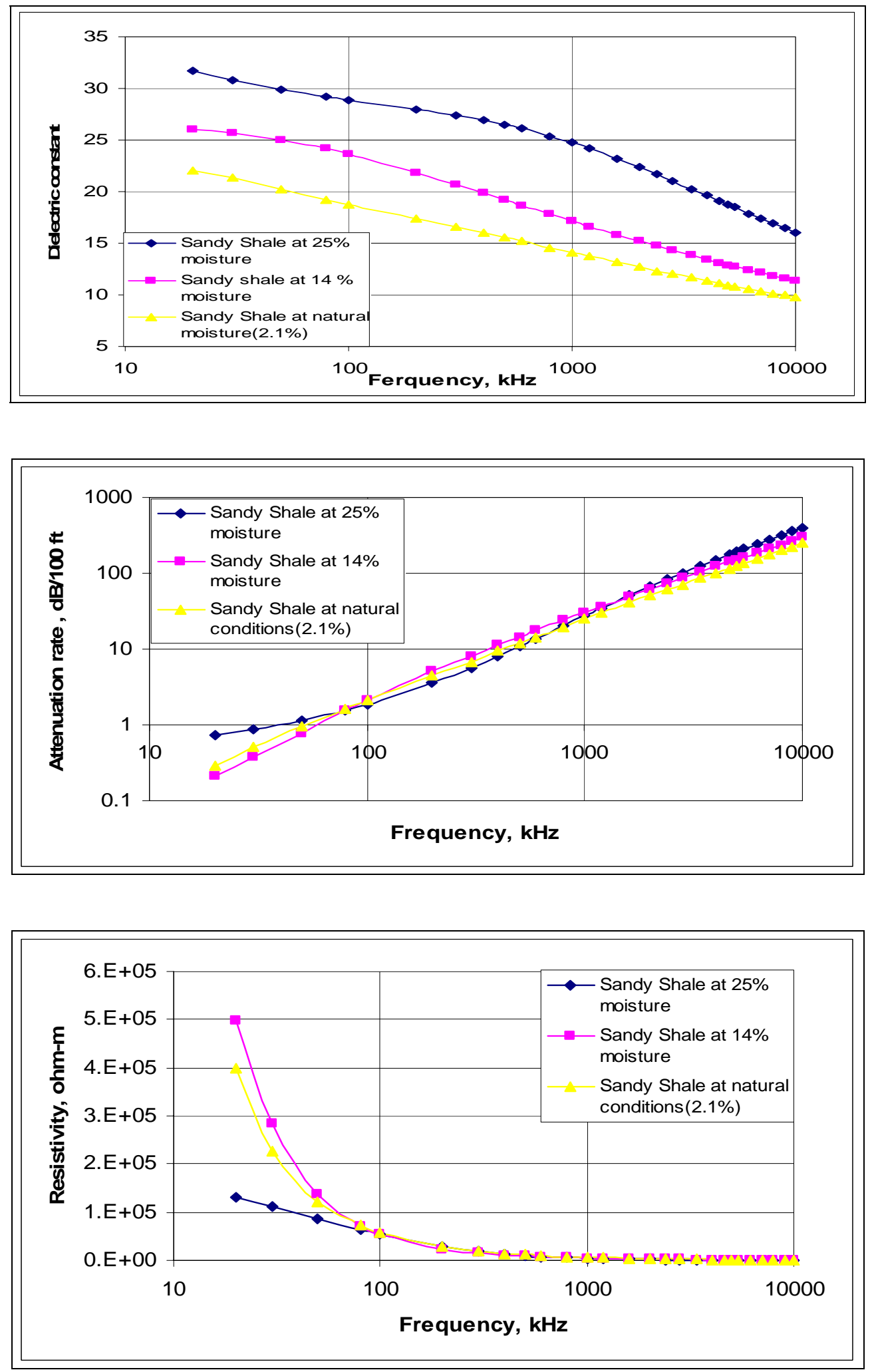

Fig. 4-10: Comparisons of the dielectric constant, attenuation rate and resistivity at different moisture levels of a sandy shale sample from the Pittsburgh Seam 
According to Parkhomenko (1967), electrical properties of the rocks (especially electrical conductivity and resistivity) vary widely over several orders of magnitudes. The low end of this range corresponds to salty fluids, ore bodies, and silica melts, and the high end to dry crystalline rock. Consequently, conductive zones generally correspond to weak zones where fluids are present in connected porosity or where fluids once were present and deposited interconnected conductive minerals (e.g., graphite, sulfides).

A sandstone sample from the Pittsburgh Seam was studied and the results are shown in Fig. 4-11. There is a large difference in the values for the dielectric constant observed for this sample. From the graph, it can be noted that with the increase of the water content in the sample, the values of the dielectric constant changed dramatically. The biggest difference in the dielectric constant occurred when the initial, "natural" moisture content of the sample was changed and reached a level of $31 \%$ humidity. The value of the dielectric constant for the first measurement was around $\varepsilon^{\prime} \approx 33$ at $20 \mathrm{kHz}$, but with the increase in the water content, it achieved a value of $\varepsilon^{\prime} \approx 51$ at $31 \%$ of water saturation. Based on literature reviews, it can be assumed that the porosity of the sample, as well as its mineral composition, played a role in that dramatic change shown in the results for the electrical properties. Looking at the different humidity levels, it can be observed that the sensitivity of the sample to the frequency and the moisture content occurs again when the initial water saturation level is compared to $19 \%$. There is a significant difference in the results for the dielectric constant in the frequencies below $1,000 \mathrm{kHz}$, but not a big difference for the frequency range above $1,000 \mathrm{kHz}$ when one compares the natural moisture content to a level of $19 \%$. 

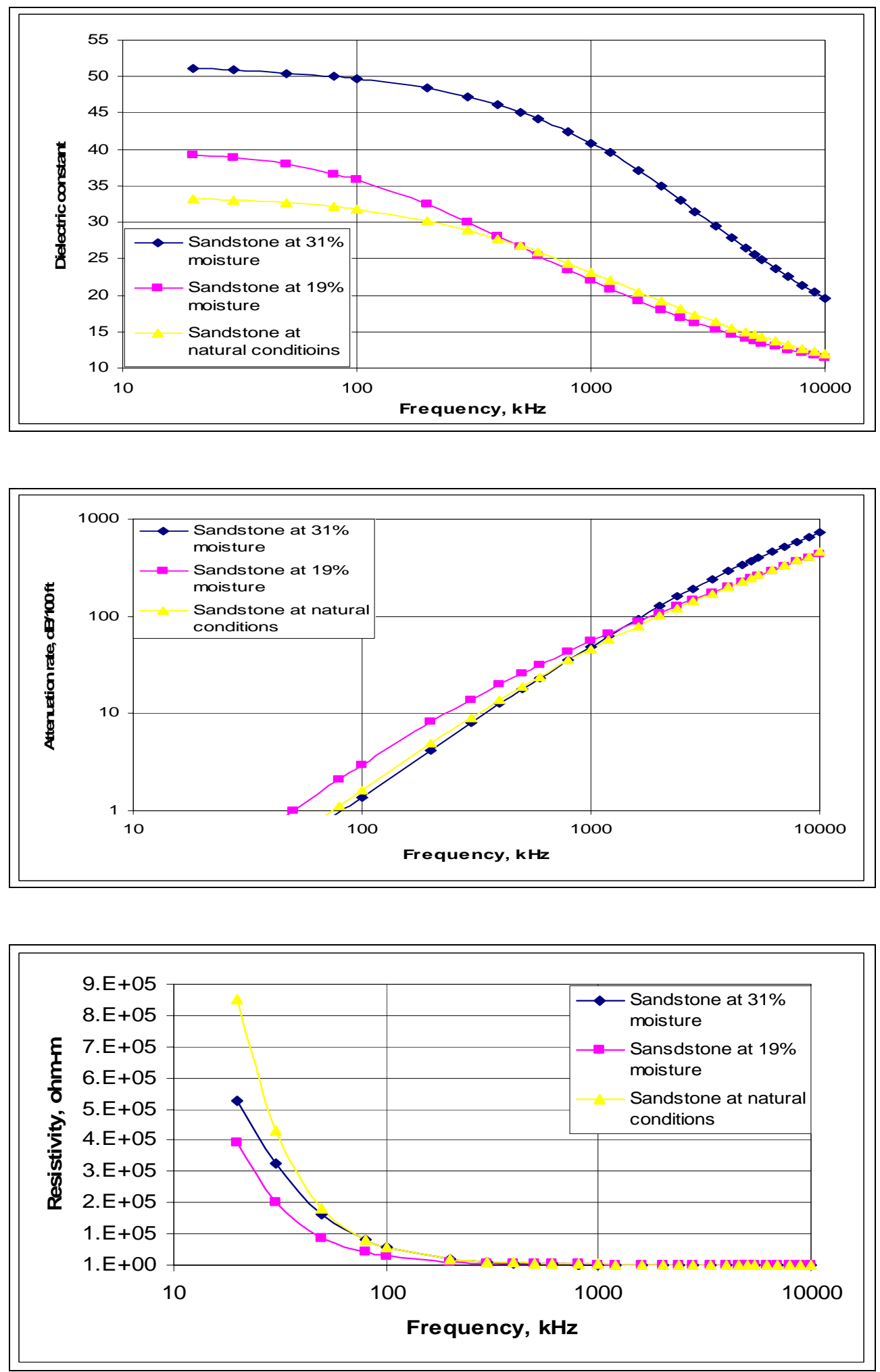

Fig. 4-11: Comparisons of the dielectric constant, attenuation rate and resistivity at different moisture levels of a sandstone sample from the Pittsburgh Seam 
The changes in the attenuation rate and the resistivity of this sample also can be observed in Fig. 4-11. As expected, the value of resistivity decreases with increase in moisture content of the rock. Rocks that have low water content or rocks that have been dried out are much more resistive than rocks that retain high values of water in their pores. The big difference in the resistivities for the sandstone sample tested occurs at about $300 \mathrm{kHz}$. After that point (above $300 \mathrm{kHz}$ ), the values are fairly close to each other. One possible explanation of the phenomena observed here is that distilled water was used to moisten the samples. In other words, the water was free of salts, and that might have caused the salt parts in the rock to dissolve, leading to a decrease in the resistivity. In addition, as mentioned earlier, another factor that could influence the resistivity is the grain size of the rock particles. Rocks with identical compositions and amounts of impurities, but which have different grain size, will differ in resistivity.

The main research interest is focused on finding the differences in the electrical properties of coal and coal measure rocks for different coal seams. Figures 4-12 and 4-13 show the measured dielectric constant and attenuation rate for coal samples collected from the Pittsburgh and Sewickley coal seams. The testing orientation for the coal samples was parallel to the coal roof line. 


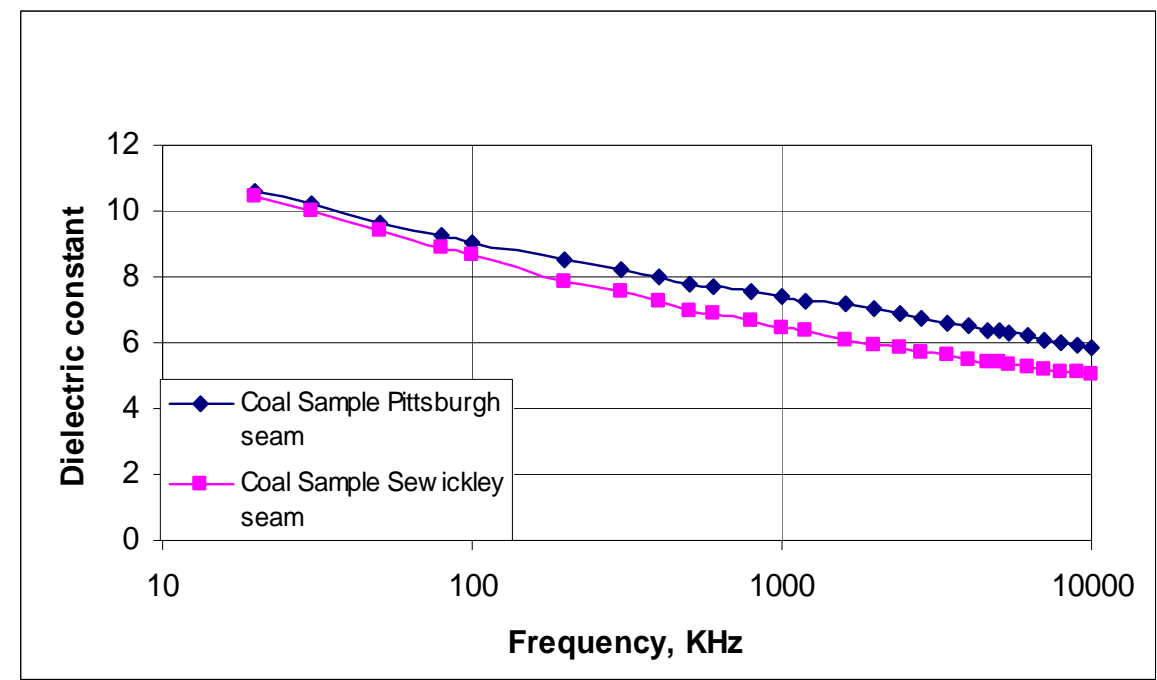

Fig. 4-12: Comparison of the dielectric constant between the Pittsburgh and Sewickley coal seams

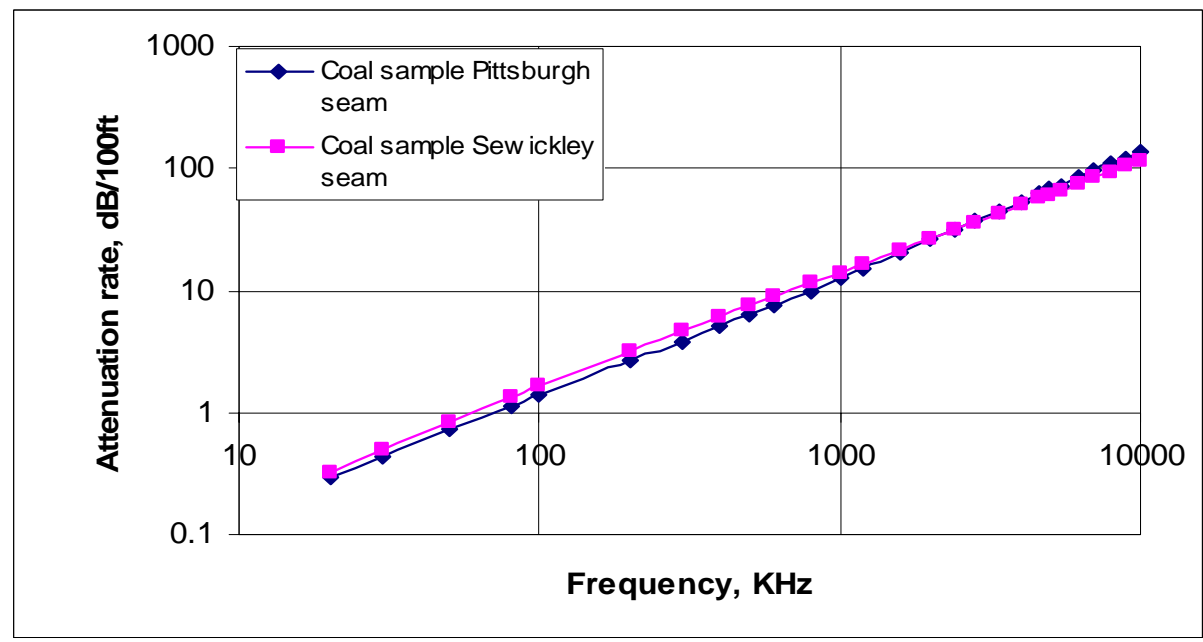

Fig. 4-13: Comparison of the attenuation rate between the Pittsburgh and Sewickley coal seams

The two figures above show a comparison of the electrical properties between the Pittsburgh and Sewickley coal seams. It can be clearly seen that there is a significant variation between the electrical properties of the two seams. The differences can be attributed to the differences in mineral composition of the two samples. It is well known that with a change in the geological conditions, differences can be expected in the 
mineral composition of the rocks. The two samples that were tested also had different moisture content. For the sample from the Pittsburgh Seam, the average moisture content was about $2 \%$, while the moisture content of the coal sample from the Sewickley Seam was about $3.5-4 \%$. In this case, regardless of the small difference in the humidity levels of the samples, the difference in the dielectric constant is very significant for frequencies above $100 \mathrm{kHz}$. For the attenuation rate shown in the figures, it is apparent that the differences for the frequencies below $1,000 \mathrm{kHz}$ are more significant than those above $1,000 \mathrm{kHz}$.

In this research project, not only were sedimentary rocks tested, but samples from three different igneous rocks were also tested. The purpose of these tests was to show how the EM properties could change in that type of rocks. It is possible for field tests to be performed in "mixed" rock conditions. In other words, during the field tests, it could be expected that the equipment will go through different geological layers and even volcanic rocks. It is important to be familiar with what can be expected in the subsurface so that the radar system can be calibrated correctly.

The samples that were tested are basalt from Hawaii, and biotite-gneiss and phonolite from Victor, Colorado. As previously mentioned, sometimes it is possible to have volcanic intrusions in sedimentary formations and for that reason these samples were tested. The dielectric data were collected at frequencies from $20 \mathrm{kHz}$ to $10,000 \mathrm{kHz}$. The results of the measurements are presented below; the first sample tested was basalt from Hawaii and the results of its low-frequency tests are presented in Figs. 4-14 and 4-15. 

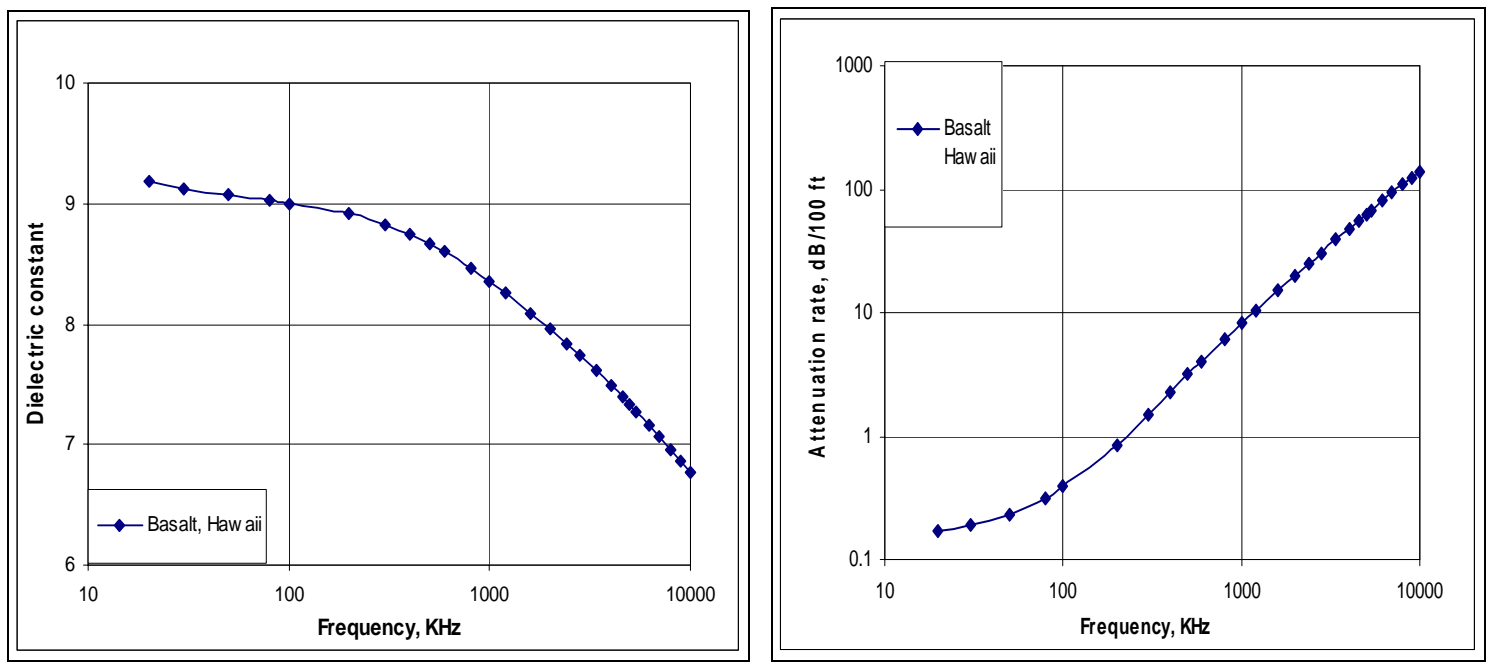

Fig. 4-14: Results of the measurements of the basalt sample, Hawaii dielectric constant and attenuation rate

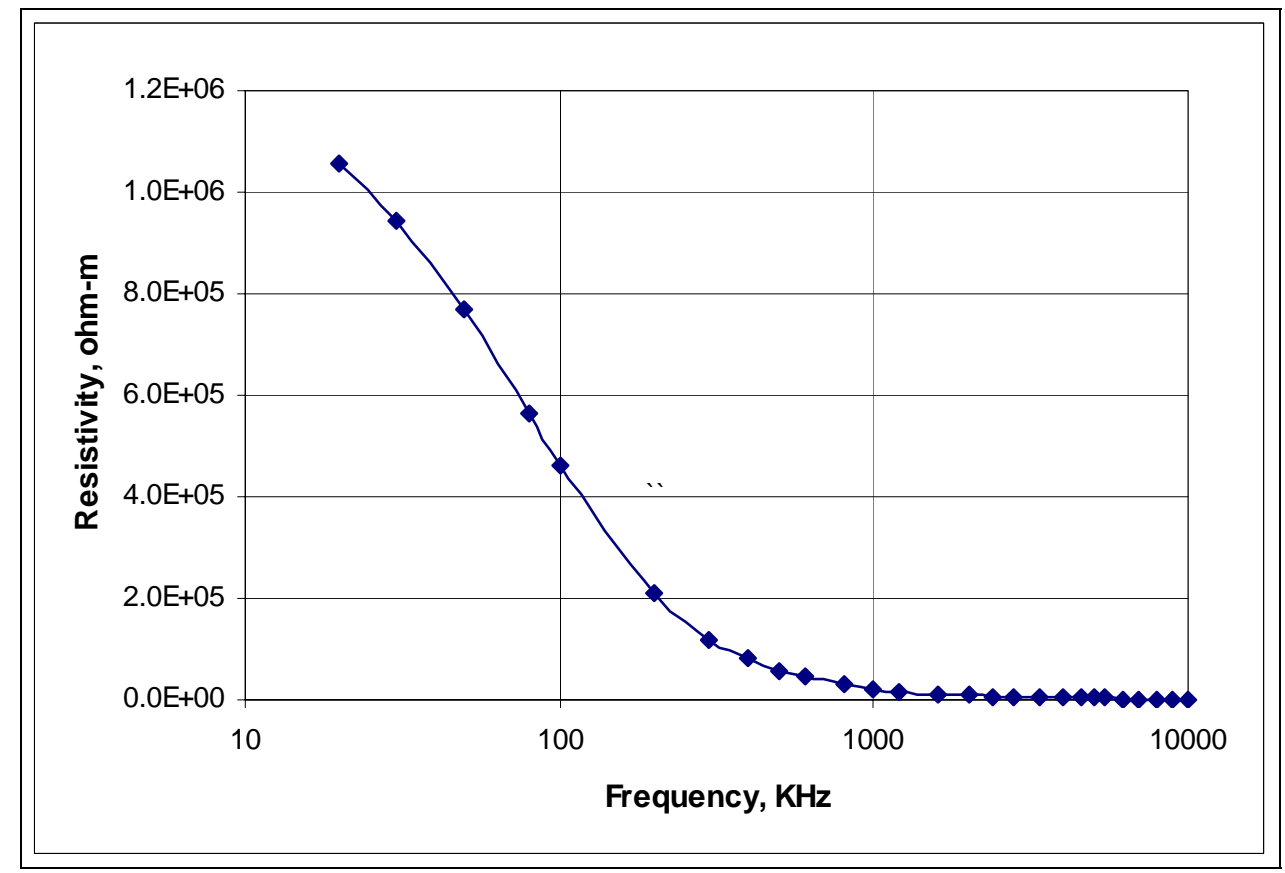

Fig. 4-15: Results of the measurements of the basalt sample, Hawaii resistivity

The highest value of the dielectric constant measured is $\varepsilon \approx 9.2$ at $20 \mathrm{kHz}$ and the lowest one is $\varepsilon \approx 6.7$ at $10,000 \mathrm{kHz}$. The other two samples tested are phonolite and 
biotite-gneiss from Victor, Colorado. The results of those measurements are presented in Figs. 4-16 and 4-17.
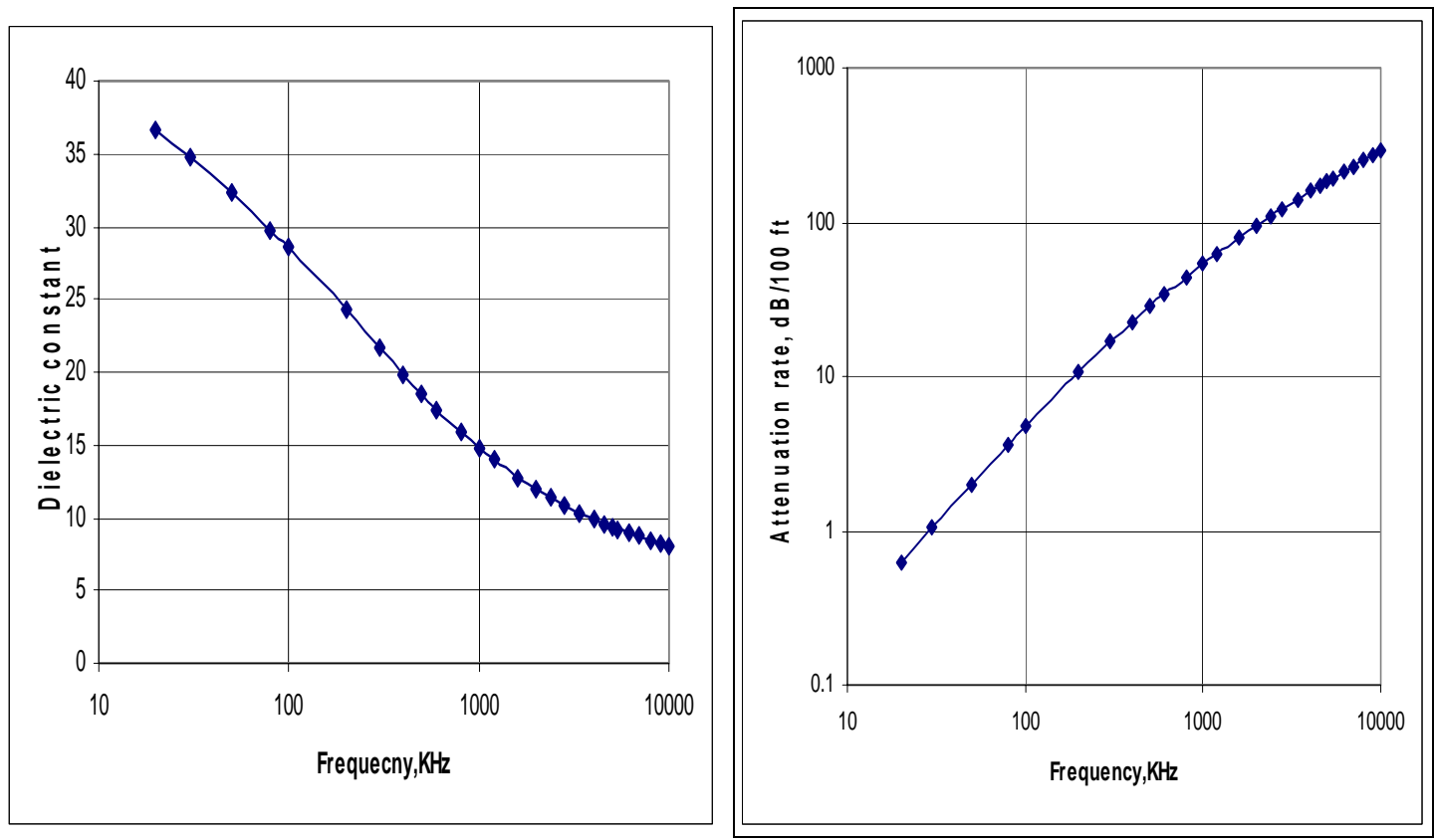

Fig. 4-16: Dielectric constant and attenuation rate for phonolite sample from Colorado
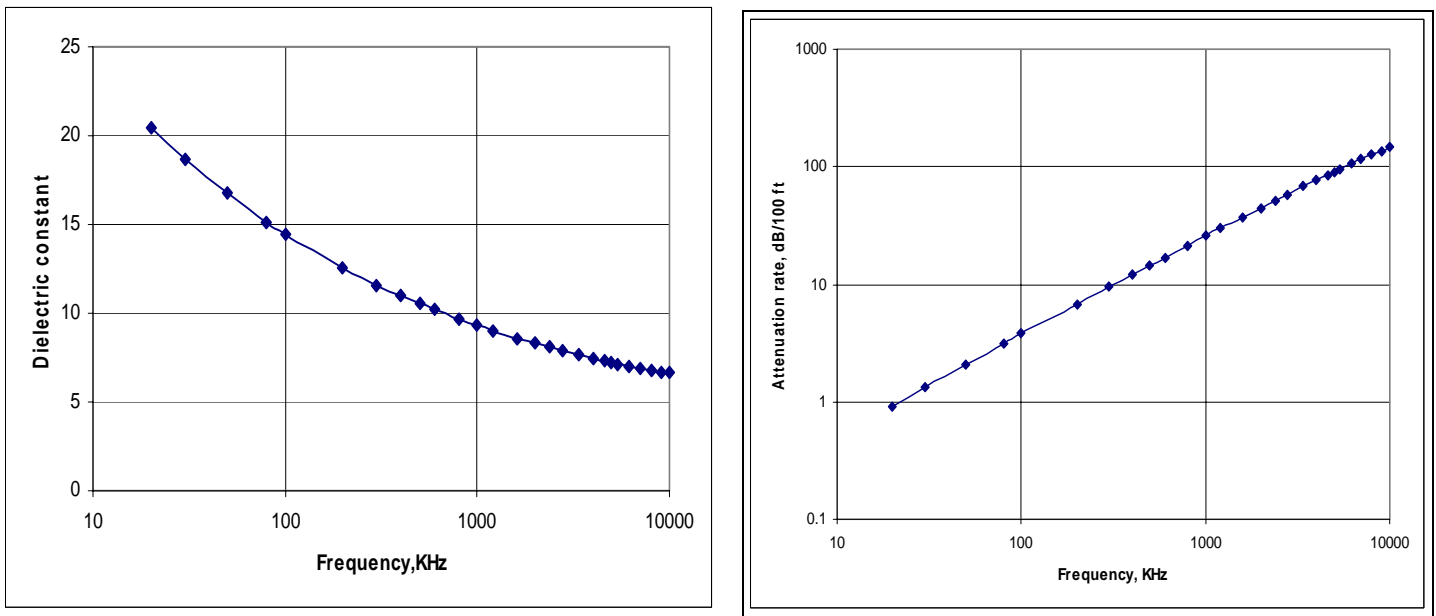

Fig. 4-17: Dielectric constant and attenuation rate for biotite-gneiss sample from Colorado

In a previous study (Hansen, et al., 1970), it was shown that the dielectric properties of volcanic rocks are sensitive to frequency, mineralogy, and water 
saturation,Based on the measurements performed during the tests in the laboratory, comparison between the dielectric constant of the tested rocks was done (Fig. 4-18).

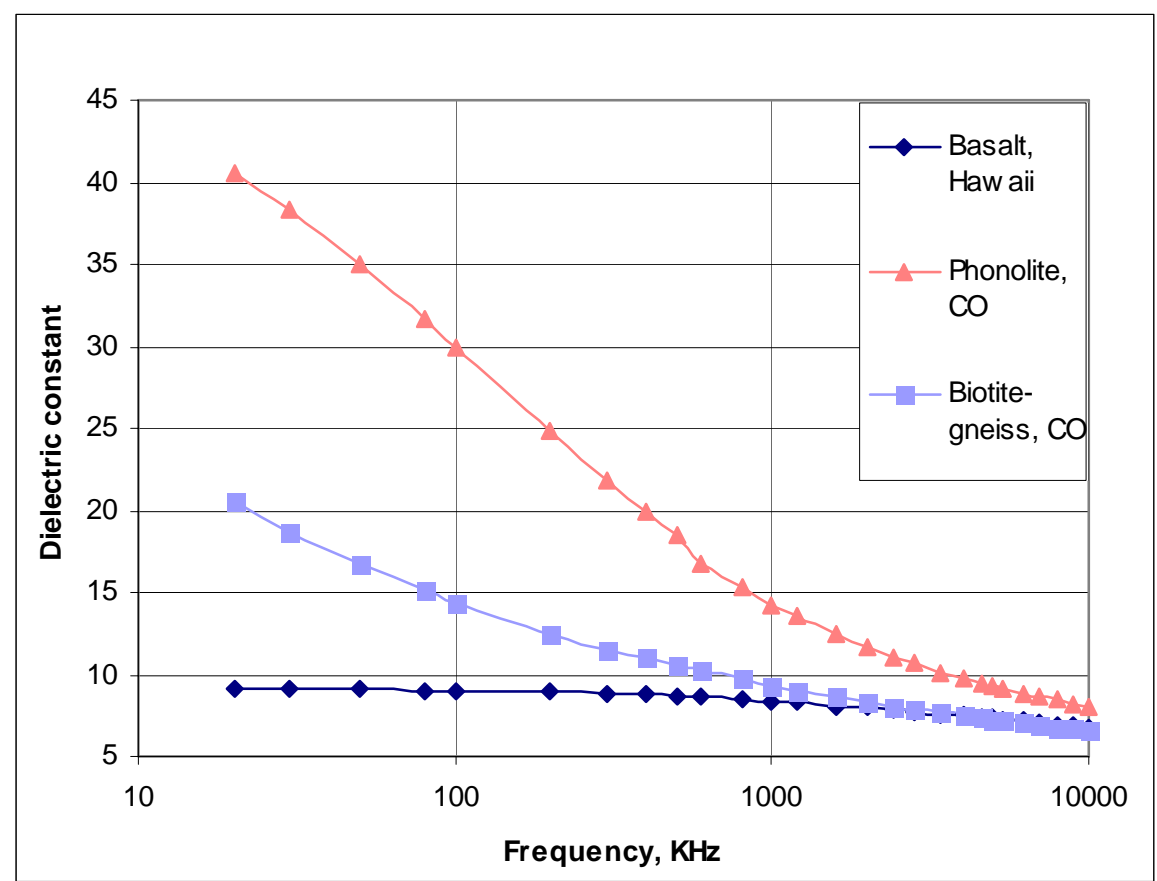

Fig. 4-18: Dielectric constant vs. frequency comparison for the three samples tested

From the comparison of the results it can be perceived how the dielectric constant is changing for three different types of igneous rocks. The same statement could be made for the attenuation rate, but the graph is not presented here. The dielectric constant of the basalt has the lowest values compared with the other two samples, due to the fact that of the three samples tested, the basalt has the lowest density (around $1950 \mathrm{~kg} / \mathrm{m}^{3}$ ). Also, it has many small air-filled pores, which affects the dielectric constant; since the dielectric constant of the air is 1 and its value is increasing with the increase of the density of the solid materials, it was expected to see those differences between the measurements. The measured results are close to the results reported in other studies of EM properties of igneous rocks and volcanic rocks in particular. The measured results are valid, as long as 
the density and porosity of the different rocks are kept in mind. It can be assumed that if the same types of rock are tested, but the samples are taken from another location in the United States, the variation in the results can be expected.

The results of all measurements done in the lower frequency range showed several important things. The moisture content of the samples has a great effect on the EM properties of the rock strata, especially on sedimentary rocks. The relationship between the dielectric constant of a rock and its water content, based on the experimental work, depends both on the frequency and the moisture content. This relationship is more visibly expressed at frequencies below $1,000 \mathrm{kHz}$, as can be seen in the graphs. In addition, the result of the measurements represents that the EM contrast between the coal and its surrounding rock is greatest at lower frequencies. Therefore, it could be said that the radar system will operate more efficiently at those low frequencies, but one should not forget that this will have a result on the radar system resolution. Not all of the graphs for the resistivity computations are presented in this research, but it is obvious that the resistivity meets the expected theoretical pattern-dropping off in its value with rise of the frequency and the moisture content.

As mentioned before, the high-frequency tests for this research must cover the frequency range from $200 \mathrm{MHz}$ to $3 \mathrm{GHz}$. Another set of equipment was used to cover the upper boundary. Once again, the measurement instruments were a network analyzer and a dielectric probe text fixture. At first, some issues with the calibration of equipment were faced, but those problems were solved. One of the major problems faced was the inconsistency of the measured values. Very large differences were observed in the values for the EM properties for repetitive measurements of the same sample under test. It was 
found that very small air gaps between the samples and the measuring electrode still occur, and that lead to big changes into the final measurements. A small adjustable "jig" was constructed in order to solve the problem with the space between the material and the electrode. The jig can be adjusted in height and uses a small plate made of plastic material. That laminate makes possible the adjustment of the sample to the electrode in every direction due to the fact that it allows bending. Two petrographic kinds of rocksvolcanic and sedimentary - were tested because they have been the subject of interest. Not all of the results are presented here, but the data are available and could be used for future interpretations.

The dielectric constant of coal (and other coal measure rocks) follows a decreasing trend as the testing frequency increases. The phenomena are shown in Fig. 4-19 for the dielectric constant of coal samples collected from the Pittsburgh and Sewickley Seams and tested with the high-frequency dielectric measurement instrumentation. The samples were cut in direction parallel to the bedding plane of the coal. Figure 4-19 shows comparison of the low- and high-frequency tests. The average dielectric constant for the two samples is roughly 4 in the operating frequency of $200 \mathrm{MHz}$ to $3 \mathrm{GHz}$ but when compared to the operating frequency from $20 \mathrm{kHz}$ to $10 \mathrm{MHz}$ (low-frequency range) it can be seen that it decreases from roughly 11 to 5 . The attenuation rates of the coal sample, as measured by high-frequency dielectric measurement instruments, are shown in Fig. 4-20. There are extra losses in the material of around $80 \mathrm{~dB} / \mathrm{ft}$ when the operating frequency increases from $20 \mathrm{kHz}$ to $200 \mathrm{MHz}$. 


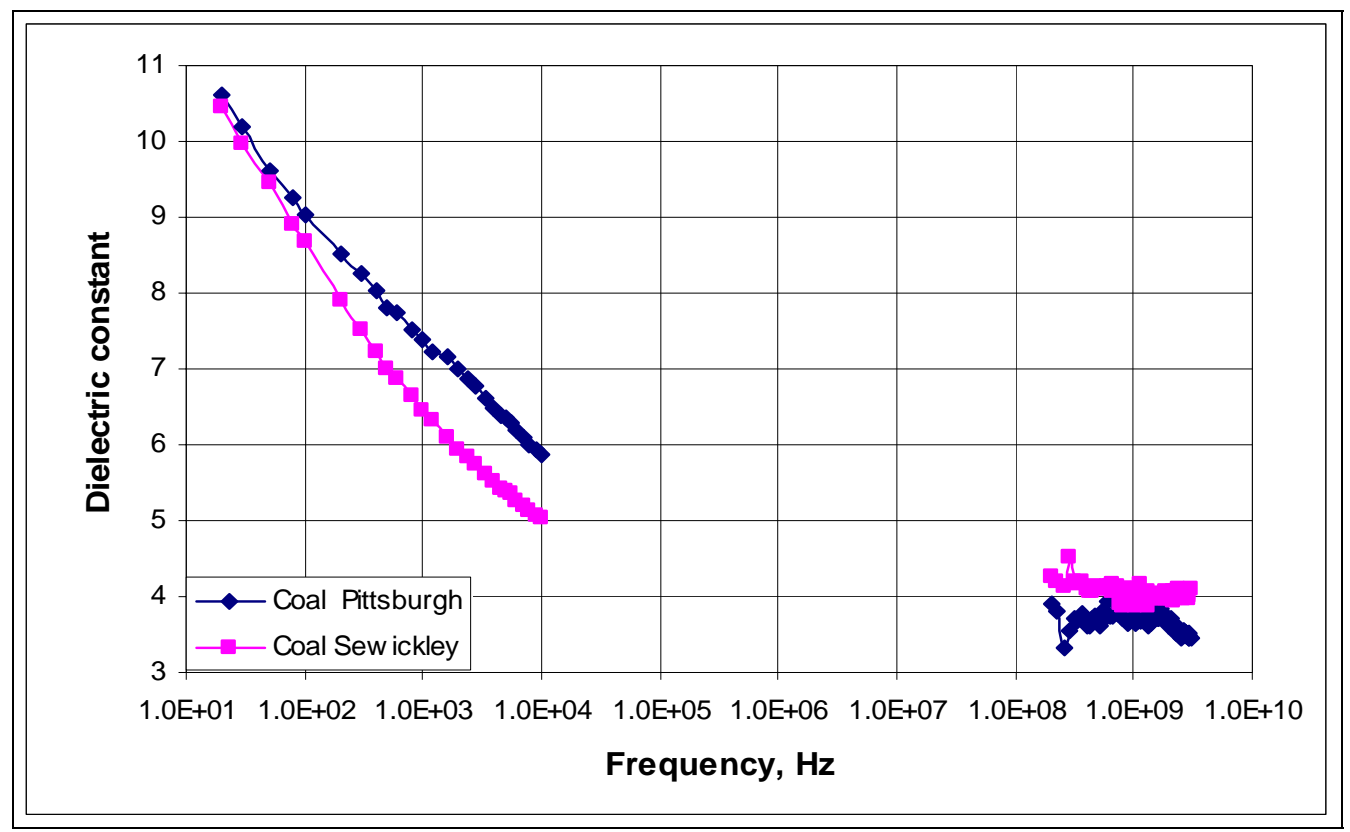

Fig. 4-19: Measured dielectric constant from coal samples collected from the Pittsburgh and Sewickley Seams in low- and high-frequency range

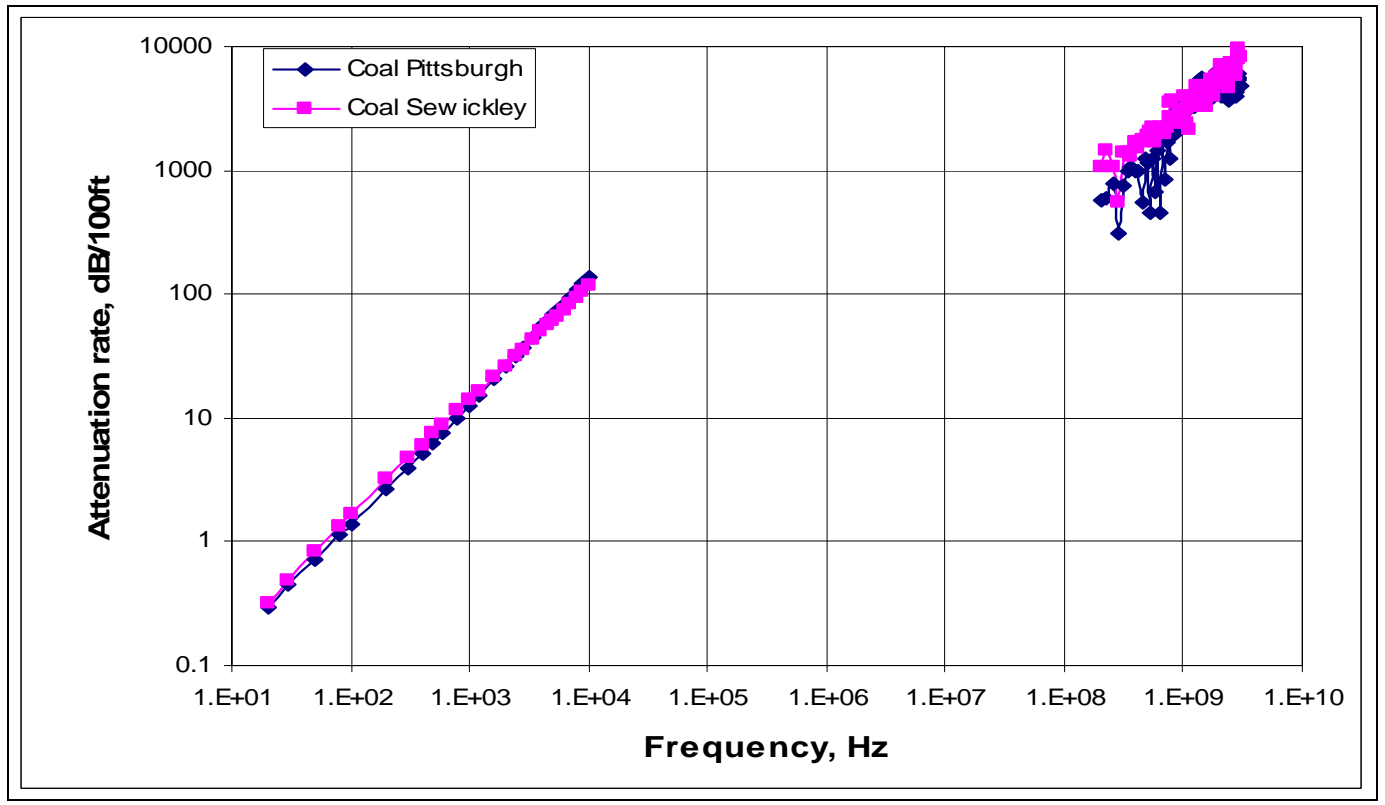

Fig. 4-20: Comparison of the attenuation rate between the Pittsburgh and Sewickley coal seams in low-and high-frequency range

The excessive losses in coal prohibit the use of high-frequency radar systems that can recognize features deep within the coal. 
Collected sedimentary rock samples were tested with their natural moisture content intact, and then dried out in an oven. The rocks were placed in an oven at $105^{\circ} \mathrm{C}$ $\left(221^{\circ} \mathrm{F}\right)$ for 24 hours to see how much of their moisture would disappear and what the effect on the EM properties would be. The sample weights before and after drying, and the loss of the water are presented in Table 4-1 for claystone and sandstone samples collected from Colorado.

Table 4-1: Moisture content determination

\begin{tabular}{|l|c|c|c|}
\hline \multicolumn{1}{|c|}{ Sample } & $\begin{array}{c}\text { Weight } \\
\text { before } \\
\text { drying } \\
\text { (grams) }\end{array}$ & $\begin{array}{c}\text { Weight after } \\
\mathbf{2 4} \text { hours } \\
\text { drying } \\
\text { (grams) }\end{array}$ & $\begin{array}{c}\text { Original } \\
\text { moisture } \\
\text { content (\%) }\end{array}$ \\
\hline $\begin{array}{l}\text { Claystone, } \\
\text { Colorado }\end{array}$ & 74.84 & 65.77 & 12.1 \\
\hline $\begin{array}{l}\text { Sandstone, } \\
\text { Colorado }\end{array}$ & 99.79 & 95.25 & 4.5 \\
\hline
\end{tabular}

It can be observed from the results presented in the table that the two samples from Colorado experienced relatively large loss in their water content. The density of the samples was different, and that also had an influence on the percentage of the water lost.

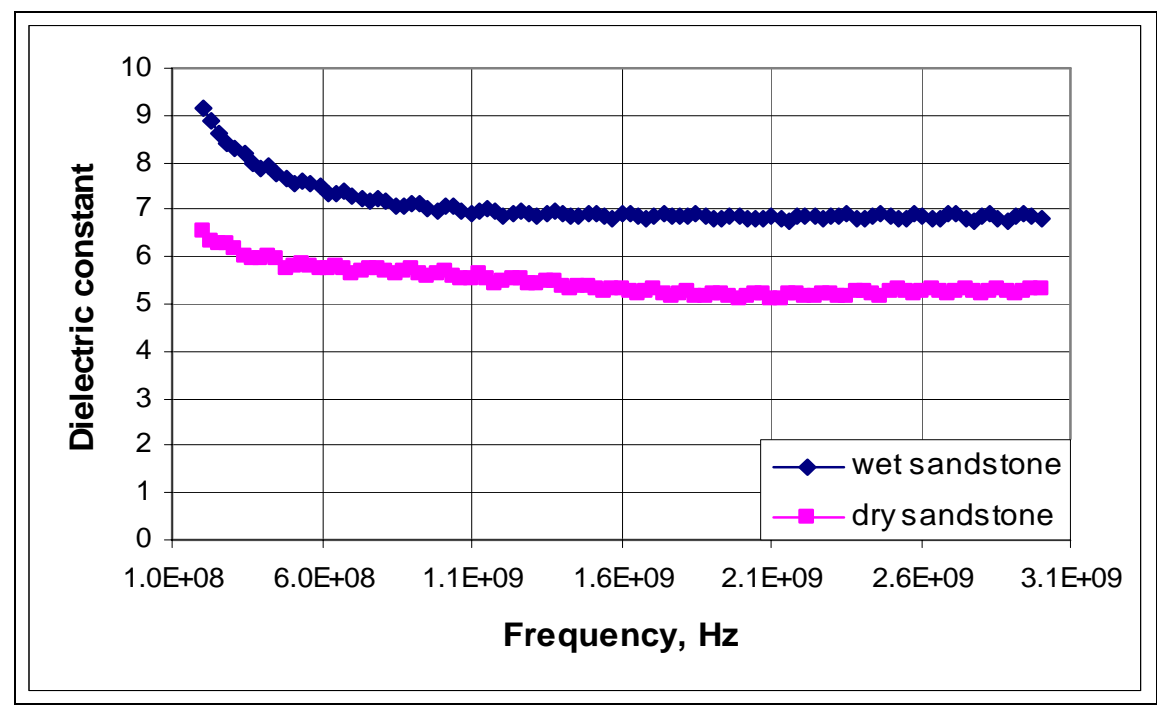

Fig. 4-21: Comparison of the dielectric constant for "wet" and dry sandstone samples from Colorado 


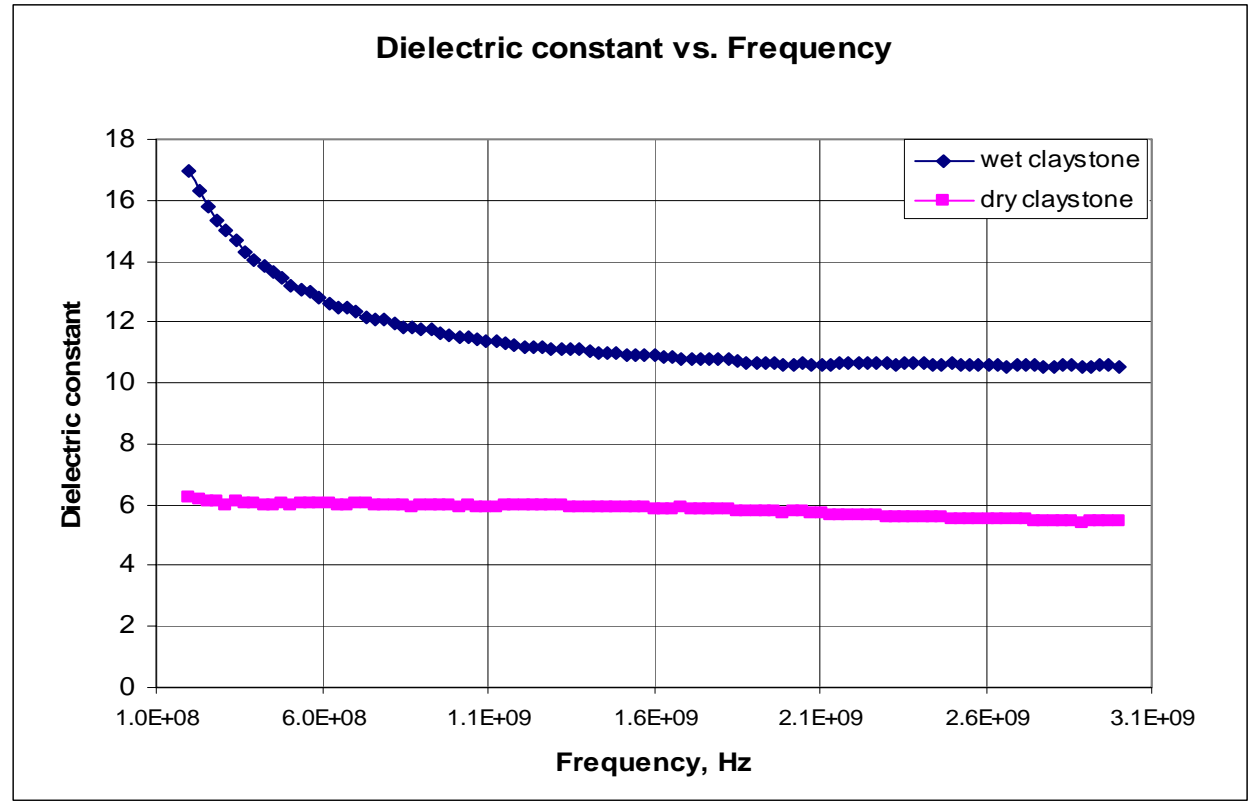

Fig. 4-22: Comparison of the dielectric constant for "wet" and dry claystone samples from Colorado

When comparing the results in Figs. 4-21 and 4-22 for "wet" and dry samples, it is obvious that both samples showed significant decrease in dielectric constant as moisture content decreases. This is particularly true for the claystone sample. It is interesting to note that the two different rocks have almost the same value of the dielectric constant after they have been dried (Fig. 4-23). 


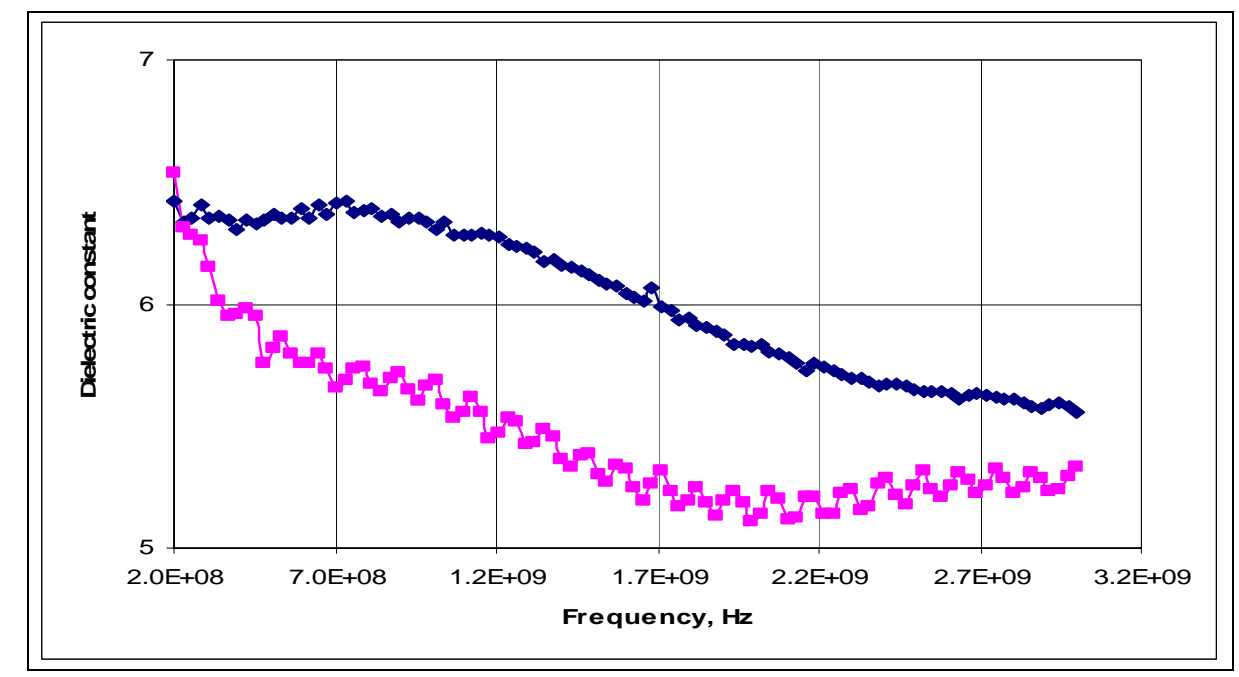

Fig. 4-23: Comparison of the dielectric constant for "wet" and dry sandstone and claystone samples from Colorado

In spite of the fact that the two samples have different mineralogy and crystalline structure, their EM properties in those conditions (i.e., decreased moisture content) and in the upper frequency range are very similar. It is obvious that a drop in the dielectric constant values occurs as a result of the reduction of water content. The dielectric constant decreases its values about $\varepsilon^{\prime} \approx 2.5$ for the sandstone, and about $\varepsilon^{\prime} \approx 10$ for the claystone. The same conclusions were reached for other samples, and an identical relationship between the EM properties was found. A change in the resistivity and attenuation rate for these samples also occurs due to the change in the water content. The results from the basalt sample mentioned earlier are presented in Fig. 4-24. 

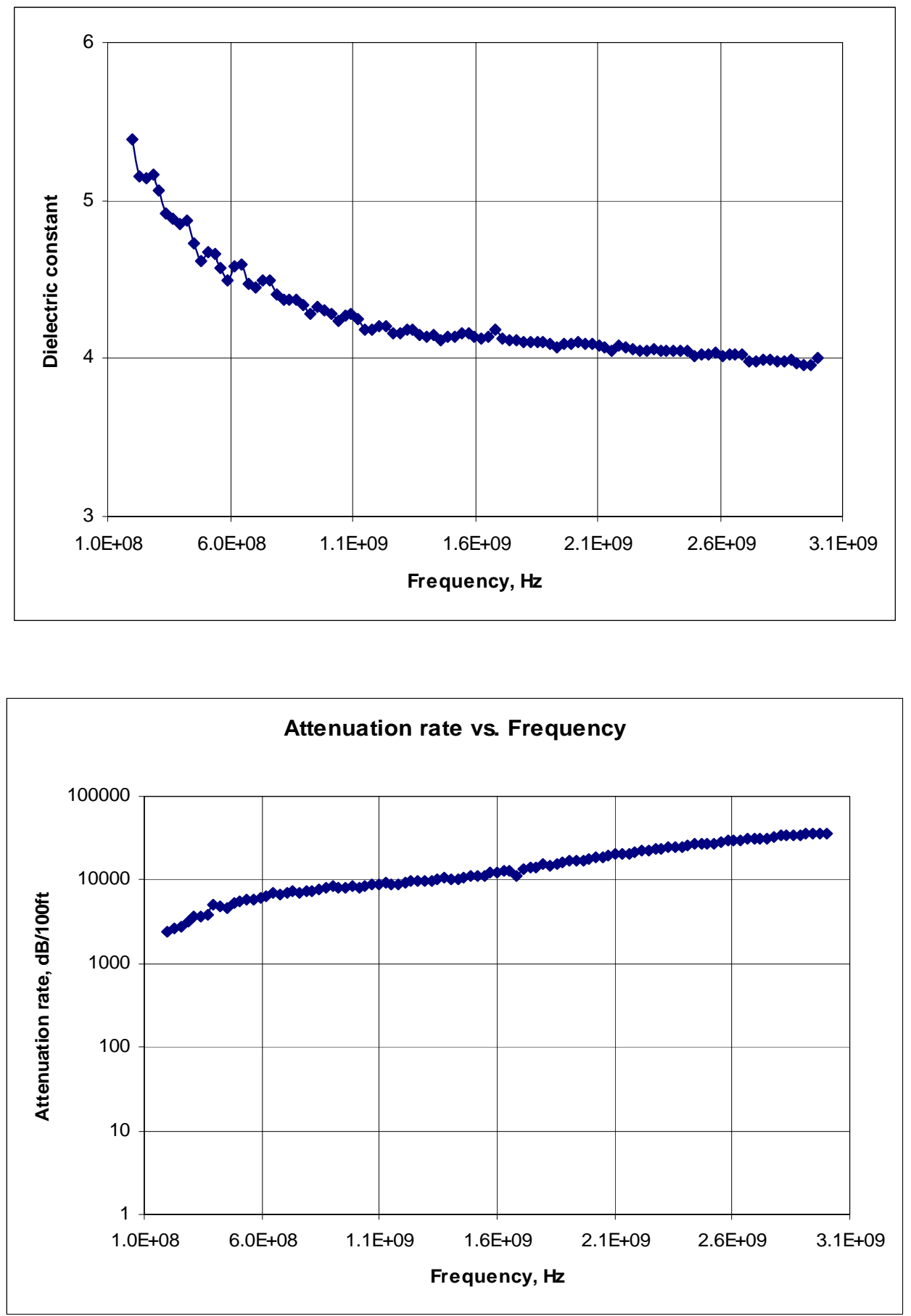

Fig. 4-24: Dielectric constant and attenuation rate for high-frequency measurements of the basalt sample, Hawaii

The attenuation rates and dielectric constant of the basalt sample were measured by the low- and high-frequency dielectric measurement equipment. From the results 
obtained, an excessive loss of approximately $21 \mathrm{~dB} / \mathrm{ft}$ can be seen when the operating frequency increases from $10 \mathrm{MHz}$ to $1 \mathrm{GHz}$. Excessive loss like this excludes use of high-frequency radar systems that can see deeply into the subsurface.

Based on the measurements performed, the ranges for the dielectric constant and the resistivity for coal measure rocks were estimated. Summary tables for the averages of the dielectric constant and the attenuation rate for frequencies that might be of interest for RIM and DSR purposes are presented in Table 4-2 and Table 4-3. More detailed information about these values is available through the database.

Table 4-2: Typical average ranges for the dielectric constant for the samples tested

\begin{tabular}{|c|c|c|c|c|c|c|c|c|c|c|}
\hline \multirow[t]{2}{*}{ Rock Type } & \multirow[t]{2}{*}{ Seam Name } & \multicolumn{9}{|c|}{ Average of the Dielectric Constant by Seam and Frequency } \\
\hline & & $20 \mathrm{kHz}$ & $50 \mathrm{kHz}$ & $80 \mathrm{kHz}$ & $100 \mathrm{kHz}$ & $10 \mathrm{MHz}$ & $200 \mathrm{MHz}$ & $1 \mathrm{GHz}$ & $2 \mathrm{GHz}$ & $3 \mathrm{GHz}$ \\
\hline Coal & Pittsburgh & 11 & $9 \cdot 9.4$ & 8.6 & 8.4 & 6.7 & 3.9 & 3.8 & 3.6 & 3.4 \\
\hline Coal & Sewickley & $9.3-16$ & $8.2 \cdot 12.3$ & $8.4-11$ & $8.0-11.1$ & $6-7.3$ & $4.2-4.4$ & 4.4 .2 & 3.7 & $2.6-4$ \\
\hline Coal & Fruitland & N/A & N/A & N/A & $\mathrm{N} / \mathrm{A}$ & N/A & $4.5 \cdot 5.1$ & $4.2-4.6$ & N/A & 3.8 .4 .5 \\
\hline Coal & $\begin{array}{l}\text { Wasatch } \\
\text { Plateau }\end{array}$ & $7,4-7.8$ & $6.6 \cdot 6.8$ & $6.3-6.5$ & $6.1-6.3$ & $4,8=4,9$ & N/A & N/A & N/A & N/A \\
\hline Sandstone & Pittsburgh & $11.1-28$ & $14-32$ & $14.0-37$ & $14.1-33$ & $9-22.1$ & 6.2 & 5.4 & 5.4 & 5.3 \\
\hline Shale & Sewickley & $13-13.2$ & $11.3-11.5$ & $10.5-10.6$ & $10.2 \cdot 10.3$ & $7,6-79$ & $\mathrm{~N} / \mathrm{A}$ & $\mathrm{N} / \mathrm{A}$ & $\mathrm{N} / \mathrm{A}$ & $\mathrm{N} / \mathrm{A}$ \\
\hline Sandy Shale & Pittsburgh & 31.7 & 29.8 & 29.2 & 28.9 & 16.1 & $6.3-8.5$ & $5.4 \cdot 7.2$ & 5.3 .6 .6 & $5.1-5.6$ \\
\hline
\end{tabular}

Table 4-3: Typical averages for the attenuation rate for the samples tested

\begin{tabular}{|l|l|c|c|c|c|c|c|c|c|c||}
\hline Rock Type & \multicolumn{1}{|c|}{ Seam name } & \multicolumn{6}{|c||}{ Average of the Attenuation Rate by Seam and Frequency, dB/100 ft } \\
\hline & & $20 \mathrm{kHz}$ & $50 \mathrm{kHz}$ & $80 \mathrm{kHz}$ & $100 \mathrm{kHz}$ & $10 \mathrm{MHz}$ & $200 \mathrm{MHz}$ & $1 \mathrm{GHz}$ & $2 \mathrm{GHz}$ & $3 \mathrm{GHz}$ \\
\hline & & & & & & & & & & \\
\hline Coal & Pittsburgh & 0.49 & 0.96 & 1.36 & 1.61 & 144.5 & 569 & 2472 & 4836 & 6718 \\
\hline Coal & Sewickley & 0.58 & 1.32 & 2.01 & 2.43 & 127.9 & 1216 & 5957 & 6504 & 11278 \\
\hline Coal & Fruitland & N/A & N/A & N/A & N/A & N/A & 1582 & 6917 & 8654 & 15223 \\
\hline Coal & Wasatch Plateau & 0.32 & 0.77 & 1.18 & 1.43 & 50.5 & N/A & N/A & N/A & N/A \\
\hline Sandstone & Pittsburgh & 0.14 & 0.5 & 0.96 & 1.37 & 726.7 & 3082 & 3683 & 4597 & 12612 \\
\hline Shale & Sewickley & 0.61 & 1.28 & 1.85 & 2.21 & 113 & N/A & N/A & N/A & N/A \\
\hline Sandy Shale & Pittsburgh & 0.72 & 1.15 & 1.55 & 1.85 & 402.8 & 3389 & 8038 & 9150 & 16887 \\
\hline
\end{tabular}

An initial statistical analysis of data for coal samples from the Sewickley and Fruitland \#8 seams in the high-frequency range was performed. The analysis looked at 
the differences in the electrical properties of coal between the two seams. The analysis was performed using free software called "R". It consists of an " $R$ "-language plus a runtime environment, but it is not user friendly and cannot plot graphs. The results of the statistical test performed showed that the two coals follow the same pattern when regression is performed, but there are differences between the coals that might be assumed to be due to their different mineral composition. A statistical F-test was run, and the $R$-square value obtained from the analysis for the two coals is $R^{2}=0.773174$, which shows fairly good correlation for the values of the dielectric constant between the two coal fields.

The database developed for this research is presented in the following chapter. 


\section{CHAPTER 5}

\section{DATABASE}

During this research data were collected from five major coal fields across the United States including nine mines. The samples were measured at low- and highfrequency range as mentioned previously. During the study, a large amount of data was accumulated. In order to make the data for electrical properties of rocks easily accessible for the potential users, a database was developed. The database was created by using Microsoft Office Access 2003. Moreover, in order to simplify the process of searching for data and to present it in a clearer manner, a Microsoft Excel Pivot Table, which is linked to the database, was created.

A database management system (DBMS), such as Microsoft Office Access, provides the user with software tools that are needed to organize data in a flexible manner (Prague et al., 2004). In other words, it includes facilities to add, modify, or delete information from the database, ask questions about the data stored in the database, and produce reports summarizing selected contents. If a database did nothing more than to store information in tables, it would be useless; therefore, the users need methods to retrieve specific information from the database. The Microsoft Office Access software allows the information to be manipulated in different and powerful ways.

The real power of the database lies in its capabilities to answer more complex requests. Access provides the capability of combining data from multiple tables and placing specific conditions on the data retrieved. The data collected in this research are 
organized in such a database. The database developed provides information about the electrical properties of rocks in a clear and organized way. The database and the pivot table are illustrated in the next sections.

\subsection{Database for the electrical properties of rocks}

The main interest of this research was to collect data for the electrical properties of coal measure rocks. Therefore, a large amount of data was accumulated and available for analysis. To analyze the data quickly, it is necessary to have easy access to all of the available information for the electrical properties. In addition, because the electrical properties of coal measure rocks have not been studied in detail previously, the main task in the study was the development of the database.

Figure 5-1 represents the scheme by which the database is organized.

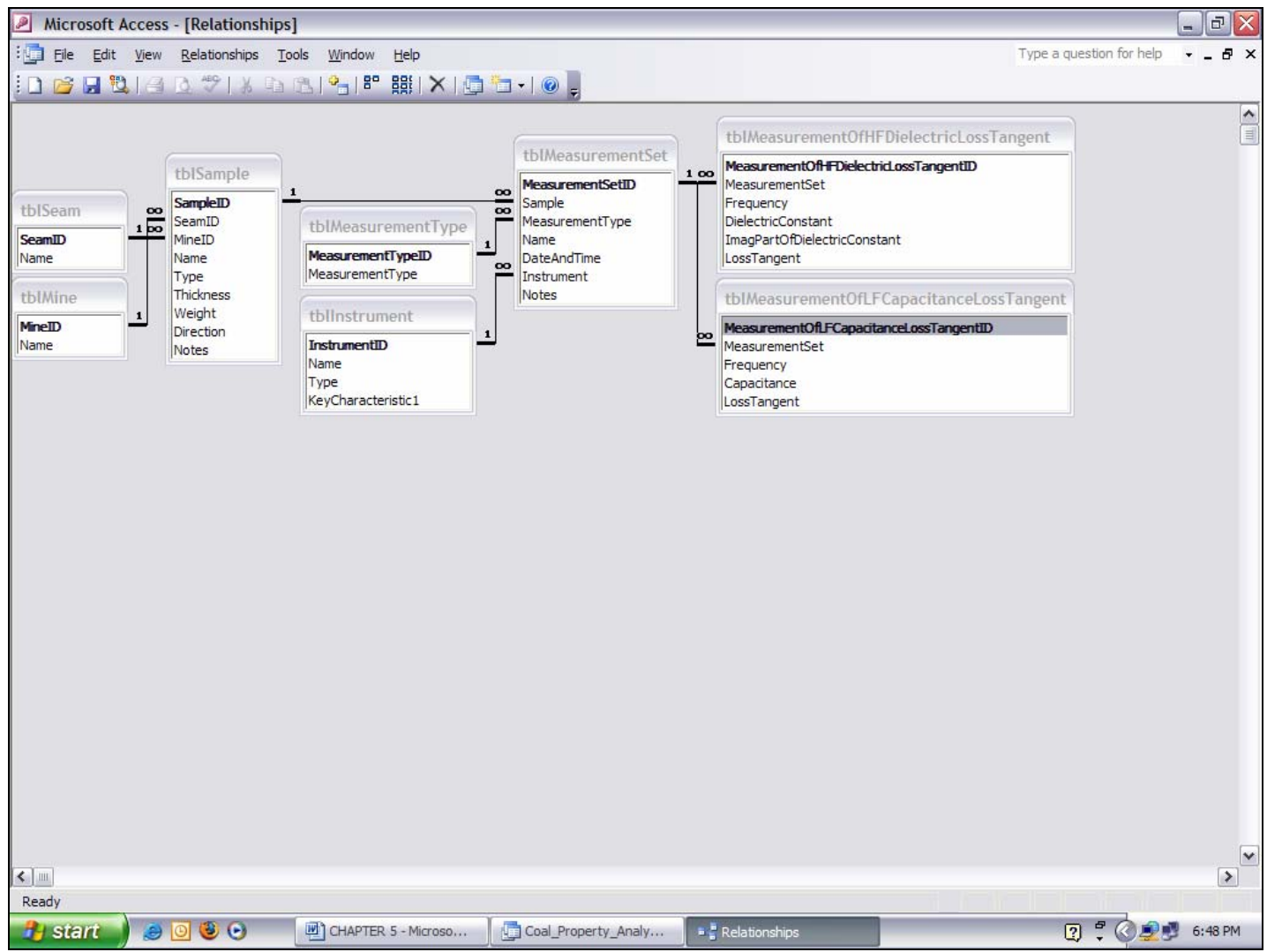

Fig. 5-1: Scheme of the database developed for the electrical properties of coal measure rocks 
Figure 5-1 illustrates the scheme for the database. Moreover, it gives all of the relationships between the different parameters that are included in the database. It can be seen from the scheme that the database is organized in such a way that it accounts for different factors. For example, one coal seam has many samples collected from it, and one mine also has many samples. Each sample was measured in low or high frequency or both. Therefore, the measurement set for a particular sample is a set of measurements in a specific frequency range.

Another important fact is that the database is set up to perform all of the necessary calculations for the electrical properties of the coal measure rocks. This is done by writing so-called "queries" in the database. Queries select records from one or more tables in a database so that they can be viewed, analyzed, and sorted on a common datasheet. The resulting collection of records, called a subset, is saved as a database object and can therefore be easily used in the future. The query will be updated whenever the original tables are updated. Three queries were used in the database created: one for the low-frequency range, one for the high-frequency range, and one combining the results for low and high frequency.

To make it more user friendly, the main switchboard (or interface) of the database was created and is represented in Fig. 5-2. 


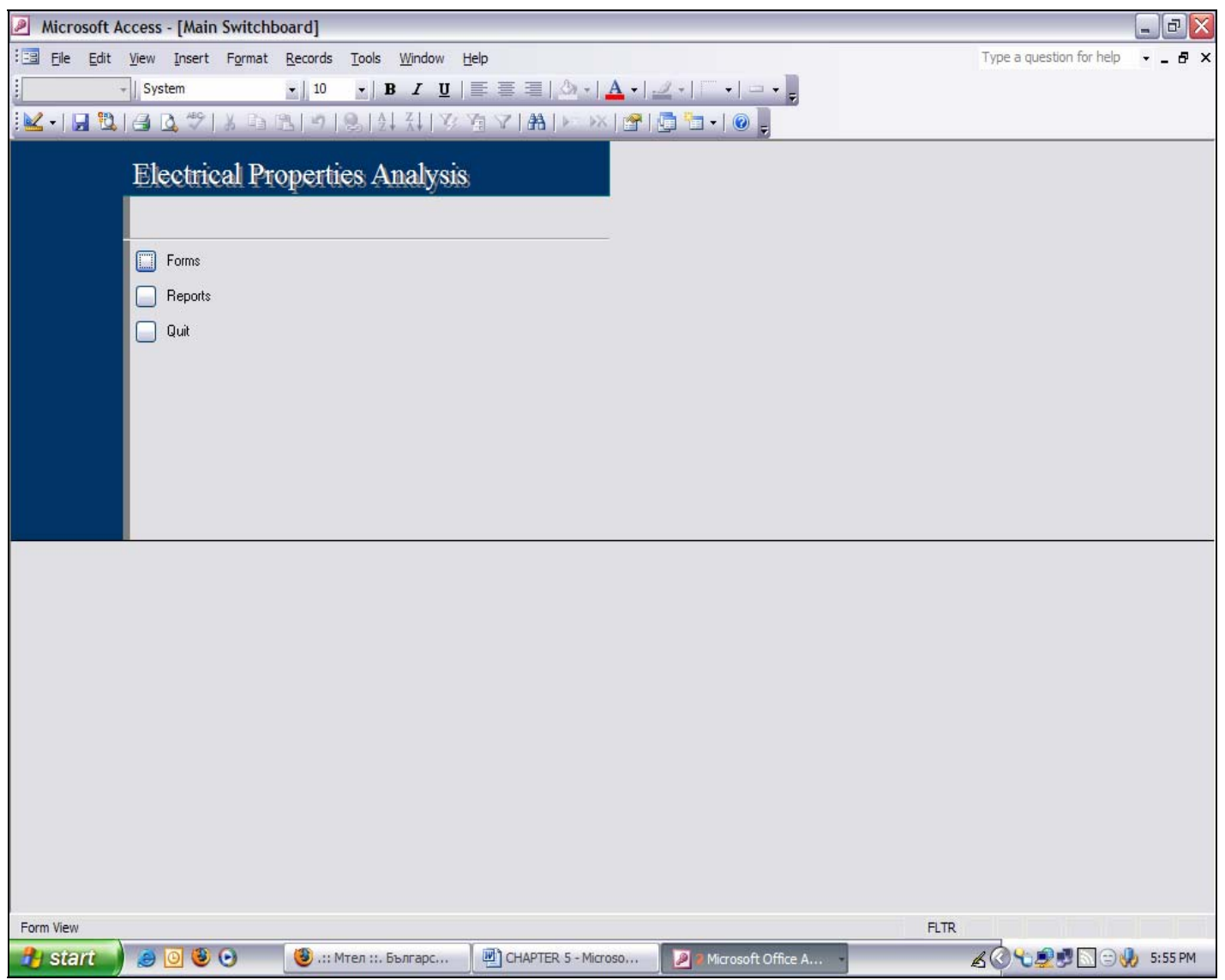

Fig. 5-2: Main switchboard of the database for the electrical properties of rocks

In Fig. 5-2, it can be seen that there are three main icons on the menu: forms, reports, and quit (exit). When the users click on one of the icons-for example on the icon "Reports" - sub-menus would open, as illustrated in Fig. 5-3. 


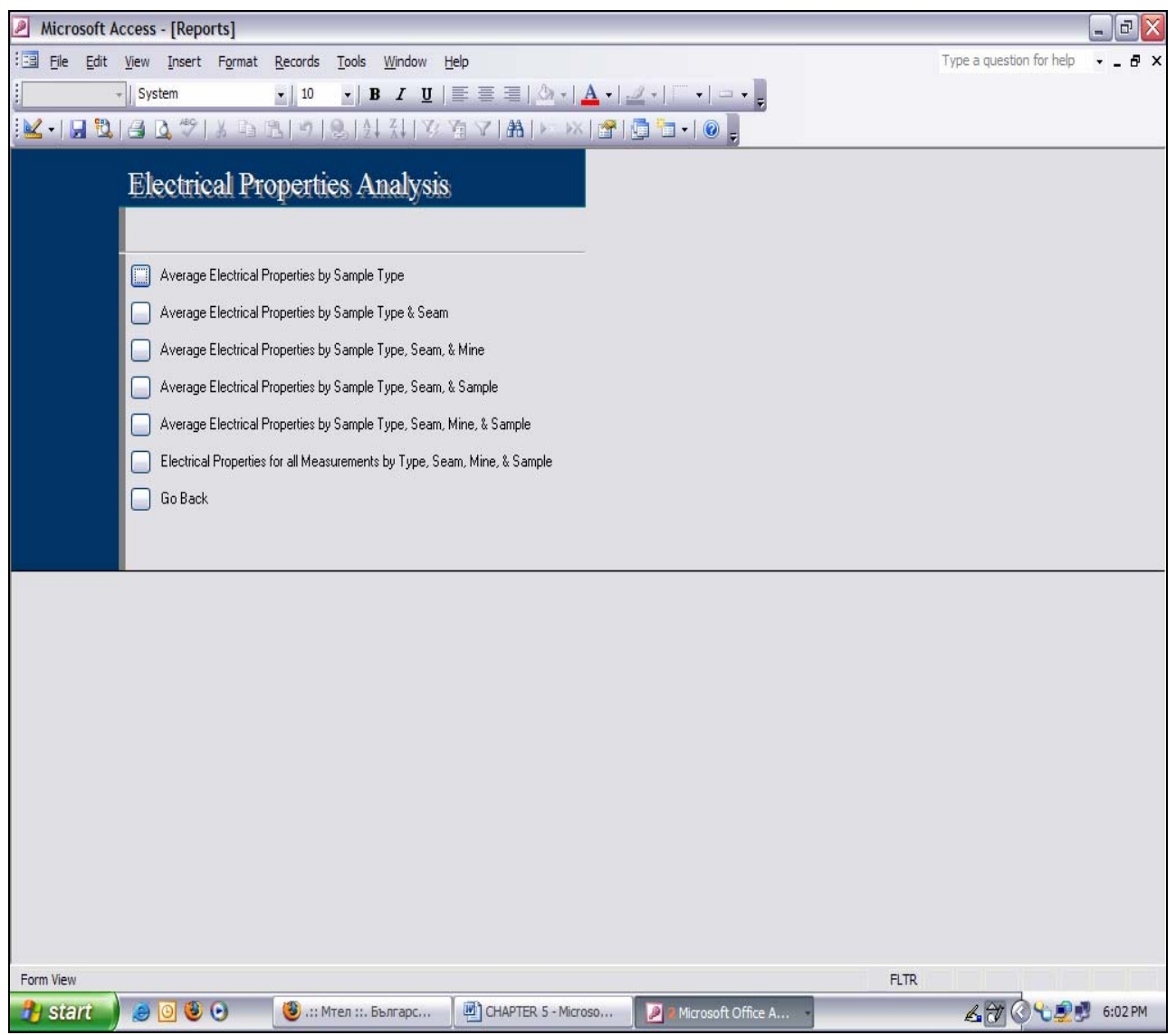

Fig. 5-3: Sub-menus in the database

In Fig. 5-3 it is obvious that the database now gives more choices. If the user is interested in specific information, he can click on one of the icons and the database will start asking him questions. The questions in this particular database are related to the sample type (what kind of rock), seam name, or which frequency range the user is interested in (low or high frequency, or both). After the user makes choices about what he needs, the report that he requested will be generated, as shown in Fig. 5-4. The reports in this particular database are designed to give averages for the electrical properties of coal measure rocks. For example, if the user is interested in knowing what the average electrical properties are for a particular coal sample from a certain coal seam, the report 
will give the exact information about the averages for all of the coal samples measured for this seam.

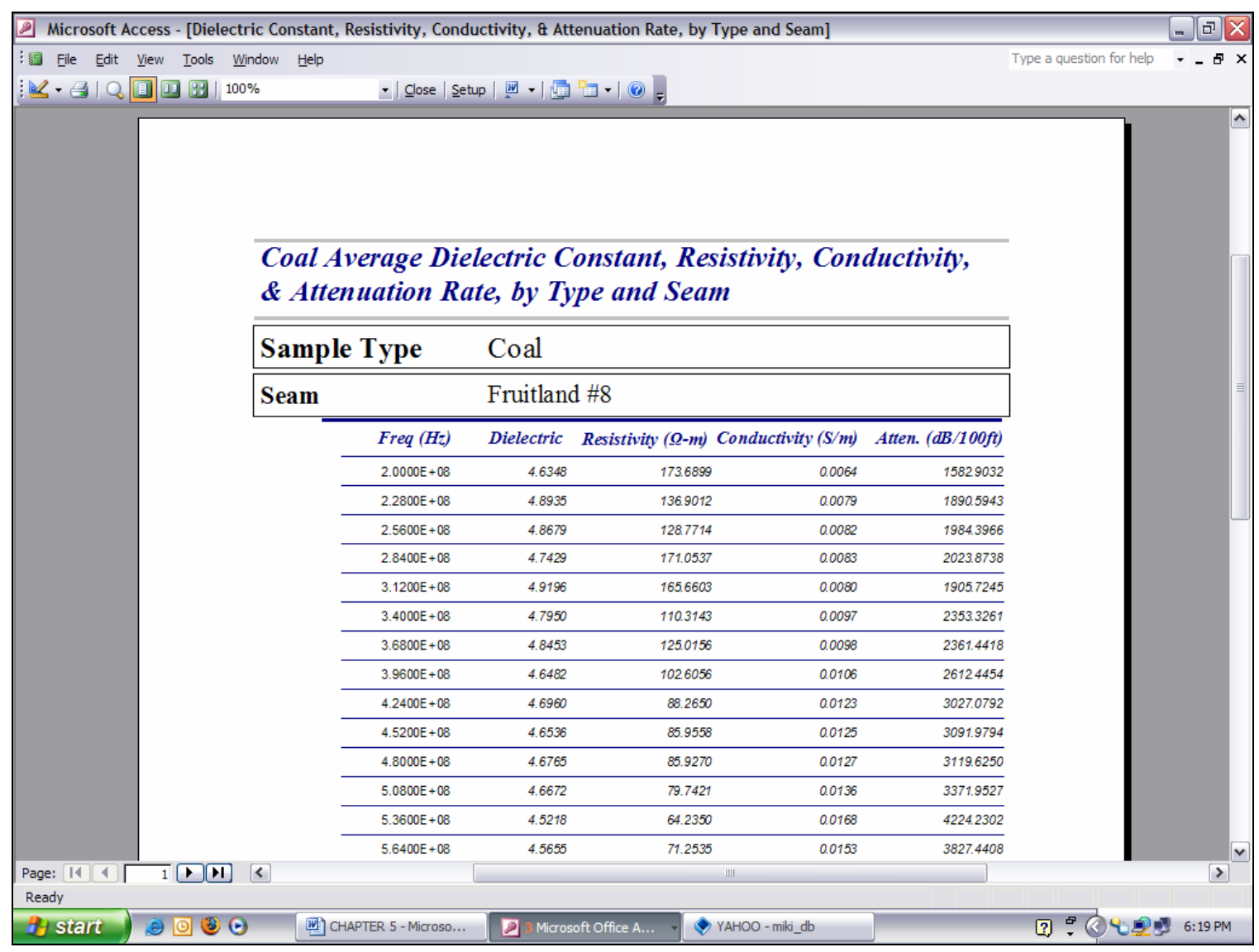

Fig. 5-4: Example of a report created by using the database for the electrical properties of rocks

Figure 5-4 presents an example of a report generated for a coal sample from the Fruitland \#8 seam. It gives all the information available including the frequency in which the sample was tested, dielectric constant, resistivity, conductivity, and attenuation rates.

The user interface of the database and the method by which the user can simply use it has been briefly described here. Generally speaking, the tables created for upload in the database comprise the fundamental building blocks of any database (Fig. 5-5). 


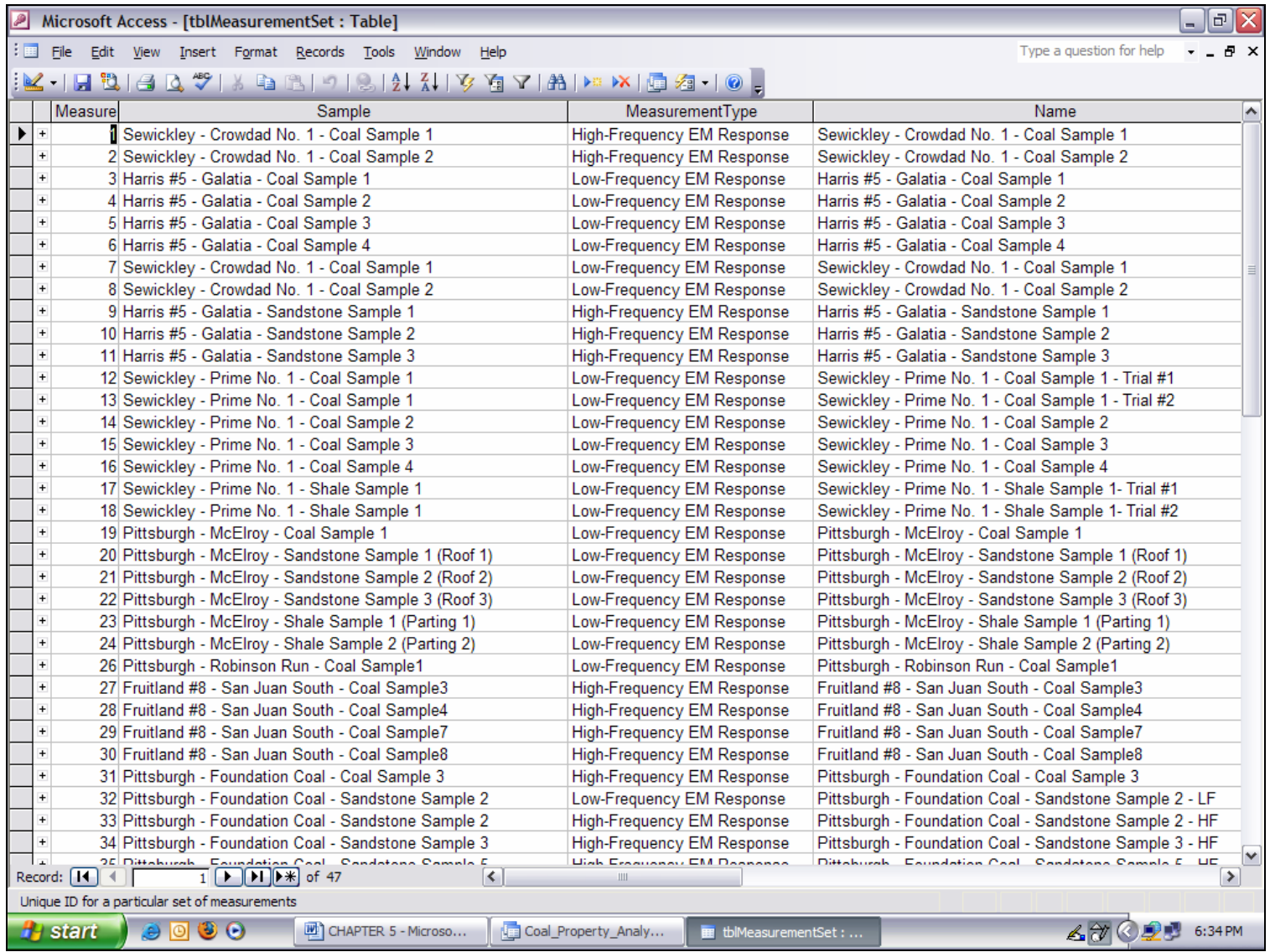

Fig. 5-5: Measurement sets included in the database for the electrical properties of rocks

The figure consists of six columns. The first column is the unique measurement ID (identification number) for each sample or the order in which the results were uploaded in the database. The second column and the fourth column give information about the seam from which the sample was collected, the specific mine site, and the type of the rock tested. This is necessary so that the collected samples can be organized by seam and mines. The third column represents the type of measurement performed on a particular sample in the low- or high-frequency range. Then the last two columns of that particular table give information about the instrumentation used for the measurements and when the information for the samples was uploaded in the database. 


\subsection{Data summary in Pivot Tables}

Pivot tables are a feature included in Microsoft Office Excel. The Pivot Table is linked to its source of data (database or other spreadsheets in Excel). In this case, it is linked to the database for the electrical properties of coal measure rocks described in the previous section. Every time changes are made in the database, the refresh function in the Pivot Table menu should be used to update the information. The three main reasons for organizing the data into a Pivot Table are:

- to summarize the data collected in compact form

- to find relationships within the data that are otherwise hard to see because of the amount of detail

- to organize the data into a format that is easy to chart

Figure 5-6 on the next page gives an illustration of the Pivot table created for the database. 


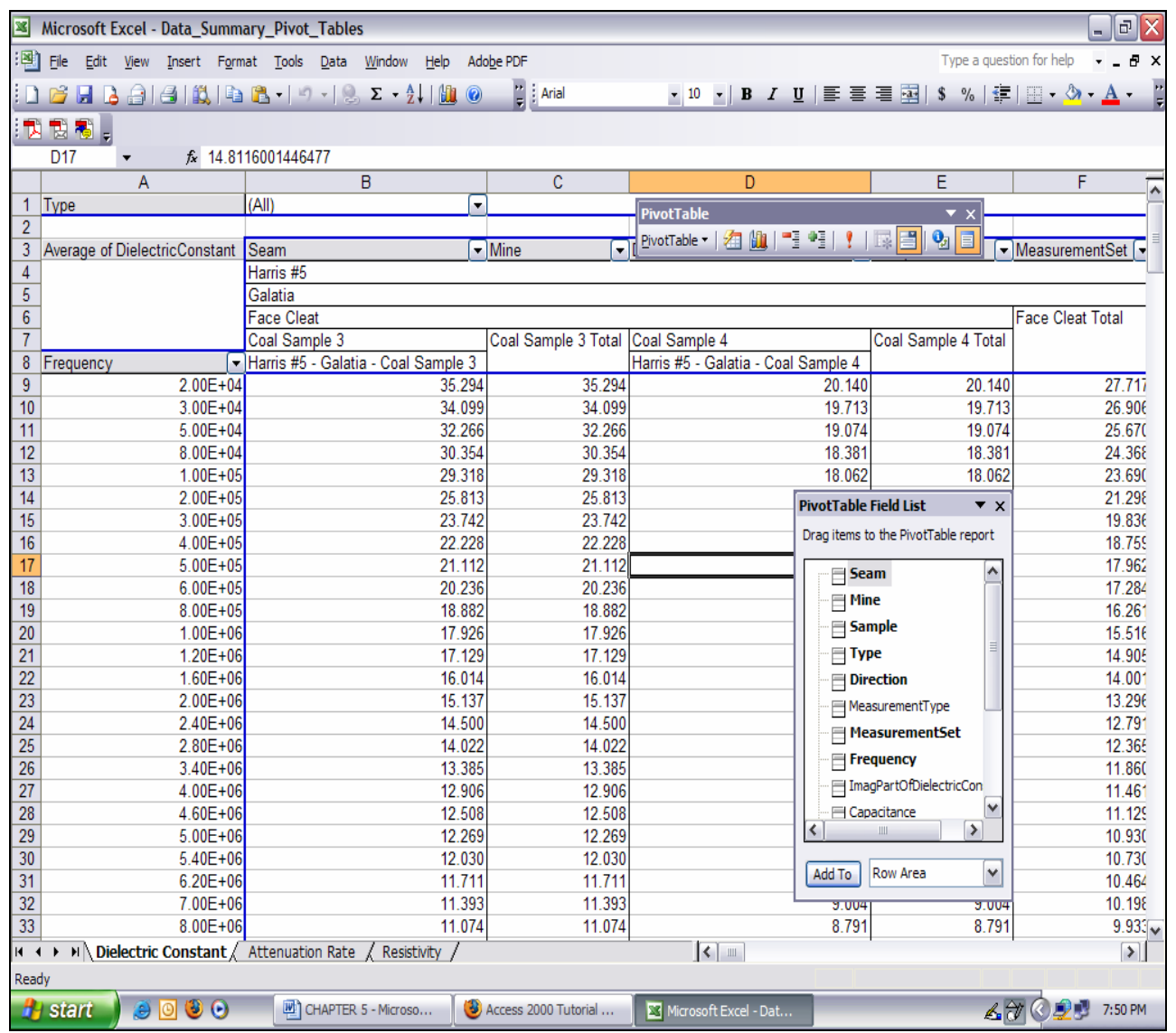

Fig. 5-6: Pivot Table for the electrical properties of coal measure rocks

One of the main advantages of using the pivot tables is the fact that the table simplifies and summarizes the data to make relationships and patterns obvious. The Pivot Table also allows including or excluding whatever data the user likes. For example, the user of this particular table could exclude all mines for a particular coal seam and leave only the rock types and still get the result in which he is interested. All of the results excluded could be easily added back by the click of a button.

The data organized into a Pivot Table could be easily plotted on graphs as shown in Fig. 5-7. 


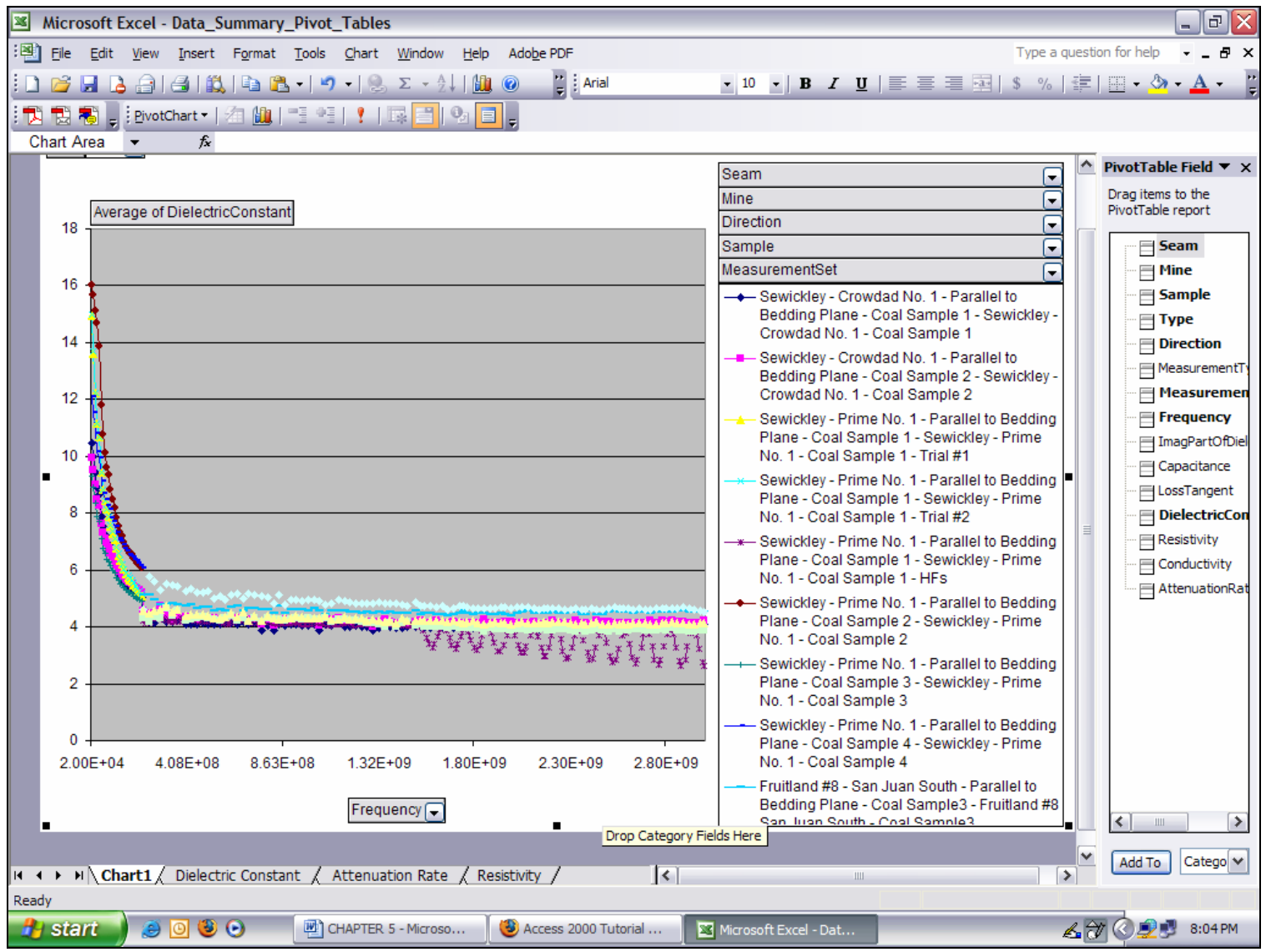

Fig. 5-7: Example of a graph created using the Pivot Table

In Fig. 5-7, it can be seen that only two seams were selected for the creation of this chart. The results for all of the coal samples that were measured for the two seams are plotted in the graph. The user has the ability to select the seam in which he is interested, mines, type of rock, and direction in which the sample was cut and measured.

Two disadvantages of the Pivot Tables in this case are that the $\mathrm{X}$-axis could not be plotted in logarithmic scale and also that the scattered plot cannot be used. However, once the user has the sorted data organized in the Pivot Table, he can easily copy and paste the data into a new Excel spreadsheet and graph the data in every way he desires.

The data collected in this research were organized in the database that was developed. For the first time, research has been done specifically for the electrical 
properties of coal measure rocks that covers five different coal fields in the United States. In addition, data summary Pivot Tables for the dielectric constant, attenuation rate, and resistivity were created to better understand the variations in the electrical properties of the rocks associated with coal seams. 


\section{CHAPTER 6}

\section{CONCLUSIONS AND RECOMMENDATIONS}

The range and resolution capability of a radar system that can be used for subsurface observations depend on the electromagnetic (EM) properties of the geological materials under investigation. The EM properties depend on a number of factors, such as mineral composition, moisture content, density, orientation, and crystalline structure of the samples. To further develop the radar system, it is essential to gain a good understanding of the electromagnetic contrast between the different layers of the geological strata in the domain of studies. Since the main application of this system will be for coal mining, it is necessary to estimate the contrast between the coal and its bounding strata. This information is mandatory so that the radar system can work properly.

The effect of the moisture content on the electrical properties of coal measure rocks was studied in detail. It can be concluded that the moisture content of the rock plays a significant role in its electrical properties. Also, the orientation of the samples to the electromagnetic field applied was observed and the results are available through the database. That leads to the conclusion that the orientation of the sample plays an important role. It was found that electrical properties could vary for the same rock type depending on the location from which it was collected (i.e., the example shown for coal from the Sewickley and Pittsburgh Seams). 
The study shows that more work for the electrical properties of coal measure rocks is needed. It is recommended that the mineral composition of the samples should be studied in the future. Also, the porosity of the samples should be observed and, when possible, a complete picture of the geological conditions from which the samples were extracted should be provided.

Due to the fact that in coal mines the surrounding strata is mainly composed of sedimentary rocks like sandstone, shale, limestone, etc., the measurements so far are focused on these types of earth materials. However, some igneous rock types were tested, due to the fact that radar system could face "mixed" conditions underground. The research presented in this thesis does not cover the frequency range between $10 \mathrm{MHz}$ and $200 \mathrm{MHz}$ due to the limitations of the equipment used. It is suggested that further studies for that range should be done. It is recommended to perform detailed statistical or geostatistical analysis of the data that are already in the database. Furthermore, modeling of the electrical properties of coal measure rocks using different methodologies can be performed.

The database for the most common rock types associated with coal seams was developed and Excel Pivot Tables were created from the database. The software used to create the database is Microsoft Office Access, and it allows easy use of the collected data. It is recommended that if there are any further studies for the electrical properties of rocks, the database be updated with the newly collected data in order to get a full picture of these properties. 


\section{REFERENCES}

Freedman, R., and J. Vogiatzis, 1979, “Theory of microwave dielectric constant logging using the electromagnetic wave propagation method", Geophysics, Vol. 44, May, 1979.

Hansen, W., W. R. Sill, and S. H. Ward, 1973, "The dielectric properties of selected basalts", Geophysics 38 (1), 135-139.

Knight, R., and A. Nur, "The dielectric constant of sandstones”, Geophysics, vol. 52, No 5, May 1987.

Lindroth, D, C. Wingquist, and A. Dehler, “Electrical properties and Attenuation Distance of Upper Pennsylvanian Coal Measure Rock From Southwestern Pennsylvania”, Bureau of Mines, Report of Investigations, 1984.

Martinez, A., A. Byrnes, 2001, "Modeling Dielectric constant values of Geologic Materials: An Aid to Ground Penetrating Radar Data Collection and Interpretation", Current Research in Earth Sciences, bulletin 247, part 1, Kansas Geological Survey at University of Kansas, 2001.

Parkhomenko, E. I., 1967, “Electrical Properties of Rocks”, Plenum Press, New York, 1967

Prague, C., M. Irwin, and J. Reardon, 2004 , “Access 2003 Bible”. Willey Pub., Hoboken, 2004

Reynolds, J., 2004 , “An introduction to Applied and Environmental Geophysics”, Willey Pub, West Sussex, England, 2004 
Stolarczyk, L.G., R. C. Fry, 1990 , "Radio Imaging Method (RIM) or diagnostic imaging of anomalous geologic structures in coal seam waveguides", Transactions of Society for Mining, Metallurgy and Exploration, Vol. 288, 1990.

Stolarczyk, L. G., and S. S. Peng, 2003, “Advanced Electromagnetic Wave Technologies for the Detection of Abandoned Mine Entries and Delineation of Barrier Pillars", Proc. Interactive Forum on Geophysical Technologies for Detecting Underground Coal Mine Voids, July 2003, Lexington, Kentucky.

Zhdanov, M., and G. Keller, 1994 , “The Geoelectrical Methods in Geophysical Exploration", Elsevier, New York, 1994

Watt, A. D., F. S. Mathews, and E. L. Maxwell, 1963, "Some electrical characteristics of the earth's crust", Proceedings of the Institute of Electrical and Electronics Engineers (IEEE), Vol. 51, Issue 6, June 1963 Page(s): 897 - 910.

Wait , J, 1963, “The possibility of guided electromagnetic waves in the earth's crust", IEEE Transactions on Antennas and Propagation, Vol. 11, Issue 3, May 1963 Page(s): 330 - 335. 